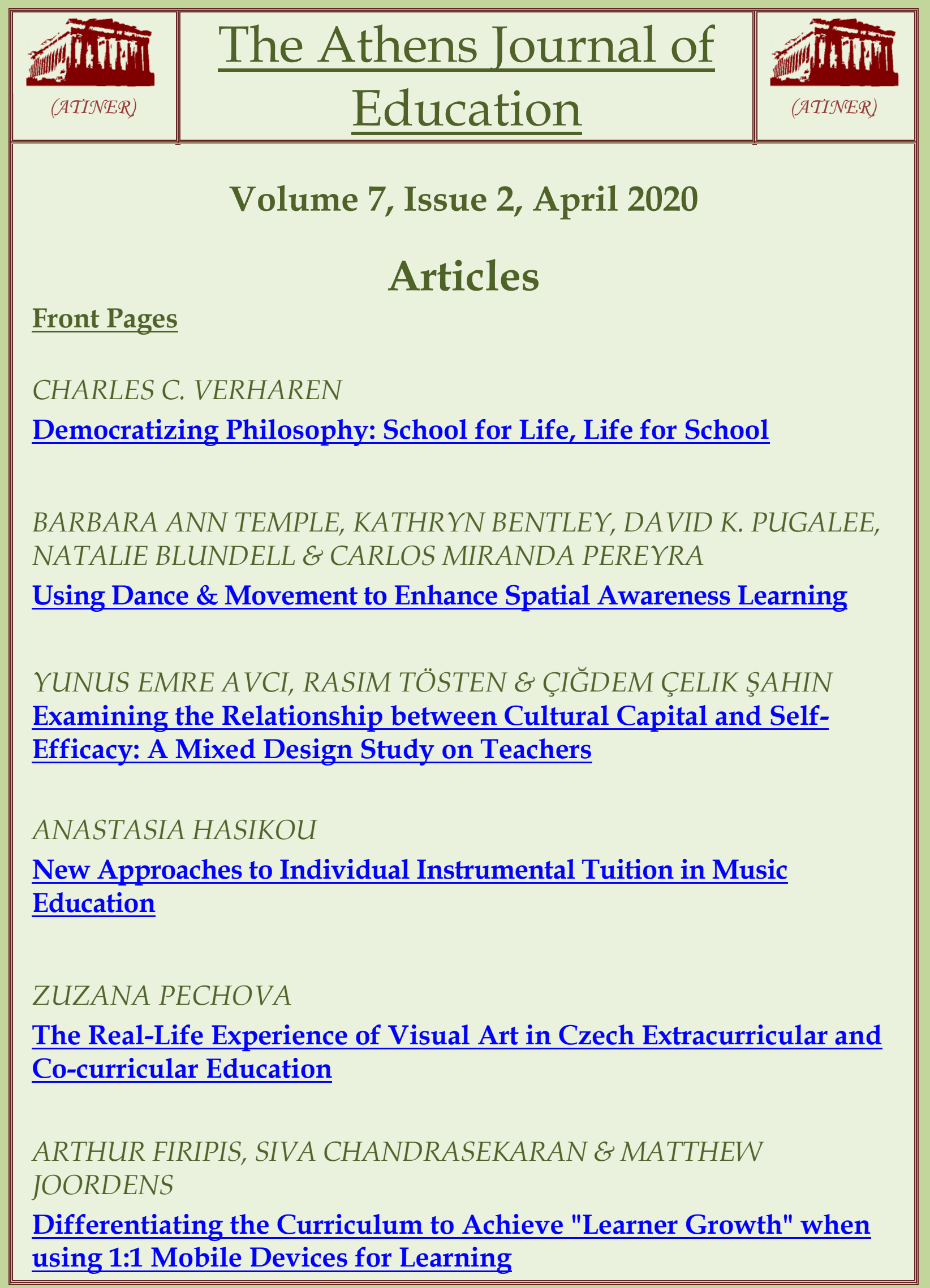




\section{Mission}

ATINER is an Athens-based World Association of Academics and Researchers based in Athens. ATINER is an independent and non-profit Association with a Mission to become a forum where Academics and Researchers from all over the world can meet in Athens, exchange ideas on their research and discuss future developments in their disciplines, as well as engage with professionals from other fields. Athens was chosen because of its long history of academic gatherings, which go back thousands of years to Plato's Academy and Aristotle's Lyceum. Both these historic places are within walking distance from ATINER's downtown offices. Since antiquity, Athens was an open city. In the words of Pericles, Athens"... is open to the world, we never expel a foreigner from learning or seeing". ("Pericles' Funeral Oration", in Thucydides, The History of the Peloponnesian War). It is ATINER's mission to revive the glory of Ancient Athens by inviting the World Academic Community to the city, to learn from each other in an environment of freedom and respect for other people's opinions and beliefs. After all, the free expression of one's opinion formed the basis for the development of democracy, and Athens was its cradle. As it turned out, the Golden Age of Athens was in fact, the Golden Age of the Western Civilization. Education and (Re)searching for the 'truth' are the pillars of any free (democratic) society. This is the reason why Education and Research are the two core words in ATINER's name. 
The Athens Journal of Education

ISSN NUMBER: 2241-7958 - DOI: 10.30958/aje

ISSN (print): 2407-9898

Volume 7, Issue 2, April 2020

Download the entire issue ( $\underline{\mathrm{PDF}})$

Front Pages

i-viii

Democratizing Philosophy: School for Life, Life for

139

$\underline{\text { School }}$

Charles C. Verharen

Using Dance \& Movement to Enhance Spatial

Awareness Learning

Barbara Ann Temple, Kathryn Bentley, David K. Pugalee,

Natalie Blundell \& Carlos Miranda Pereyra

Examining the Relationship between Cultural Capital and Self-Efficacy: A Mixed Design Study on Teachers

Yunus Emre Avci, Rasim Tösten \& Çiğdem Çelik Şahin

New Approaches to Individual Instrumental Tuition in 193

Music Education

Anastasia Hasikou

The Real-Life Experience of Visual Art in Czech

203

Extracurricular and Co-curricular Education

Zuzana Pechova

Differentiating the Curriculum to Achieve "Learner

Growth" when using 1:1 Mobile Devices for Learning

Arthur Firipis, Siva Chandrasekaran \& Matthew Joordens 


\section{Athens Journal of Education Editorial and Reviewers' Board}

Editors

- Dr. John Spiridakis, Academic Member, ATINER \& Professor, St. John University, USA.

- Dr. Alexander Makedon, Head, Education Unit, ATINER.

- Dr. Julia Underwood, Academic Member, ATINER \& Professor, Azusa Pacific University, USA.

- Dr. Zoi Philippakos, Academic Member, ATINER \& Assistant Professor, University of Tennessee, Knoxville, USA.

\section{Editorial Board}

- Dr. Sharon Vaughn, Academic Member, ATINER \& Professor and Executive Director, The University of Texas at Austin and The Meadows Center for Preventing Educational Risk, USA.

- Dr. Effie Kritikos, Academic Member, ATINER \& Professor and Division Chair of Education, Governors State University, USA.

- Dr. Elsa Fourie, Academic Member, ATINER \& Professor \& Director, North-West University, South Africa.

- Dr. Effie Efthymiou, Academic Member, ATINER \& Assistant Professor, United Arab Emirates University (UAEU), UAE.

- Dr. Ashlea Rineer-Hershey, Assistant Professor and Education Transition Programming Coordinator, Slippery Rock University, USA.

- Dr. Lorna Hamilton, Academic Member, ATINER \& Senior Lecturer, School of Education University of Edinburgh, UK.

- Dr. Yaacov Julian Katz, Academic Member, ATINER \& Lecturer and Researcher in Social Psychology of Education, Bar-Ilan University, Israel.

- Dr. Mary Ellis, Academic Member, ATINER \& Senior Lecturer, National Institute of Education (Nanyang Technological University), Singapore.

- Dr. Sandra M. Harris, Academic Member, ATINER \& Assessment Director, Walden University, USA.

- Dr. Jose Francisco Duran Medina, Professor, Department of Pedagogy, University of CastillaLa Mancha, Spain.

- Dr. Roger B. Hill, Professor, University of Georgia, USA.

- Dr. Azita Manouchehri, Professor, Ohio State University, USA.

- Dr. Macleans A. Geo-JaJa, Professor of Economics and Education, David O. McKay School of Education, Brigham Young University, USA.

- Dr. Dijana Karuovic, Professor, Technical Faculty “Mihajlo Pupin” Zrenjanin, Serbia.

- Dr. Mohinder Partap Satija, Professor, Guru Nanak Dev University, India.

- Dr. Aieman Ahmad Al-Omari, Professor, The Hashemite University, Jordan.

- Dr. Michael F. Shaughnessy, Professor, School of Education, Eastern New Mexico University, USA.

- Dr. Trish Stoddart, Professor, Education Department, University of California, USA.

- Dr. Kamini Jaipal Jamani, Associate Professor, Brock University, Canada.

- Dr. Francisco Javier Fernandez Rio, Associate Professor, Educational Sciences Department, University of Oviedo, Spain.

- General Managing Editor of all ATINER's Publications: Ms. Afrodete Papanikou

- ICT Managing Editor of all ATINER's Publications: Mr. Kostas Spyropoulos

- Managing Editor of this Journal: Ms. Despina Katzoli ( $\underline{\text { bio }})$

\section{Reviewers' Board}

Click Here 


\section{President's Message}

All ATINER's publications including its e-journals are open access without any costs (submission, processing, publishing, open access paid by authors, open access paid by readers etc.) and is independent of presentations at any of the many small events (conferences, symposiums, forums, colloquiums, courses, roundtable discussions) organized by ATINER throughout the year and entail significant costs of participating. The intellectual property rights of the submitting papers remain with the author. Before you submit, please make sure your paper meets the basic academic standards, which includes proper English. Some articles will be selected from the numerous papers that have been presented at the various annual international academic conferences organized by the different divisions and units of the Athens Institute for Education and Research. The plethora of papers presented every year will enable the editorial board of each journal to select the best, and in so doing produce a top-quality academic journal. In addition to papers presented, ATINER will encourage the independent submission of papers to be evaluated for publication.

The current issue is the second of the seventh volume of the Athens Journal of Education (AJE), published by published by the Education Unit of ATINER.

Gregory T. Papanikos

President

ATINER 


\section{Athens Institute for Education and Research}

\section{A World Association of Academics and Researchers}

\section{2nd Annual International Conference on Education 18-21 May 2020, Athens, Greece}

The Education Unit of ATINER organizes its 22nd Annual International Conference on Education, 18-21 May 2020, Athens, Greece sponsored by the Athens Journal of Education. The aim of the conference is to bring together scholars and students of education and other related disciplines. You may participate as stream leader, presenter of one paper, chair a session or observer. Papers (in English) from all areas of education are welcome. Please submit a proposal using the form available (https://www.atiner.gr/2020/FORM-EDU.doc).

\section{Academic Members Responsible for the Conference}

- Dr. Gregory T. Papanikos, President, ATINER.

- Dr. David Philip Wick, Director, Arts, Humanities and Education Division, ATINER \& Professor of History, Gordon College, USA.

- Dr. John Spiridakis, Co-Editor, Athens Journal of Education \& Professor, St. John University, USA.

- Dr. Alexander Makedon, Head, Education Unit, ATINER \& Independent Scholar (Retired Full Professor, Chicago State University, USA).

- Abstract Submission: 4 May 2020

\section{Important Dates}

- Acceptance of Abstract: 4 Weeks after Submission

- Submission of Paper: 20 April 2020

\section{Social and Educational Program}

The Social Program Emphasizes the Educational Aspect of the Academic Meetings of Atiner.

- Greek Night Entertainment (This is the official dinner of the conference)

- Athens Sightseeing: Old and New-An Educational Urban Walk

- Social Dinner

- Mycenae Visit

- Exploration of the Aegean Islands

- Delphi Visit

- Ancient Corinth and Cape Sounion

More information can be found here: www.atiner.gr/social-program

\section{Conference Fees}

Conference fees vary from $400 €$ to $2000 €$

Details can be found at: https://www.atiner.gr/2019fees 


\section{Athens Institute for Education and Research}

A World Association of Academics and Researchers

\section{$4^{\text {th }}$ Annual International Symposium on "Higher Education in a Global World", 6-9 July 2020, Athens, Greece}

The Education Unit of ATINER is organizing the $4^{\text {th }}$ Annual International Symposium on "Higher Education in a Global World", 6-9 July 2020, Athens, Greece sponsored by the Athens Journal of Education. The aim of the symposium is to examine educational developments throughout the world in universities, polytechnics, colleges, and vocational and education institutions. Academics and researchers from all areas of education are welcomed. You may participate as stream organizer, presenter of one paper, chair a session or observer. Please submit a proposal using the form available (https://www.atiner.gr/2020/FORM-COLEDU.doc).

Important Dates
- Abstract Submission: 25 May 2020
- Acceptance of Abstract: 4 Weeks after Submission
- Submission of Paper: 8 Iune 2020

\section{Academic Member Responsible for the Conference}

- Dr. Gregory T. Papanikos, President, ATINER.

- Dr. Sharon Claire Bolton, Vice President of Research, ATINER \& Professor, The Management School, University of Stirling, Scotland.

- Dr. David Philip Wick, Director, Arts, Humanities and Education Division, ATINER \& Professor of History, Gordon College, USA.

- Dr. John Spiridakis, Co-Editor, Athens Journal of Education \& Professor, St. John University, USA.

- Dr. George Priovolos, Director, Center for Small and Medium-Sized Enterprises (CSME) \& Professor, Iona College, USA.

\section{Social and Educational Program}

The Social Program Emphasizes the Educational Aspect of the Academic Meetings of Atiner.

- Greek Night Entertainment (This is the official dinner of the conference)

- Athens Sightseeing: Old and New-An Educational Urban Walk

- Social Dinner

- Mycenae Visit

- Exploration of the Aegean Islands

- Delphi Visit

- Ancient Corinth and Cape Sounion

More information can be found here: https://www.atiner.gr/social-program

\section{Conference Fees}

Conference fees vary from $400 €$ to $2000 €$

Details can be found at: https://www.atiner.gr/2019fees 


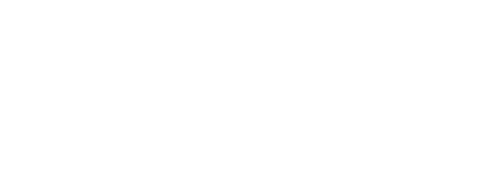




\title{
Democratizing Philosophy: School for Life, Life for School
}

\author{
By Charles C. Verharen*
}

\begin{abstract}
Re-visioning education is critical to developing new ways of thinking and acting in the face of global threats to life from global climate change and weapons of mass destruction. Like philosophy in Quine's words, education is "losing contact with the people." Education suffers this loss in part because education has lost contact with philosophy. The paper first addresses the relations between philosophy and science. Nietzsche is a primary guide on this question. While his elitism must be dismissed, his apocalyptic vision of philosophy may help students become more deeply engaged in all levels of schooling. The paper's second concern is whether philosophy can be infused into all other subjects. The conclusion considers whether it is practical to teach philosophy to all students. Schooling that democratizes philosophy can reveal that many more human beings are gifted than we could have imagined. W.E.B. Du Bois in fact argues that virtually all humans should receive higher education. A compelling reason to democratize philosophy is to further democracy itself.
\end{abstract}

Keywords: Du Bois, education, historically black colleges and universities, Nietzsche, philosophy.

\section{Introduction}

Nietzsche in Beyond Good and Evil (1992, p. 402, Nietzsche's emphasis) stresses the origins of morality in danger and the need for collective action in the face of danger: "Again danger is there, the mother of morals, great danger." Four existential crises confront the world: the sixth mass extinction, global climate change, weapons of mass destruction and the immiseration of billions in the Global South (Gardiner, 2011; Kolbert, 2014; Wilson, 2016). For the first time in our $\sim 300,000$ year history, humans may acquire the power to alter life globally. This danger calls for a new morality (Verharen et al., 2011). Nietzsche (ibid, p. 406) offers the promise that grave danger may stimulate the creation of a new morality: "The greater the danger is, the greater is the need to reach agreement quickly and easily about what must be done". Re-visioning education is critical to developing new ways of thinking and acting in the face of unprecedented dangers. Like philosophy in Quine's (1972, p. 191) words, education is "losing contact with the people." Education suffers this loss in part because education has lost contact with philosophy.

The paper's first part shows how school may be connected to life and philosophy to school. My primary guide in the paper's second part is Nietzsche.

*Professor, Howard University, USA. 
His apocalyptic vision of philosophy may help students become more deeply engaged in all levels of schooling. Nietzsche argues that new creations in philosophy evolve out of grave dangers. A committed elitist, Nietzsche held that only a few select human beings could respond to those crises by creating new commanding values. With more than a century's experience of democracy beyond Nietzsche's, we can argue for a democratization of philosophy. On the verge of being able to disrupt in dramatic ways life on the planet, we need all the help we can get.

The paper's third part shows how philosophy can be infused into all other subjects in an education powerful enough to address our contemporary dangers. The conclusion considers whether it is practical to teach philosophy to all students. Schooling that democratizes philosophy can reveal that many more human beings are gifted than we could have imagined. W.E.B. Du Bois (2001) in fact argues that virtually all humans should receive higher education. A compelling reason to democratize philosophy is to further democracy itself.

\section{Connecting School to Life and Philosophy to School}

Nel Noddings' Philosophy of Education (2011) claims that education is lost on many students because they feel no deep connection to the material taught. United States drop-out rates, particularly in our inner cities, confirm her wisdom. How can we meet the needs of children who do not respond to contemporary educational practices in satisfactory ways? School for many students is an odious task that can only be endured with great helpings of discipline.

This essay works toward restoring the connotation of the word school to its ancient Greek sense of leisure by infusing philosophy into the curriculum. Disaffected students think of school as drudgery rather than leisure. Plato to the contrary thought that school is the loftiest of human pursuits. On one reading, Plato's Republic is a blueprint enabling the philosopher to spend her entire life in school-save for the twenty years from ages 50-70 she must reluctantly spend as philosopher-queen. Aristotle's Nichomachean Ethics argues that the lucky man (and Aristotle did mean man) will spend the greater part of his life in the schole of thinking (Nussbaum, 1986).

Although Noddings defines philosophy in her opening lines as "love of wisdom," she does not carefully explicate that expression. Jane Heal (2012, p. 39) defines wisdom through ethics: "Being wise is a matter of having a good (or the right, or some admirable) stance to the world, such that one apprehends, feels, acts in ways that are good (or right, or somehow admirable). Plato and Aristotle define wisdom much more broadly. Philosophers have only a highly generalized knowledge of everything" (Metaphysics 982a21-24). Detailed knowledge is left to specialists in other disciplines. For Aristotle, philosophy is more like poetry than history because both poetry and philosophy try to capture universals, while history is content with the particular (Poetics 1451b1-11).

W.V.O. Quine follows Aristotle in claiming that knowledge is a spectrum, ranging from the hyper-generalizations of philosophy through the more modest 
generalizations of science, culminating in the practical arts of engineering (Quine quoted in Magee 1982, p. 143-44). Because of the highly generalized status of philosophy, philosophers cannot substantiate their theories through empirical investigation. Scientists' theories in their most powerful guise are less general than those of philosophers (Quine, 1951). Nevertheless, philosophy drives science by addressing questions completely beyond the competence of scientists to answer consensually, given the limits of knowledge of their times.

Contemporary cosmology and neuropsychology present clear evidence for this claim. Quantum mechanics has pushed contemporary physicists to propose a variant of Pythagoras' claim that all things are numbers. The research program is called "string theory." Physicists also begin to suggest that there may be billions of universes beyond ours. Most provocatively, they hypothesize that we ourselves may be simulations in the computational systems of species far ahead of us in the evolutionary process (Greene, 2011).

Neuroscientists now explore the mystery of consciousness (Thagard, 2010). They propose research programs showing that our linguistic and ethical capacities are innate - just as Plato suggested, but for radically different reasons (Joyce, 2006; 2001). Such speculation about the origins of the universe and the nature of consciousness must have been counted as utterly "wild guesses" just a few decades ago. However, it is precisely this kind of radical philosophical speculation that spurs current research in cosmology and neuropsychology.

Thousands of years may separate philosophical speculation from scientific application, as in the case of Democritus' atomism or Pythagoras' number-based ontology. The capacity of scientific generalizations like Newton's to predict and control experience may blind us to the limitations of scientific knowledge. Stephen Hawking (2010, p. 5; see Papazoglou, 2012, p. 10) claims - without success - that physics can now answer cosmological questions about our origins and purpose: "philosophy is dead." Confident of our control of experience, we may be reluctant to engage in philosophical speculation that might yield new scientific theories with more massive capacity for connectivity. Rare geniuses like Einstein replace old philosophical assumptions that served perfectly well for the prediction and control of experience for hundreds of years with astonishing new ones.

Focusing students' attention on the wildly imaginative and speculative nature of philosophy can help them understand that they are apprentices in the arts of solving problems. As students, they are immersed in one of the most fundamental of all human problems: what is education and how should it be conducted? Their own dissatisfaction with current answers to those questions can serve as the best stimulus for them to rethink and revise their experience of education. If students come to see themselves as apprentices in the art of solving problems, they may no longer see school as the work of memorizing facts and learning routines that are of little apparent relevance to their lives.

Can we give students a sense that they are partners in the adventure of solving unsolved problems? In my introductory philosophy courses, I tell students that the greatest problem they face in their lives is the perennial philosophical question: How should I live my life? The history of philosophy broadly conceived is a cascading series of answers to that question. Given the magnitude of our global 
problems, it should be clear to students that our current philosophies are inadequate for their tasks. I charge my students with the mission of coming up with better ways to ensure our own survival and flourishing in the face of the sixth mass extinction (Kolbert, 2014) — and to pass the joy of life on to future generations.

Every K-16 course should explore the idea that philosophy itself is the essence of education in the word's historical sense of a leading out from ignorance to knowledge, and from knowledge to wisdom. For Dewey (1916, p. 338; see Kitcher, 2011, p. 249), philosophy is education: "If we are willing to conceive education as the process of forming fundamental dispositions, intellectual and emotional, toward nature and fellow men, philosophy may even be defined as the general theory of education." Every classroom should be a place where students participate in humanity's ongoing pursuit of wisdom. A key to philosophy of education must be philosophy in education.

As Nel Noddings put it, education has lost contact with the students. Dewey (1938, p. 43) points out a primary reason for this: a failure to emphasize "the importance of the participation of the learner in the formation of the purposes which direct his activities in the learning process." Dewey (ibid.) claims that the greatest flaw in traditional education is "its failure to secure the active cooperation of the pupil in construction of the purposes involved in his studying." The introduction has made the claim that philosophy's primary task is the solution of what appear - at first glance - to be intractable problems. Students who do not realize that their primary mission is to prepare themselves to address those problems cannot connect school to life. The next section focuses on Nietzsche's conviction that philosophy's most fundamental problem is how to guarantee that humanity will survive and flourish.

\section{Nietzsche's Metaphilosophy}

In Beyond Good and Evil, Nietzsche (1992, p. 420) offers a poetic description of the philosopher: "a fatal human being around whom there are constant rumblings and growlings, crevices, and uncanny doings." Nietzsche separated philosophy from science. The distinction between the two subjects lies in their degrees of generalization. At their intersection, philosophy and science are indistinguishable, like color bands on a spectrum. Philosophy's forte is generalization. Science's is specialization. In Nietzsche's (1992, p. 314) eyes, the inauguration of the $\mathrm{PhD}$ degree in German universities in the $19^{\text {th }}$ century heralded the separation of the two fields:

"The dangers for a philosopher's development are indeed so manifold today that one may doubt whether this fruit can still ripen at all. The scope and the tower-building of the sciences has $[\mathrm{sic}]$ grown to be enormous, and with this also the probability that the philosopher grows weary...so he never attains his proper level, the height for a comprehensive look, for looking around, for looking down." 
The success of the sciences in predicting and controlling experience forces philosophers into the respective specializations of philosophy so prominent in contemporary philosophy. Imitating scientists, philosophers have become specialists or even handmaidens to science.

Against this tide, Nietzsche (1992, p. 325) advocates a return to the primal essence of philosophy - the creation of new values as an expression of life's force:

"Genuine philosophers... are commanders and legislators: they say, "thus it shall be!" They first determine the Whither and For What of man, and in so doing have at their disposal the preliminary labor of all philosophical laborers, all who have overcome the past. With a creative hand they reach for the future, and all that is and has been becomes a means for them, an instrument, a hammer. Their "knowing" is creating, their creating is a legislation, their will to truth is-will to power."

Philosophy stands outside of science in several ways. It judges the value of science with respect to life: the philosopher "demands of himself a judgment... about life and the value of life" (Nietzsche, 1992, p. 314). And philosophy creates the diverse methodologies or research paths that inspire scientific creativity. Nietzsche identifies the philosopher as a "genius - that is, one who either begets or gives birth, taking both terms in their most elevated sense...." He contrasts the philosopher with the "scholar, the scientific average man" who "always rather resembles an old maid: like her he is not conversant with the two most valuable functions of man" (Nietzsche, 1992, p. 314, my emphasis). Those two functions are the "begetting" and "giving birth" to the direction of life - and science as a part of life. Philosophical guidelines create new knowledge by creating generalizations that reduce the manifold of experience.

The philosopher is the advance guard on reduction's path. Scientific reductions are limited to specializations like physics, chemistry and biology. Within those fields are even sharper reductions. Newton reduced the difference between motions in the heavens and on the earth to universal laws. Darwin reduced the differences between human and all other life forms to the common process of evolution. Maxwell reduced electricity and magnetism to a common set of fundamental laws. Teams of contemporary physicists reduce nuclear and electromagnetic phenomena to electroweak laws. And string theorists in pursuit of theories of everything or grand unifying theories seek the marriage of gravitational with electromagnetic and nuclear phenomena.

Nietzsche's reduction exhibits a far greater and deeper scope. He would like to reduce all experience to its foundation in value. And like Hume, he finds the source of all value in feeling. The force of life or the will to power is in turn the source of feeling. Philosophy at its maximum performance aims to create new values, new rules for the direction of life under conditions of maximum uncertainty. Down from that almost impossible goal are the lesser tasks of philosophy: to create new ways to solve problems not in the whole of life but in the details of life. 
The German invention of the $\mathrm{PhD}$ degree maps - albeit unconsciously - this function of philosophy forcefully. Think of the irony of receiving a degree in chemistry or business that is nevertheless a degree in philosophy. What have engineering or neuroanatomy to do with philosophy? Our careful separation of philosophy from the sciences and engineering is a creation of $20^{\text {th }}$ century separation of intellectual powers. As Descartes strove for a distinctive philosophical method that would yield the objectivity of the mathematics and sciences of his day, $20^{\text {th }}$ century philosophers like Quine (1972) saw philosophy as a handmaiden to science.

Analytic philosophy, philosophies of language, mathematics, logic and science became the staples of philosophy departments in elite universities in English-speaking nations. In France, Jacques Derrida (1985; 1997; 2001) inaugurated the deconstruction of meanings as a primary method of philosophy. Philosophy's old mission, creating values and rules for the direction of life, was left to modest redoubts in those departments or more robust fortresses in European universities.

Why regress to Nietzsche's vision for philosophy now? If danger is morality's source, then new dangers call for new philosophies. In the Gay Science, Nietzsche (2001, p. 6, Nietzsche's emphasis) affirmed the primary role of philosophy:

"I am still waiting for a philosophical physician, in the exceptional sense of the word - one who has to pursue the problem of the total health of a people, time, race or of humanity - to master the courage to push my suspicion to its limits and to risk the proposition: what was at stake in all philosophizing hitherto was not at all 'truth' but something else - let us say health, growth, future, power, life."

The Gay Science (2001, p. 27) presents Nietzsche's rationale for his philosophical deliberations on value: Humans dedicate themselves to a

"single task, each and every one of them: to do what benefits the preservation of the human race. Not from a feeling of love for the race, but simply because within them nothing is older, stronger, more inexorable and invincible than this instinct - because this instinct constitutes the essence of our species and herd."

Nietzsche's flaw is to reserve the practice of philosophy only for the elite. The Gay Science (2001, p. 330) claims that a philosopher's virtues "must have been acquired, nurtured, inherited, and digested" to prepare him for "great responsibilities, the loftiness of glances that dominate and look down, feeling separated from the crowd and its duties...." Nietzsche despised the socialism emerging in his times. Confronting Darwin's theory of evolution, especially as promulgated through Herbert Spencer's emphasis on "survival of the fittest," Nietzsche (1999) in Thus Spake Zarathustra fantasized that a "new man" shaped by the will to power would supplant humanity just as humans supplanted the other 
higher primates (see Johnson, 2010 for Nietzsche's anti-Darwinism and Richardson, 2004 for his pro-Darwinism).

Philosophy's resurgence depends on educators' recognition that philosophy can never be finished. The philosopher's mistake is to imagine that her particular choice of a foundational value may capture an eternal truth. In Human, All Too Human (1992, p. 157), Nietzsche highlights the philosophers' temptation to imagine that their work may be a final solution to a heretofore intractable problem:

"Philosophers' error. The philosopher supposes that the value of his philosophy lies in the whole, in the structure; but posterity finds its value in the stone which he used for building, and which is used many more times after that for building better. Thus it finds the value in the fact that the structure can be destroyed and nevertheless retains value as building material."

The world's most renowned philosophers have seized upon important aspects of the nature of life and how we should live, but a new value is always waiting in the wings. Nietzsche's wisdom is to insist that philosophy can never be finished. If Nietzsche is right that new philosophies emerge from new dangers, then we must impatiently await the next great philosophers. Unlike Nietzsche, however, we should believe that philosophers are made rather than born. As Beyond Good and Evil (Nietzsche, 1992, p. 330) has it, "For every high world one must be born; or to speak more clearly, one must be cultivated for it: a right to philosophy - taking that word in its great sense - one has only by virtue of one's origins; one's ancestors, one's 'blood' decide here, too." Against Nietzsche, the more minds working on the problem, the better the chances of a solution emerging.

Philosophy as the evolving quest for the meaning and direction of life has barely begun its task. While our human heritage runs back millions of years, we as Homo sapiens have only been on the planet for perhaps 300,000 years. We must see ourselves as utterly naïve, jejune, callow-featherless for the flights of fancy that the future will bring should we be wise enough to control the powers that science, technology, mathematics and engineering (STEM) unleash. Oppenheimer's purported recitation of Vishnu's line in the Bhagavad-Gita is still apropos: "Now I am become death, the destroyer of worlds." Ironically, as we will see in the essay's conclusion, recent philosophers claim that new technologies may serve to guarantee the future of life on earth (Verdoux, 2011).

\section{Philosophy's Place in K-16 Curricula}

Tim Crane cites Wilfrid Sellars' sense of philosophy: "The aim of philosophy, abstractly formulated, is to understand how things in the broadest possible sense of the term hang together in the broadest possible sense of the term" (Sellars cited in Crane, 2012, p. 21). Sellars' description is incomplete. Philosophy also aims to understand how "things fall apart," in Yeats' immortal words (Staub, 1989). However, Sellars' sentiment captures the generality of philosophy. The expression 
hang together is perhaps the simplest formulation of thinking as an agent of connectivity.

Sellars seizes upon Nietzsche's conviction that philosophical vision must be from a great height so that it may encompass all experience. Examining the principles whereby everything hangs together captures Nietzsche's sense that philosophy must be the driving force of life. Ever seeking to expand the range of one's vision, searching for hidden principles beneath obvious principles, viewing the history of those principles with an eye toward replacing them-all these express Nietzsche's definition of philosophy. Nietzsche has made no new discovery in defining philosophy's roles, as both Plato and Aristotle saw philosophy as synoptic, foundational and self-correcting.

Introducing philosophy into education means exposing students to the deepest controversies in every subject they study (Graff, 1992). In my introductory philosophy classes I ask students to explain why my pen falls when I drop it. They of course answer that it falls because of the force of gravity. Paraphrasing the title of a wonderful book (Loewen, 2007), I say that this answer is one of the lies your teachers told you.

A better answer to the question is that no one knows why objects with mass behave in gravitational ways. Theories abound. Physicists used to speculate that gravity was a force carried by particles called gravitons. Recent experiments detected gravitational waves. However, waves require a medium whose nature must be a matter for speculation. Einstein claims that mass warps the shape of space to cause gravitational phenomena. But why does mass warp space? Descartes explained gravitational movement through vortices in a hypothetical ether, the plenum of space. Newton saw gravitational force as acting at a distance through the vacuum of space, but he famously said he had no idea how that could happen: "hypotheses non fingo."

Introducing philosophy into the curriculum in this example would mean simply confessing our ignorance and asking students for help: "We don't know why the pen falls, but we can describe its behavior very precisely. We would very much like to discover why it falls. Would you please help us out with our research?" Posing such a question and making such a request, even to very young students, can give them an avenue to turn school away from the drudgery of factgathering into the joy of exploration and discovery (Matthews, 1996; 1982).

This proposal is hardly new. Philosophers of education like Rousseau, Dewey and Montessori have capitalized on the model of education as discovery. What is new in this essay's proposal is that philosophy be introduced systematically into every subject at every level of education. Matthew Lipman's Philosophy for Children Program (2012) at Montclair State University offers a K-12 philosophy curriculum. However, the program offers course modules in philosophy rather than saturation of the curriculum with philosophy.

Introducing philosophy into the K-12 curriculum will show students that some problems simply never go away. Scientific problems begin as philosophical problems and then vanish. The conviction that the earth is the center of the universe was virtually universal until Aristarchus proposed a sun-centered world more than 2,000 years ago. Only in 1836 did his conviction receive empirical 
confirmation through advanced technologies for confirming celestial parallax. The deepest scientific problems can never escape philosophy. The ultimate cosmological question —-where did it all come from?"- is unanswered for both ancient Greek and contemporary cosmologists.

Dewey remarks on philosophical problems, "We do not solve them: we get over them" (Dewey, 1910, p. 19; see Kitcher, 2011, p. 252). From Nietzsche's point of view, Dewey could not be more wrong. We "try on" solutions, sometimes for the moment, sometimes for the millennia. For Nietzsche, "real" philosophy creates new solutions to old problems. That very process creates new problems. The generality of philosophical problems and answers renders them more unfit for verification than scientific generalizations.

A seductive test of both philosophical and scientific generalizations is Dewey's (1938), however: pragmatic application. This process requires varying time spans across the two disciplines. Aristotle has commanded numerous followers for over 2,000 years (Collins, 2000). Newton's science of mechanics had a much briefer lifespan, although his generalizations still have practical uses for predicting and controlling lesser masses and velocities. Quine and his fellow naturalists are right to say that all philosophical claims are "vulnerable to revision in the face of empirical evidence" (Lewens, 2012, p. 47). Philosophy is indeed an experimental discipline, though its experiments may run for thousands of years (Appiah, 2008).

Philosophy's problems are compelling and urgent. While with Socrates we can be certain our solutions must be passing fancies, we must commit ourselves to those fancies in order to get on with life. We can wait millennia for consensual answers to purely scientific problems. But we must have instant solutions to the deepest philosophical problems in order to know how to live. Contemporary philosophers question the power of philosophy to solve problems: "Many contemporary philosophers see themselves as problem solvers-like natural scientists. This seems to be mistaking the characteristic philosophical vocation. To philosophize is to engage in a reflective activity, but it is hardly a domain where one expects to solve problems" (Hedley, 2012, p. 115). Against this sentiment, philosophical problems must be solved in order know how to live. They may only be solved for the nonce-or perhaps for millennia in the case of long-lived philosophies like those of Socrates, Plato and Aristotle.

Introducing philosophy into education means exposure to controversy at multiple levels of generality. Certainly this is true for the grand problems of life such as Kant's "what can I know," "how should I live" and "what may I hope for." But it's also true for problems of fine-grained detail. Every intellectual discipline's mission is to solve problems within a specific area of experience. The philosophies of those disciplines dictate their unsolved problems and the controversial methods for research into their solutions. Such controversy is the life-blood of every discipline, from fine arts and practical arts through history, science and particularly philosophy itself. Controversy in the fields of mathematics, logic and grammar is more difficult to glimpse for the uninitiated. However, non-Euclidean geometries, Gödel's discoveries of inconsistency and incompleteness in formal systems, Chomsky's postulation of a universal grammar and the failure of Russell to derive 
mathematics from logic disclose the deeply contentious nature of these fields. The Bourbaki group inverted Russell's hypothesis to claim that logic is simply a part of mathematics following from set theory.

Grounded in uncertainty and controversy, emboldened by its synoptic and foundational vision, critical of all its predecessors, saturating all intellectual disciplines (including itself - hence the journal Metaphilosophy), philosophy has the power to turn every discipline into a "blood sport." Philosophy on Nietzsche's definition is like life itself, red in tooth and claw: "I love only what a person hath written with his blood" (Nietzsche, 1999, p. 23).

Educators will have good reasons to resist this model of philosophical education. Students must learn the basics of a discipline before they can be competent to criticize well-established disciplinary practices. Teachers must retain autonomy in the classroom to ward off chaos. However, apprenticeship in the basics of a subject must be conducted with student focus on the problem to be solved-with philosophical awareness that alternative solutions may exist. Students should be sensitized to search for those alternatives as soon as they are grounded in the field's basic methods of research.

\section{Conclusion: Democratizing Philosophy: Whose School? Whose Life?}

To summarize once again the results of this research in Dewey's (1916) words above, philosophy is education and education is philosophy. If this premise is true, the consequences for education are provocative. If Nietzsche is right that danger is the source of morality and that grave danger demands a global response, then the survival of life as we know it commands a global infusion of philosophy into education. The Senegalese historian, Cheikh Anta Diop (1990), puts it this way. Evolution drives us to survive. And creativity is our means of survival. As the leisure that makes creativity possible, school is the instrument of survival. We cannot have life without school. Conversely we cannot have school without life. What is more important - survival or creativity? Life or school? All are inseparable and philosophical reflection is their driving force.

The final questions are: Whose school? Whose life? A proper school aims at our schooled capacity to solve life's problems. If we now face the gravest selfcaused dangers to our survival, should not all humans have access to an education grounded in philosophy and aimed at the survival of life on earth? Preposterous! However, Nietzsche would insist that philosophical commands be outrageous to their first hearers. Think of Thomas Jefferson's (2011) absurd - for the timesproposal that rich men should pay for the grammar school education of poor men's sons. W.E.B. Du Bois (2001) uttered his own command about proper schooling in the context of African American experience. He said that the point of a black university is not to train professional problem-solvers to go into their supporting communities to get high paid jobs. Rather university students should go into those communities in order to teach community members how to solve their own problems. Service learning with éclat! 
Going even further, Du Bois said that African American colleges and universities (HBCUs) should create models whereby virtually every human being would have a university education. His inspiration for this proposal was the African American civil war troops in Missouri who took the idea of universal public education back to the South. In Du Bois' eyes, those troops inspired an ideal for HBCUs to follow-universal public education not simply at the elementary and high school levels for African Americans, but also universal higher education (Verharen, 2001).

Alain Locke (1989), the first African American Harvard $\mathrm{PhD}$ in philosophy, Rhodes scholar and founder of Howard University's philosophy department, echoed Du Bois in advocating university-level education for adults who had missed that privilege. Anna Julia Cooper (1988), the first African American woman to receive her $\mathrm{PhD}$ in philosophy from the Sorbonne, used her house near the Howard University campus as a night school for adult university-level education. Howard University's founding mission was to offer a first-rate education in problem-solving to students who would not otherwise have the opportunity. Civil War general Oliver Otis Howard thought that freed African Americans were most in need of higher education to solve their problems autonomously (Logan, 2004). Du Bois capitalized on General Howard's wisdom to insist that all humans be invested with a university-level education. In his vision, universities must no longer be instruments for the production of an elite corps of professional problem-solvers. Rather they must become instruments for empowering those populations most in need.

Distribution of university education to a global audience requires its deinstitutionalization. Visiting Africa for the first time, Du Bois reveled in the West African integration of education with life: "[children] sat in council with their elders and learned the history and science and art of the tribe, and practiced all in their daily life. There could not be uneducated people. There could be no education that was not at once for use in earning a living and for use in living a life" (Du Bois, 2001, p. 84).

Can new technology help turn Du Bois' dream into reality? Harvard and MIT's collaboration on the edX project distributes STEM courses around the globe through Massive Open Online Courses (MOOCs). Stanford's Sebastian Thrun offered an online course on introductory artificial intelligence to 160,000 from 190 countries (Auleta, 2012, p. 47). Udacity and Coursera augment leading research universities' efforts to distribute university-level education throughout the world through for-profit credit certification. The world's leading research universities like Oxford and Cambridge join Harvard and MIT in offering MOOCs. While MOOCs have severe student-retention problems, new adaptations of socially relevant computing, wireless broadband access to global networks and distance learning grounded in expert tutorial computer programs can make it possible for the university to come to the community rather than vice versa (Bowen, 2013).

On a final note, a compelling reason to democratize philosophy is to further democracy itself. In its present guise, what passes for democracy relies on the "wisdom of the crowd" for its justification. In Du Bois' vision of the future, a true 
democracy would guarantee that every member of that "crowd" be educated in schools infused with philosophy. Educated like Nietzsche in one of Germany's finest $\mathrm{PhD}$ programs, $\mathrm{Du}$ Bois had to overcome his former elitist view that only the "talented tenth" could profit from higher education. If his ideal is preposterous, then Du Bois salutes Nietzsche's (1992, p. 737) command that philosophy be provocative: "How I understand the philosopher-as a terrible explosive, endangering everything...." The latest biography of Nietzsche (2018) is simply titled, I Am Dynamite.

\section{References}

Appiah, K. (2008). Experiments in Ethics. Cambridge: Harvard University Press.

Aristotle. (1941). The Basic Works of Aristotle. R. McKeon, ed. New York: Random House.

Auleta, K. (2012, April 30). Annals of higher education: Get rich U. New Yorker, 38-47.

Bowen, W. (2013). Higher Education in the Digital Age. Princeton, N.J.: Princeton University Press.

Collins, R. (2000). The Sociology of Philosophies: A Global Theory of Intellectual Change. Cambridge: Belknap.

Cooper, A. (1988). A Voice from the South. New York, NY: Oxford University Press.

Derrida, J. (1985). The Margins of Philosophy. (A. Bass, Trans). Chicago: University of Chicago Press.

Derrida, J. (1997). Le Droit à la Philosophie du Point de Vue Cosmopolitique. Paris: UNESCO/Verdie.

Derrida, J. (2001). L'Université sans Condition. Paris: Éditions Galilée.

Dewey, J. (1910). The Influence of Darwin on Philosophy and Other Essays in Contemporary Thought. New York: Henry Holt.

Dewey, J. (1916). Democracy and Education. Ed. J. Boydston. (S. Hook. Trans.) Series: Collected Works of John Dewey. (Middle Works: Volume 9). Carbondale, IL: Southern Illinois University Press.

Dewey, J. (1938). Experience and Education. J. Boydston (Ed.). (S. Cahn. intro.). Series: Collected Works of John Dewey. (Later Works: Volume 13). Carbondale, IL: Southern Illinois University Press.

Diop, C. (1990). The Cultural Unity of Black Africa. No trans. cited. Chicago: Third World Press.

Du Bois, W. (2001). The Education of Black People: Ten Critiques, 1906-1960. Herbert Aptheker (Ed.). New York, NY: Monthly Review Press.

Gardiner, S. (2011). A Perfect Moral Storm: The Ethical Tragedy of Climate Change. Oxford: Oxford University Press.

Graff, G. (1992). Beyond the Culture Wars: How Teaching the Conflicts Can Revitalize American Education. New York: Norton.

Greene, B. (2011). The Hidden Universe. New York, NY: Vintage.

Hawking, S., \& Mlodinow, L. (2010). The Grand Design. New York: Bantam Press

Heal, J. (2012). Philosophy and its Pitfalls. Metaphilosophy, 43(1-2), 39-45.

Hedley, D. (2012). Forms of Reflection, Imagination, and the Love of Wisdom. Metaphilosophy, 43(1-2), 112-124.

Jefferson, T. (2011). Notes on the State of Virginia. Chapel Hill: University of North Carolina Press. 
Johnson, D. (2010). Nietzsche's Anti-Darwinism. Cambridge: Cambridge University Press.

Joyce, R. (2006). The Evolution of Morality. Cambridge: MIT Press.

Joyce, R. (2001). The Myth of Morality. Cambridge: Cambridge University Press.

Kitcher, P. (2011). Philosophy Inside Out. Metaphilosophy, 43(3), 248-260.

Kolbert, E. (2014). The Sixth Extinction: An Unnatural History. New York: Henry Holt.

Lewens, T. (2012). A Surfeit of Naturalism. Metaphilosophy, 43(1-2), 46-57.

Locke, A. (1989). The Philosophy of Alain Locke: Harlem Renaissance and Beyond. Philadelphia, PA: Temple University Press.

Loewen, J. (2007). Lies My Teacher Told Me: Everything Your American History Textbook Got Wrong. New York: Touchstone.

Logan, R. (2004). Howard University: The First Hundred Years 1867-1967. New York: New York University Press.

Magee, B. (ed.) (1982). Men of Ideas: Some Creators of Contemporary Philosophy. Oxford: Oxford University Press.

Matthews, G. (1996). The Philosophy of Childhood. Cambridge: Harvard University Press

Matthews, G. (1982). Philosophy and the Young Child. Cambridge: Harvard University Press.

Nietzsche, F. (1992). Basic Writings of Nietzsche. Trans. Walter Kaufman. New York: The Modern Library.

Nietzsche, F. (1999). Thus Spake Zarathustra. (Thomas Common, Trans.) New York: Dover.

Nietzsche, F. (2002). Beyond Good and Evil. R.-P. Horstmann, J. Norman, (Eds.) (J. Norman Trans.). Cambridge: Cambridge University Press.

Nietzsche, F. (2001). The Gay Science. B. Williams (Ed.), (J. Nauckhoff Trans.). Cambridge: Cambridge University Press.

Noddings, N. (2011). Philosophy of Education. Boulder, CO: Westview Press.

Nussbaum, M. (1986). The Fragility of Goodness: Luck and Ethics in Greek Tragedy and Philosophy. Cambridge: Cambridge University Press.

Papazoglou, A. (2012). Philosophy, its Pitfalls, Some Rescue Plans, and Their Complications. Metaphilosophy, 43(1-2), 2-19.

Philosophy for Children. (2012). Retrieved from https://bit.ly/2FbkIJ4

Quine, W. (1972). Theories and Things. Cambridge: Harvard University Press.

Quine, W. (1951). Main Trends in Recent Philosophy: Two Dogmas of Empiricism. Philosophical Review, 60(1), 20-43.

Richardson, J. (2004). Nietzsche's New Darwinism. Oxford: Oxford University Press.

Staub, E. (1989). The Roots of Evil: The Origins of Genocide and Other Group Violence. Cambridge: Cambridge University Press.

Thagard, P. (2011). The Brain and the Meaning of Life. Princeton, NJ: Princeton University Press

Verdoux, P. (2011). Emerging Technologies and the Future of Philosophy. Metaphilosophy, 42(5), 682-707.

Verharen, C., Tharakan, J., Middendorf, G., Castro-Sitiriche, M., \& Kadoda, G. (2011). Introducing Survival Ethics into Engineering Education. Science and Engineering Ethics, 19(2), 599-623.

Verharen, C. (2001). "What They Lose on Earth by Being Black": Du Bois and the Future of African American Education. C.L.R. James Journal, 8(2), 121-151.

Wilson, E. O. (2016). Half Earth: Our Planet's Fight for Life. New York: Liveright. 



\title{
Using Dance \& Movement to Enhance Spatial Awareness Learning
}

\author{
By Barbara Ann Temple ${ }^{*}$, Kathryn Bentley ${ }^{*}$, David K. Pugalee*, \\ Natalie Blundell \& $\&$ Carlos Miranda Pereyra
}

\begin{abstract}
By accessing creative portions of the brain through dance, Pre-K students can more easily learn math concepts like spatial awareness and critical math knowledge prior to formal assessment in elementary school. This early foundational learning creates educational equity by resulting in a month of additional math learning before ever stepping into an elementary classroom. At a very fundamental level, when students have access to math learning in Pre-K through the performing arts, they are more than a month ahead of their non-Pre$\mathrm{K}$ peers when they enter a Kindergarten classroom, (Ludwig, Marklein, \& Song, 2016). Arts-integrated math learning engages both hemispheres of the brain and all types of students, especially English Language Learners (ELL) and those from lower socioeconomic status, benefit academically from such experiences. Math and movement residencies bring equity and access to the classroom by preparing students with critical foundational knowledge in math prior to encountering formal math concepts in Kindergarten.
\end{abstract}

Keywords: dance \& movement, geometry, kinesthetic learning, social constructivism, spatial awareness.

\section{Introduction and Aims of Research}

Experiential learning in and through the arts benefits young students in Pre-K classrooms by engaging both creative right-brain activity with the more rational functions of the left brain. The average traditional classroom teacher (CT) does not possess the knowledge or skills to engage the brain holistically and simultaneously in this way. These strategies are not traditionally taught in public school teacher training, thereby creating disparities in equity and access for students. Mayer (2017) posits that the application of psychology to education has been ineffective primarily because it has been operating as a one-way street where educators have attempted to apply principles from psychology and neuroscience.

This inequity can be mitigated through arts-infused learning. Wolf Trap (WT) Institute for Early Learning Through the Arts administers seven-week arts-

\footnotetext{
*Vice President, Education Arts \& Science Council (ASC), USA.

${ }^{\dagger}$ Affiliate Director, North Carolina Wolf Trap Arts \& Science Council (ASC), USA.

*UNC Charlotte Center for Science, Technology, Engineering, and Mathematics (STEM) Education, USA.

${ }^{\S}$ Artistic and Executive Assistant, National Orchestra at the John F. Kennedy Center for Performing Arts, USA.

** Davidson College Impact Fellow Arts \& Science Council (ASC), USA.
} 
integrated residencies that provide Pre-K teachers with skills that work to engage students holistically. Professional Teaching Artists (TA) work with CTs to acquire arts strategies to be used throughout their careers.

\section{The Aim of the Research is to Answer these Questions}

- What happens to Pre-K students' acquisition of spatial awareness skills when they experience math literacy through dance and movement?

- How does learning improve when the performing arts are used to teach math?

\section{Literature Review}

Theorists and early education scholars advocated for interdisciplinary learning in the traditional classroom. John Dewey, an early twentieth century education reformer, argued for the importance of active learning and of drawing on personal experience when in the classroom (Dewey, 1902). Similarly, developmental psychologist Howard Gardner (1999) argued for the existence of multiple, categorical, intelligences within the singular human intellect. These two assertions combine to create a compelling argument for breaking away from traditional rote learning experiences and turning toward more real-world, creative, interdisciplinary experiences that create educational equity for students with diverse learning abilities and backgrounds.

Research reveals that children from a lower socioeconomic status often start Kindergarten significantly behind their peers (O’Brien \& Dervarics, 2007). This opportunity gap between students of poverty and students of medium or high socioeconomic status is narrowed through Pre-K programs in public schools that allow more students to perform at grade level when entering Elementary School. Additionally, there is some evidence that this gap would widen without schooling and that students from lower socio-economic groups experience a 'summer learning loss' at a higher rate than peers (Bradbury, Corak, Waldfogel, \& Washbrook, 2017). The social constructivist approach to Wolf Trap learning, exercised by both teachers and students, establishes a foundation for continued success in math learning. As students engage in the social activity of dance during math lessons, they learn more from engaging with each other and with the teacher than when learning independently. This situated cognition of learning spatial geometry through participating in dance is strengthened by students' social interactions with their peers (Vygotsky, 1978). As Pre-K students first learn about the notion of space and how they exist within the space around them, they begin learning spatial geometry. When young children discover new pathways in space that represent early spatial geometry, they gain self-confidence because the arts empower them to be actively engaged in their own learning (Pugalee, Harbaugh, \& Quach, 2009; Temple, 2007; Holloway, 2001; Burton, Horowitz, \& Abeles, 1999; Catterall, Chapleau, \& Iwanaga, 1999; Eisner, 1998). 
Success in STEAM disciplines (Science, Technology, Engineering, Arts and Mathematics) is closely linked to spatial abilities. A study at the University of Chicago found that "Improving children's spatial skills may have positive impacts on their future success in [STEM]...by enhancing numerical skills that are critical for achievement in all STEM fields," (Gunderson, Ramirez, Beilock, \& Levine, 2012). Specifically, acquiring spatial awareness will help students "mentally manipulate objects" which will serve them in the future when reading graphs and understanding diagrams (Gunderson et al., 2012). These studies indicate that these skills, required of any engineer or scientist, must be taught as early as possible. Wolf Trap math residencies translate to higher scores in math assessment. Through a grant from the U.S. Department of Education, the study on improved math performance in Wolf Trap residencies revealed students acquired an additional 26 days of math learning (Ludwig et al., 2016). In a similar study, the mean gain score for residency classrooms in mathematics was two times higher than non-residency classrooms (Klayman, 2004).

Figure 1. Using Scarves \& Body Movement to Show an Understanding of Position Words (i.e., under)

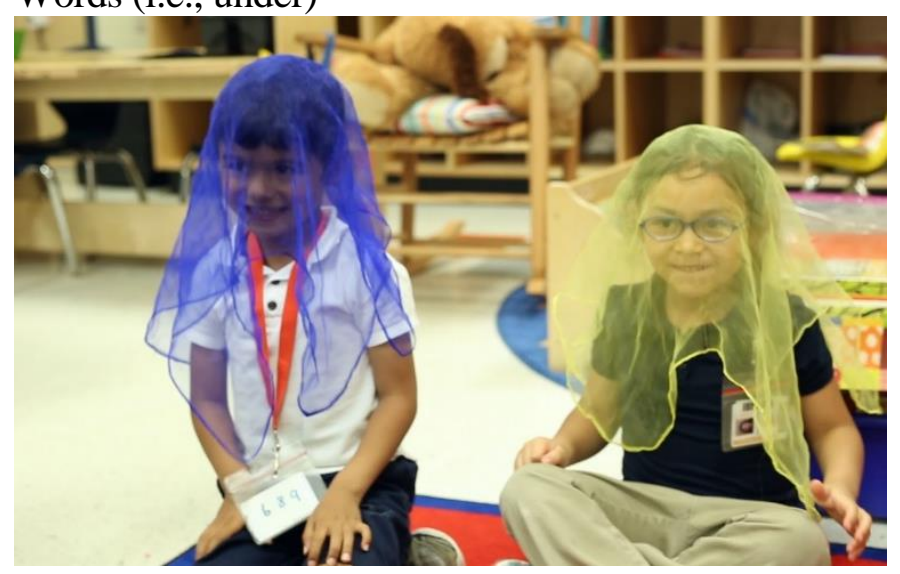

Source: Driscoll, 2017.

What does it mean to be spatially aware? Spatial awareness can be defined as "an awareness of the body in space, and the child's relationship to the objects in the space," (Hohmann, Weikart, \& Epstein, 2008). As children's brains develop, so too does their understanding of their body's relation to the world around them. At first it is difficult for young children to understand early spatial concepts such as "on," "under," "over," and "behind." Children develop spatial awareness through whole-body activities (see Figure 1). Once children understand early spatial concepts, they can then advance to more challenging math concepts in the future. For many preschool children, an understanding of spatial concepts predicts later success in math, reading, and following directions.

Why is spatial awareness important to math development? Spatial awareness is an important aspect of early childhood development. In many classrooms across the country, teachers are not stressing the concepts of geometry and spatial awareness. This is a disservice to children as they begin their school career. The extent of geometry instruction for many children is the act of sorting shapes made 
from cut outs and identifying the basic shapes (i.e., circle, square, triangle). Mathematical competency for children relates to their spatial awareness, which includes a recognition of shapes in their surrounding environment and involves counting objects in their surroundings. On a neuropsychological level, similar parts of the brain are used when performing spatial tasks as when performing number tasks. This spatio-numerical link is a foundation of an imperative for teachers: an intentional focus on spatial reasoning and geometry at an early age better prepares students for mathematics throughout their educational careers. Unfortunately, children who are less capable of reading lines and simple objects around them will more than likely also be unable to recognize forms and geometric plans. Children are capable of diving deeper into these concepts that they are given credit for. This early instruction will influence their learning in other areas of the school curriculum. So connected are spatial reasoning and mathematics that the spatial thinking skills of children can be used to predict math competency for adults (Yarmohammadian, 2014; Cheng \& Mix, 2013; Hubbard, Piazza, Pinel, \& Dehaene, 2005; Walsh, 2003; Dehaene, Bossini, \& Giraux, 1993).

While there may be a clear connection between mathematics and spatial thinking, its significance is integral to other areas of development, from physical education to art and language. Despite its prominence of spatial reasoning in various subjects, especially math, and recommendations by the NCTM that at least $50 \%$ of mathematic instruction be focused on spatial thinking, geometry and spatial reasoning continue to remain undervalued and under-taught (Moss, Bruce, Caswell, Flynn, \& Hawes, 2016; Bruce, Flynn, \& Moss, 2012; Sarama \& Clements, 2009; National Council of Teachers of Mathematics [NCTM], 2006).

Figure 2. Building Spatial Awareness by Forming Shapes with Their Bodies
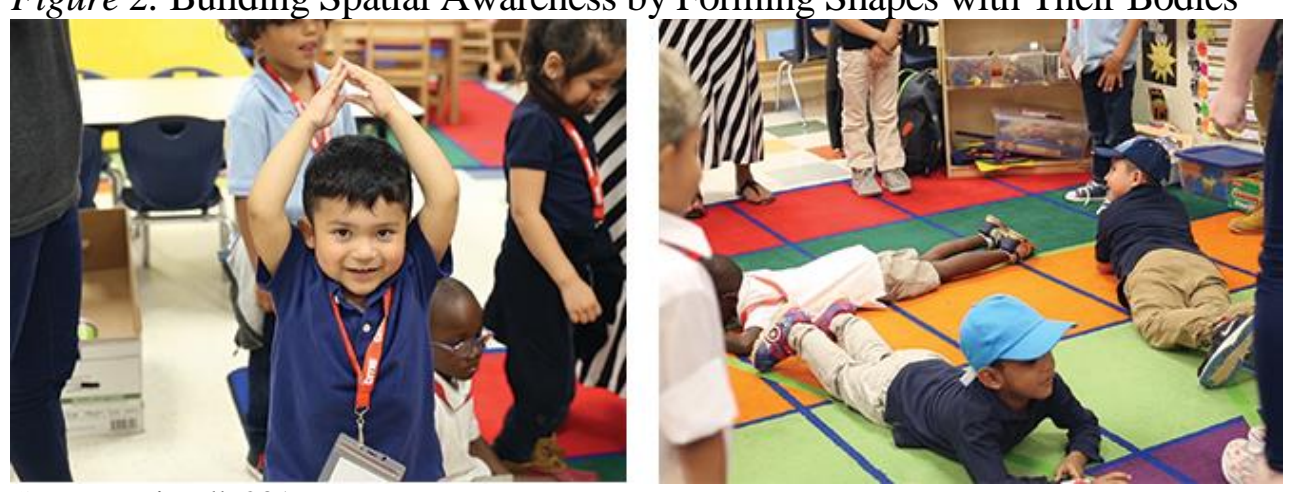

Source: Driscoll, 2017.

How does engaging in dance \& movement promote increased spatial awareness? Dance and movement are key to the development of spatial abilities in children. Physical movement is a child's natural first approach to learning. Dance elements such as body awareness, pathways, and creating shapes with the body all build spatial awareness in young children (see Figure 2). Integrating these dance elements into daily math lessons allows possibilities for exploring locomotor and non-locomotor movements. During dance or movement exercises, a child's understanding of spatial language enables him/her to move one's body through space. 


\section{Background and Ideology of Wolf Trap Residencies}

Wolf Trap residencies are a partnership between a Teaching Artist and an early childhood educator. The partnership provides professional development for early childhood educators while helping children learn through active participation. To qualify as a Wolf Trap Teaching Artist, individuals are required to have at least three years of experience working professionally in their artistic field. The artists become certified Wolf Trap professionals through intensive training by master Teaching Artists from the Wolf Trap Institute for Early Learning through the Arts headquarters. During the training, the Teaching Artists are instructed in early childhood developmental domains, developmentally appropriate practice, twenty-first century skills, intentional teaching, lesson design and coaching. They observe the skills and strategies of master Teaching Artists while designing their own arts-infused lessons.

The goal of the Wolf Trap Institute for Early Learning through the Arts is to provide professional development for each Pre-K and Kindergarten Classroom teacher for a period of three years (see Figure 3). In doing so, the classroom teacher has the opportunity to receive professional development training in all three of the performing arts: dance and movement, music, and drama. After three years of Wolf Trap residencies, a classroom teacher develops a good understanding of arts integration. Between residencies classroom teachers are able to have time to implement and practice the strategies presented during a residency. Wolf Trap has an exponential positive effect on students: Teachers are not only benefitting the three classrooms in which the residencies are administered, they continue to benefit every classroom they teach for the rest of their teaching career as well as in classrooms where they have shared with their colleagues how to use the performing arts to teach math concepts.

Figure 3. Engaging a Teacher \& Student in Movement Activity

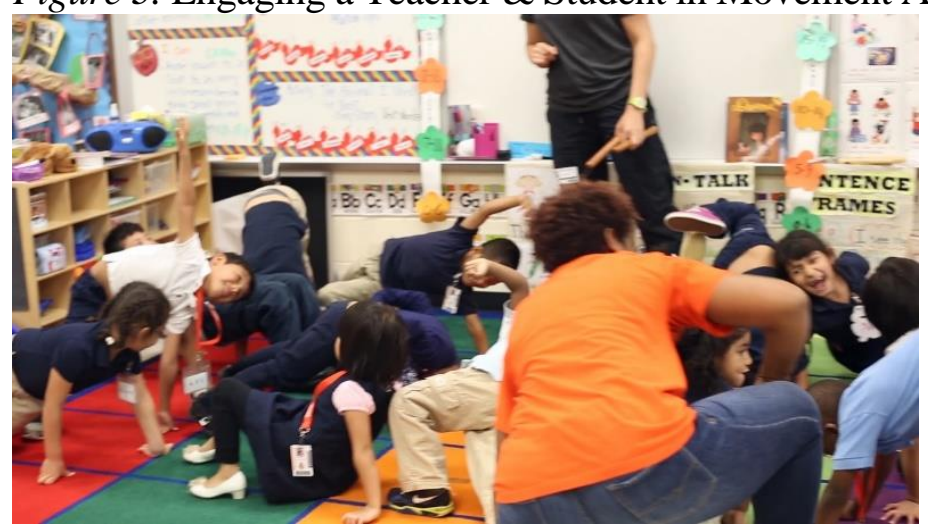

Source: Driscoll, 2017.

\section{Case Study Methodology}

The authors used ethnographic techniques of interview and observation to collect teacher narratives on student math learning in a high poverty school. The 
authors used these techniques to understand how the arts specifically created equity within Pre-K classrooms.

\section{Case Study Setting}

Mecklenburg County, North Carolina has a population just over 1 million and demographic data reports that just under half the county's population is a nonWhite minority (United States Census Bureau, 2015). In the local CharlotteMecklenburg School system (CMS), 77 of the total 170 public schools are categorized as Title I (high poverty)(Charlotte-Mecklenburg Schools, 2016). Creekside Elementary School houses 39 Kindergarten through 5th grade classrooms, and 16 Pre-K classrooms. Socioeconomic data revealed 98.89 percent of four-person families whose children attend Creekside earn an annual income of $\$ 24,600$ or less (Department of Health and Human Services, 2017).

\section{Data Collection}

The authors interviewed two Pre-K teachers directly involved in a math-based WT Residency in Dance and their two corresponding TAs for a 7-week residency in their respective classrooms. For the purpose of this particular case, we focused on the concept of spatial awareness in Geometry lessons. Both Pre-K teachers were asked the same questions: What specific spatial awareness words, positions, and exercises did your students learn through dance/ movement and why were they important? What were the specific components of dance/movement that helped your students increase their spatial awareness? We conducted the interviews at the conclusion of the 7-week residency and both teachers were present during the interview period.

Participants. The WT STEM (Math) residencies in dance and movement were conducted in two Pre-K classrooms of 18 students each. Ms. Jones' class consisted of four native English speakers and 14 non-English speakers. Elizabeth, a Wolf Trap Teaching Artist in dance \& movement, worked with Ms. Jones' classroom for the math residency in this case. Together, Elizabeth and Ms. Jones identified specific math learning goals and arts strategies for the residency. First, students would understand and describe spatial relationships and shapes through body strength, balance, flexibility and stamina. Second, students would increase their ability to move their bodies in space (running, jumping, and skipping).

Ms. Graham taught the second Pre-K classroom consisting of three native English speakers and 15 non-English speakers. Stacy, a Wolf Trap Teaching Artist in dance \& movement, worked with Ms. Graham's Pre-K students. Based on the specific needs of her students, Ms. Graham worked with Stacy to identify specific math learning goals and arts strategies for the residency. First, students should be able to understand and describe spatial relationships, shapes, and patterns through axial, locomotor, non-locomotor, and body shapes. Second, students should be able to understand and describe spatial relationships, shapes, and patterns by moving in time to different patterns of beat, rhythm, and music. 


\section{Data Analysis}

Through qualitative data, the authors uncovered fascinating findings that ultimately helped answer the two main research questions. Below, the interview responses from classroom teachers and Teaching Artists are categorized to answer these two research questions. One question focused on the specific acquisition of new math knowledge through dance and movement. The second question focused specifically on how learning improved through the performing arts.

\section{What Happened to Pre-K Students' Acquisition of Spatial Awareness when Math Lessons were Integrated with Dance and Movement?}

The kinesthetic act of movement through dance created access for Pre-K students to acquire spatial awareness. Dance and movement were key to the development of spatial abilities in the children and resulted in active engagement, attention to focus, and increased self-confidence (see Figure 4). Integrating dance into daily curriculum supported acquisition of spatial understanding and increased self-awareness.

Figure 4. Developing Self-Confidence While Taking Risks in Front of Peers

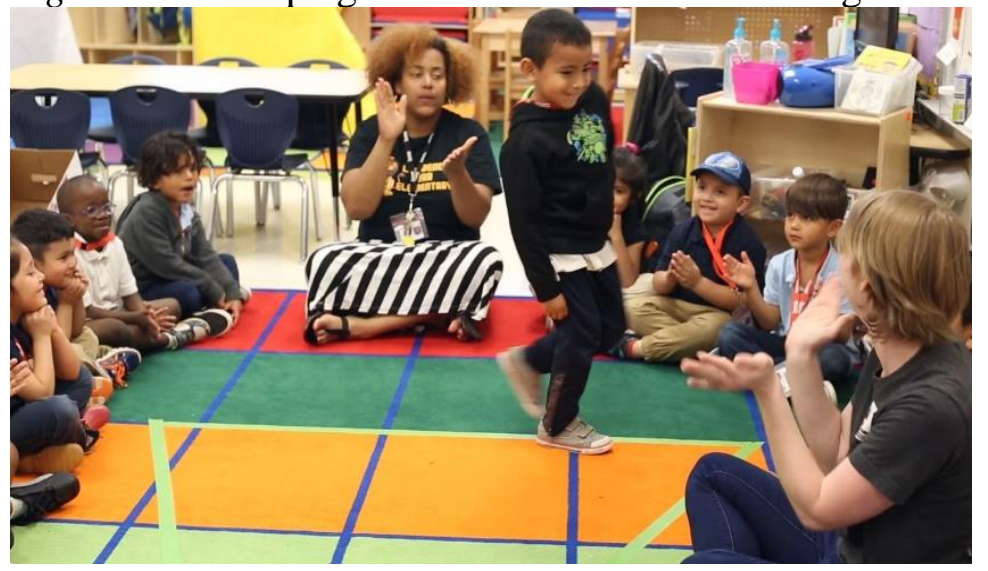

Source: Driscoll, 2017.

Elizabeth: Being spatially aware allows the children to move in a group setting with other bodies without safety issues...They learned how to control their bodies.

When math and dance were combined to teach students about spatial awareness, the classroom became safer, focused, and accident-free. Fewer physical accidents in the classroom created a healthier learning environment where students were more capable of sustained learning for long periods of time.

Stacy: Dance inherently requires and develops constant spatial awareness. Dancing in groups allows children to gain a general understanding of how much space their body takes up and how to move safely next to their friends and objects in the room. 
This newly acquired sense of personal space transferred to tasks that students completed as a group. The improvement of spatial awareness through math and dance allowed entire classrooms to complete simple daily tasks more efficiently.

Ms. Jones: The exercises [where students] walk on different shapes and lines taped to the floor helped them walk in a straight line [as a group] in the hallway, for example.

These seemingly simple tasks of walking in a straight line as a classroom to the cafeteria are profoundly difficult for a Pre-K child with little to no spatial awareness. However, when the children in this case learned these skills, teachers saw major improvements in the efficiency of moving Pre-K students from point A to point $\mathrm{B}$.

Additionally, crossing the midline of the body helps build pathways in the brain and is an important skill required for the appropriate development of motor and cognitive skills. Many Pre-K activities require a child's ability to cross the midline of the body. By crossing a hand, arm, foot, or leg to the opposite side of the body, children build increased brain functions to perform more advanced tasks. When you move your arms or legs across to the other side of the body, both sides of the brain are activated making reading, comprehension, writing, and math easier to take place (see Figure 5). Children will also have trouble with self-care skills, sports and physical activities when they have not developed the ability to cross the midline. Such activities, through dynamic development of imagery, show how the use of body movements and other motor components connect visualization and movement in supporting learning (Presmeg, 2006; 1991).

Figure 5. Crossing the Midline while Building Pathways in the Brain

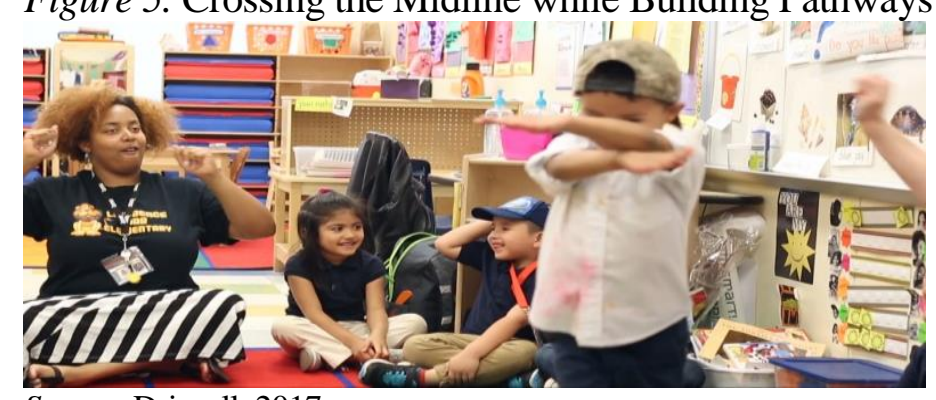

Source: Driscoll, 2017.

The crossing from one side of the body to the other side is a type of bilateral movement. Children who are unable to develop this bilateral skill often have difficulty learning to read. Similar to bilateral body movements, reading requires the eyes to move from left to right across the page and across the midline of the brain. When young children lack practice in bilateral movements, the task of moving eyes from left to right across a page can be taxing for the eyes, resulting in the inability to understand the meaning of the text. Furthermore, bilateral skills also assist in the development of handwriting skills. Greenes, Ginsburg, and Balfanz (2004) report that body movements and the related sounds are effective in supporting young children's understanding of mathematics concepts. Other researchers have shown that body movements have a positive impact on young 
students' cognition learning and academic achievement (Chandler \& Tricot, 2015; Erikson, Hillman, \& Kramer, 2015; Bartholomew \& Jowers, 2011; Tomporowski, Davis, Miller, \& Naglieri, 2008).

In this particular case, there were many dance and movement activities that developed cross-lateral motions. As children moved along different pathways, repeated dance patterns, or created body shapes, they connected these movements with a growing understanding of geometric concepts. At the Pre-K level, some children are only familiar with the basic shapes, (i.e., circle, square, and triangle). They may know the name of the shape but are unable to describe the shape attributes. During the dance activities, students were given the opportunity to learn the vocabulary needed to describe different geometric shapes. They learned how to sort shapes and how to use attributes to describe why a figure does or does not belong to a shape category.

\section{How Did Learning Improve when the Performing Arts Were Used to Teach Math?}

The performing art of dance - when used in math lessons - helped students feel more comfortable breaking from more traditional learning, thereby they gained comfort in risk and newness.

Stacy: As students' spatial awareness develops, they are able to make more exciting choices and begin to take risks and problem solve. The benefits of practicing and developing these skills in movement experiences positively affect the ways in which children interact with space in the classroom and at home (ex: following directions, fine and gross motor skills, playing safely with others)

Ms. Graham: I enjoy seeing my students make connections between the Wolf Trap residency and their real life. We use position words when we're out on the playground. I try to extend the lessons and draw these connections by saying "you're going down the slide" or "you're under the slide." They really use these words now.

By increasing children's spatial awareness through dance and math in the classroom, the teachers also increased students' opportunities to expand their learning beyond the walls of the classroom. As students increased their spatial awareness, they also increased their vocabulary. This was evident as students were better able to recognize and describe shapes they noticed in the environment They were able to use what they learned to talk about situations and experiences in the classroom, cafeteria, playground and in conversation about things that happened in their daily lives. They recognized shapes in books they were reading and on the walls around the school. Their school hallways were designed with geometric shapes and the children became proficient at naming shapes as they stepped on them. 
Learning the concept of spatial awareness through dance and repetition contributed to the development of self-efficacy in the Pre-K students.

Ms. Jones: I saw their confidence grow with identifying and describing shapes. Toward the beginning the students went directly to the station with the shape they knew best and felt most comfortable describing. But toward the end, I saw them feel more comfortable going to a shape that was newer to them.

Ms. Jones' observations of her students' increased self-confidence in experiencing shapes through movement is important for understanding math learning. Something equally as important took place within the students: they took risks and developed self-efficacy as they believed they could attempt to describe a shape unfamiliar to them. Their active participation in learning the concept of shapes through dance and movement enabled them to experiment with new learning in a safe environment.

Ms. Graham: I saw a confidence boost when we were learning shapes. Toward the beginning, I saw the students copying each other when they were asked to make shapes with their bodies. But toward the end, it was amazing to see the variety of shapes. They were being creative. Everybody finally felt comfortable to make their own shape.

The student-centered approach to math literacy learning through the arts fostered a socially-constructed new knowledge and understanding of spatial awareness. Notice that as the students' self-confidence grew, their creativity also increased throughout the residency. Within this participatory classroom, students not only learned new shapes through teacher instruction but also learned new shapes from one another (Vygotsky, 1978). This social constructivist approach to math literacy learning through the arts empowered students to become leaders within the collaborative classroom. In that leadership role, students became active participants in their own learning (see Figure 6).

Figure 6. Learning New Concepts through Social Interaction

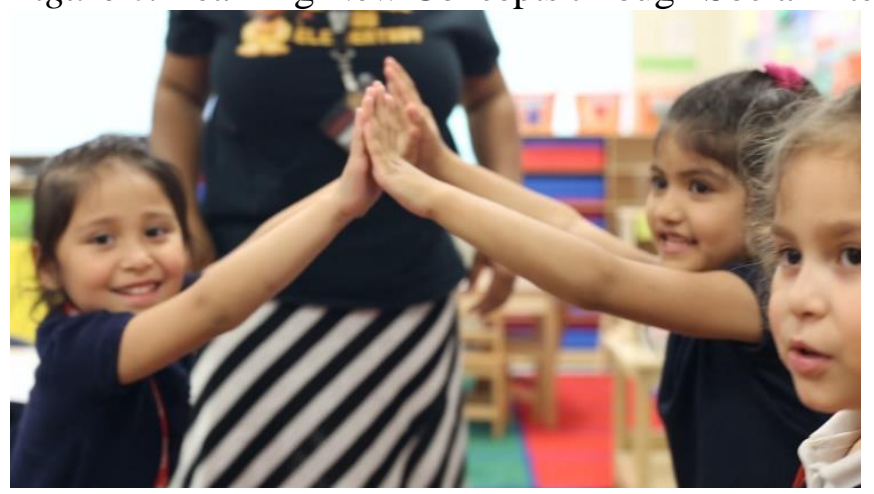

Source: Driscoll, 2017.

Ms. Jones: I see a big difference in participation [now that the residency is complete]. They weren't so sure and didn't want to join in during the first few 
sessions. But toward the end, they have to lead the song, and you can see that they get it, you can see they gained confidence.

In this case study, the arts cultivated access to a new language of math. Regardless of the linguistic capital each student brought to the classroom at the beginning of the residency, the arts removed barriers in learning new math concepts. By creating a safe space and "moments of inclusion," new math skills were developed through social interaction more easily (Temple, 2007; Holloway, 2001; Bourdieu \& Passeron, 1977) (see Figure 7).

Figure 7. Empowered as active participants in their own learning

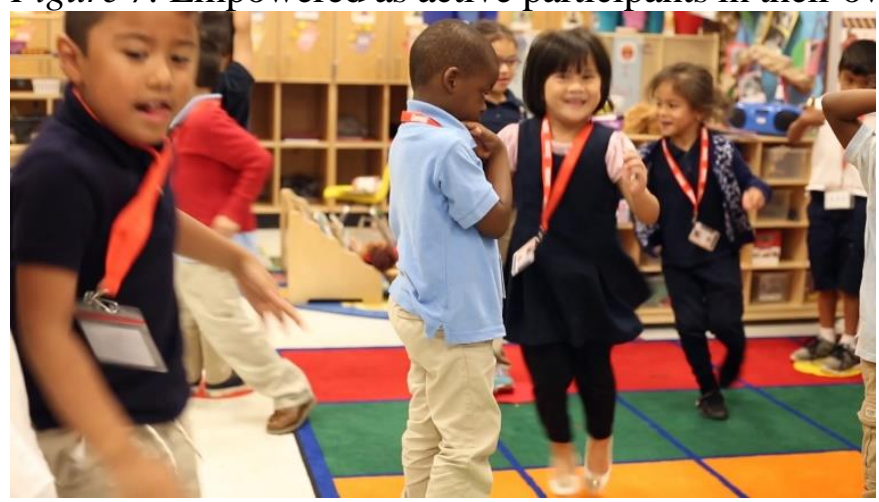

Source: Driscoll, 2017.

Ms. Graham: The residencies help reinforce [position] words that normally pose a challenge like "behind," "over," "under." We used the snowman from the story, so they got in front of the snowman, behind the snowman. At the end of the residency... they were finally getting the hang of it.

Together, the Pre-K students developed a common language centered on spatial awareness using position words within their math lesson. Students finally understood their own body's relation to space and objects in space (see Figure 8).

Figure 8. Listening \& Following Directions as the Teaching Artist Demonstrates Position Words with Scarves

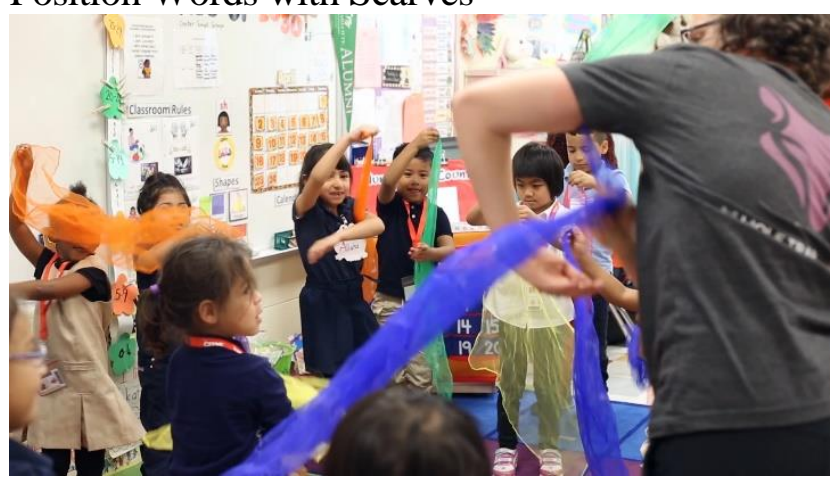

Source: Driscoll, 2017. 


\section{Implications}

Pre-K learning prepares students for learning in Elementary Education, contributing to their readiness for future learning and success later in life. Formal assessments which identify students for accelerated learning programs identify "spatial intelligence" as one of four identified areas (West Windsor-Plainsboro, 2015). By demonstrating a strong spatial intelligence, paired with talents in other academic arenas, students have an increased chance of being chosen for an accelerated academic program. Students who are exposed to and gain spatial awareness skills as early as Pre-K have more experience with these processes and are therefore more likely to meet, if not exceed, math learning standards for their age.

The Partnership for $21^{\text {st }}$ Century Learning (2016) research coalition created a framework which identifies skills that will prepare this next generation of students for future complex work environments: creativity, critical thinking, communication, and collaboration. This framework responds to the Mayer (2017) recommendations for using psychology and science to make unique contributions: a focus on subject area learning, use of authentic learning tasks, a focus on cognitive processes while learning and learning outcomes, and attention to instructional techniques that guide cognitive processing.

The Wolf Trap residencies outlined in this case provided the perfect foundational learning environment for Pre-K students to begin an educational journey directly aligned with our nation's goals in mind. The knowledge of spatial sense acquired through dance and movement during math lessons created opportunities for continued learning and reinforcement in other instructional arenas during the school day. Additionally, spatial thinking and geometry learning at the Pre-K level "reduces differences related to gender and socioeconomic status that may impede full participation in a technological society," (Get Set for School, 2011). The student acquisition of spatial awareness through dance created an equitable opportunity for Pre-K students to be better prepared for Kindergarten and for a successful life in a complexifying society.

\section{Conclusions}

This qualitative case study supports the existing, related research. The case study revealed that as a result of Wolf Trap dance residencies in math lessons, Pre-K students acquired strong foundational geometry skills, resulting in increased confidence, participation, and formation of real-life math connections outside the classroom. The following were the results of the qualitative case study centered on Pre-K students who experienced movement residencies in math experiences at Creekside Elementary School:

- Increased knowledge in spatial awareness and early geometry concepts including: Recognized and described the attributes of common shapes; Understood spatial relationships; Used position words that identified 
different positions in space; Understood positional words in order to follow specific directions during transitions; Used the body to make physical representations of the four common shapes; Applied movement activities to reinforce concepts of shapes

- Increased confidence when speaking in front of peers

- Increased willingness to participate

- Increased connections to math concepts outside classroom

From these results, the researchers concluded that Wolf Trap residencies met and actually exceeded local and national classroom standards. The teachers' new creative abilities acquired from the residency allowed them to engage all students in math lessons, regardless of language limitations, not only within the classroom but also outside the walls of the classroom. The students' increased confidence and willingness to participate in math-focused movement residencies displayed a positive relationship to math learning, suggesting that these students will likely approach Kindergarten math lessons with willingness, excitement, and a solid foundation in math learning.

\section{Acknowledgements}

Our thanks to the wonderful classroom teachers and Wolf Trap Teaching Artists without whom our work would not have been possible. We would also like to thank ASC Studio 345 Teaching Artist Nicole Driscoll for her wonderful photo contributions.

\section{References}

Bartholomew, J.B., \& Jowers, E.M. (2011). Physically active academic lessons in elementary children. Preventive Medicine, 52(Suppl), S51-S54.

Bourdieu, P., \& Passeron, J.C. (1977). Reproduction: In education, society, and culture. London: SAGE Publications.

Bradbury, B., Corak, M., Waldfogel, J., \& Washbrook, E. (2017). Too many children left behind. Schools and Society: A Sociological Approach to Education.New York: Russell Sage Found.

Bruce, C., Flynn, T., \& Moss, J. (2012). Early mathematics: Challenges, possibilities and new directions in the research (Mathematics for Young Children: Literature Review). Comprehensive literature review submitted to the Literacy and Numeracy Secretariat, Ontario Ministry of Education. Toronto, Ontario, Canada.

Burton, J., Horowitz, R., \& Abeles, H. (1999). Learning in and through the arts: Curriculum Implications. In Edmund B. Fiske, (Ed.), Champions of Change: The Impact of the Arts on Learning (pp.36-46). Washington, DC: President's Committee on the Arts and Humanities.

Catterall, J.S., Chapleau, R., \& Iwanaga, J. (1999). Involvement in the arts and human development: Extending an analysis of general associations and introducing the special cases of intensive involvement in music and theatre arts. (Americans for the 
Arts Monograph No. 11). Los Angeles, CA: University of California at Los Angeles, Graduate School of Education and Information Studies.

Chandler, P., \& Tricot, A. (2015). Mind your body: The essential role of body movements in children's learning. Educational Psychology Review, 27(3), 365-370.

Charlotte-Mecklenburg Schools. (2016). All school SES level 2016. Charlotte, NC.

Cheng, Yi-Ling, \& Mix, Kelly S. (2013). Spatial training improves children's mathematics ability. Journal of Cognition and Development, 15(1), 2-11.

Dehaene, S., Bossini, S., \& Giraux, P. (1993). The mental representation of parity and number magnitude. Journal of Experimental Psychology: General, 122(3), 371-396.

Dewey, J. (1902). The Child and the Curriculum. Chicago, Illinois: The University of Chicago Press.

Department of Health and Human Services. [DHHS] (2017). Annual Update of the HHS Poverty Guidelines. (FR Doc. 2017-02076).

Eisner, E.W. (1998). The kind of schools we need: Personal essays. Portsmouth, NH: Heinemann.

Erickson, K.I., Hillman, C.H., \& Kramer, A.F. (2015). Physical activity, brain, and cognition. Current Opinion in Behavioral Sciences, 4, 27-32.000

Gardner, H. (1999). Intelligence Reframed: Multiple Intelligences for the $21^{\text {st }}$ Century (32). New York, NY: Basic Books.

Get Set for School. (2011). Get Set for Readiness, Writing, Language, and Math: A Pre-K Roadmap for School Success. Gaithersburg, MD.

Greenes, C., Ginsburg, H. P., \& Balfanz, R. (2004). Big math for little kids. Early Childhood Research Quarterly, 19(1), 159-166.

Gunderson, E., Ramirez, G., Beilock, S., \& Levine, S. (2012). The relation between spatial skill and early number knowledge: The role of the linear number line. Developmental Psychology, 48(5), 1229-41. The University of Chicago: Department of Psychology and Committee on Education.

Hohmann, M., Weikart, D., \& Epstein, A. (2008). Educating Young Children: Active Learning Practices for Preschool and Child Care Programs (428). Ypsilanti, MI: High Scope Press.

Holloway, D.L. (2001). Authoring identity and agency in the arts. Dissertation Abstracts International, 62(02), 426.

Hubbard, E.M., Piazza, M., Pinel, P., \& Dehaene, S. (2005). Interactions between number and space in parietal cortex. Nature Reviews Neuroscience, 6(6), 435-448.

Klayman, D. (2004). Executive summary of the final evaluation report of fairfax pages professional development project: An effective strategy for improving school readiness. Potomac, MD: Social Dynamics LLC.

Ludwig, M.J., Marklein, M.B., \& Song, M. (2016). Arts Integration: A Promising Approach to Improving Early Learning. Washington, DC: American Institutes for Research.

Mayer, R.E. (2017). How can brain research inform academic learning and instruction? Educational Psychology Review, 29(4), 835-846.

Moss, J., Bruce, C.D., Caswell, B., Flynn, T., \& Hawes, Z. (2016). Taking Shape: Activities to Develop Geometric and Spatial Thinking. Toronto, CA: Pearson Canada, Inc.

National Council of Teachers of Mathematics, Inc. [NCTM] (2006). Curriculum Focal Points. Reston, VA: Reys, B.

O'Brien, E. M., \& Dervarics, C. (2007). Pre-Kindergarten: What the research shows. Alexandria, VA: Center for Public Education.

Pugalee, D.K., Harbaugh, A., \& Quach, L.H. (2009). The human graph project: Giving students Mathematical power through differentiated instruction. In M.W. Ellis (Ed.), 
Mathematics for Every Student: Responding to Diversity, Grades 6-8. National Council of Teachers of Mathematics.

Partnership for 21st Century Learning [P21]. (2016). Framework for 21st Century Learning. Washington, DC: P21.

Presmeg, N.C. (2006). Research on visualization in learning and teaching mathematics. Handbook on the Psychology of Mathematics Education, 205-235.

Presmeg, N. C. (1991). Classroom aspects which influence use of visual imagery in high school mathematics. In F. Furinghetti (Ed.), Proceedings of the $15^{\text {th }} P M E$ International Conference, 3, 191- 198.

Sarama, J., \& Clements, D. (2009). Building Blocks and Cognitive Building Blocks: Playing to know the world mathematically. American Journal of Play, 1, 313-337.

Temple, B.A. (2007). Creating studios of literacy learning through the arts: A narrative case study in arts integration for urban high school education. Charlotte, NC.: The University of North Carolina at Charlotte.

Tomporowski, P. D., Davis, C. L., Miller, P. H., \& Naglieri, J. A. (2008). Exercise and children's intelligence, cognition, and academic achievement. Educational Psychology Review, 20, 111-131.

United States Census Bureau. (2015). QuickFacts: Mecklenburg County, North Carolina. Retrieved from www.census.gov.

Vygotsky, L.S. (1978). Mind in society: The development of higher psychological processes. Cambridge: Harvard University Press.

Walsh, V. (2003). A theory of magnitude: common cortical metrics of time, space and quantity. Trends in Cognitive Sciences, 7(11), 483-488.

West Windsor-Plainsboro Regional School District. (2015). Gifted and Talented Program Review Internal Report. Plainsboro, NJ.

Yarmohammadian, A. (2014). The Relationship between Spatial Awareness and Mathematic Disorders in Elementary School Students with Learning Mathematic Disorder. Psychology and Behavioral Sciences. 3(1), 33-40. 



\title{
Examining the Relationship between Cultural Capital and Self-Efficacy: A Mixed Design Study on Teachers
}

\author{
By Yunus Emre Avci*, Rasim Tösten ${ }^{\dagger} \&$ Çiğdem Çelik Şahin
}

Cultural capital expresses all the cultural acquisitions that individuals gain both through inheritance and through different channels in the course of their lives. Teachers' self-efficacy perceptions play an important role in their demonstrating more effort and responsibility to provide support to students' learning. The main purpose of this study is to examine the relationship between teachers' selfefficacies and cultural capital levels. The study was used an explanatory mixed method. In the quantitative part of the study, to measure cultural capital competencies of teachers, the "Cultural Capital Scale" developed by Tösten (2014) was used. As to measure teachers' self-efficacy perceptions, the "Teachers' Self-efficacy Scale" developed by Tschannen-Moran and Woolfolk Hoy (2001) and adapted into Turkish by Çapa, Çakıroğlu and Sarıkaya (2005) was used. In the qualitative part of the study, a structured interview form developed by the researchers was used. 885458 teachers working in Turkey compose the population of the quantitative part of the study. 2452 teachers determined by the stratified sampling technique participated in the study in the academic year of 2016-2017. As the sample strata, the development classification of the Ministry of Development was taken as a basis. The study group of the qualitative part consisted of 29 teachers who were determined by the easily accessible sampling method. As a result of the study, it was determined that the teachers' self-efficacy perceptions were "fairly adequate" and their cultural capital competencies were "moderate." When the relationship between teachers' self-efficacy perceptions and cultural capital competencies is examined, it is observed that there is a "positive" relationship at the "moderate" level. As a result of the analyses, cultural capital competencies that teachers had were found to be a significant predictor of self-efficacy perceptions. It was observed that the teachers put forward mainly intellectual accumulation when they were asked how cultural capital competencies and how the areas in which cultural capital competencies contribute to the perception of self-efficacy could be increased. The most mentioned areas by the teachers in relation to the things that could be done to increase cultural capital competencies were reading, participation in cultural activities, cultural education, and training.

Keywords: Self-efficacy, cultural capital, education.

\footnotetext{
*Lecturer, Siirt University, Turkey

${ }^{\dagger}$ Lecturer, Siirt University, Turkey.

¥Teachers, Adana Science and Art Center, Turkey.
} 


\section{Introduction}

When examined the term "Cultural Capital" and "Self-Efficacy" in educational researches, it is seen that these terms are widespread in all around the world, in Asia, Europe and the US (Tavakoli, Pahlavannezhad, \& Ghansooly, 2017; Woulfe, 2008; Scholz et al., 2002; Cheng, 2011; De Graaf, De Graaf and Kraaykamp, 2000; Kim and Omizo, 2005; Goddard, Hoy, and Woolfolk-Hoy (2000). In one's life, cultural capital defines the class s/he belongs to, the achievement, roles and the way s/he brings up children. In the school context, the teachers are at the center of successful education of the students. After a detailed research on cultural capital, and its affects, it is considered that to focus on the relationship between cultural capital and self-efficacy of the teachers which is rarely studied. It is thought to present the results which are important for the educational area.

As indicated in the studies, the impact of the self-efficacy perceptions of teachers on the success of the learning process is a fact. Their cultural structure has an influence that extends to their professional achievements. The examination of the cultural capital competencies of teachers in Turkey, the impact on their selfefficacy perceptions, the contribution of cultural capital competencies to the selfefficacy perception, and how cultural capital competencies can be increased will reveal the impact on a successful education process. Besides, in these days when the success of education in Turkey is discussed, to investigate this issue and to make determinations based on scientific facts are also important.

It is believed that there is a relationship between teachers' self-efficacy beliefs and cultural capital competencies. It is important to examine the relationship between cultural capital and self-efficacy when it is considered that self-efficacy and cultural capital competencies have an effect on increasing the individuals' performance. The relationship between self-efficacy perceptions and cultural capital is a new research subject. It was observed that the studies in the international literature which examine the teachers' self-efficacy and cultural capital competency levels and the relationship between them were limited (Tavakoli, Pahlavannezhad, \& Ghansooly, 2017; Woulfe, 2008; Scholz et al., 2002). Therefore, it is estimated that the contribution of this study to the literature will be important since teachers' self-efficacy levels and cultural capital competencies, the relationship between them, the effect of cultural capital on selfefficacy perceptions and the increase of these competencies are examined in this study.

\section{Self-efficacy}

It is important that teachers, who are primarily responsible for the learning success, believe in themselves, are aware of their skills and are sure of their competencies. The efficacy belief refers to the knowledge, skills, and attitudes that are considered important for a role in the community, and the individual equivalent of it is self-efficacy (Yeşilyurt, 2013). Self-efficacy is the belief in competency to accomplish tasks, concerning one's motivational beliefs, values, 
goals (Eccles \& Wigfield, 2002) and self-confidence (Alivernini \& Lucidi, 2011). The self-efficacy belief is a matter which is considered important from the psychology and management knowledge point of view and has been studied frequently for the last thirty years. Self-efficacy derived from Bandura's (1997) social grip term is related to the beliefs or judgments of individuals on the competencies of accomplishing tasks or responsibilities. In other words, selfefficacy is the behaviors related to the one's belief in concepts such as awareness, knowledge, skills, perspectives, and needs that make up one's behaviors. Bandura (1986) defined self-efficacy as the belief in one's competencies exhibited at a particular level.

The high self-efficacy belief causes an individual to improve his/her performance by moving away from thoughts that negatively affect him/her and by finding the source of motivation that is needed. The low self-efficacy belief makes it more challenging to overcome difficulties encountered (Bussey \& Bandura, 1999). The beliefs of people in their own abilities affect not only their motivation but also the severity of stress and depression experienced in risky or stressful situations (Bandura, 1989). Emotional reactions can directly or indirectly affect actions by changing the process of thought. People who think they can get over the risks are less uncomfortable with the risks. They can reduce their stress and worries by controlling potential risks (Bandura, 1995). This is another key element of self-efficacy.

Self-efficacy is one of the important elements in the system that makes up human capacity. Similar skills and tasks exhibited by different people under different circumstances are related to the change in the self-efficacy beliefs of individuals. If individuals do not believe in the capacity and abilities they own or they hesitate, this capacity and equipment may not be adequately assessed. Therefore, the self-efficacy perception enables the complete fulfillment of tasks by using skills and coping with obstacles (White, 1982). A strong self-efficacy perception brings insistence, effort, and resistance with it. Moreover, the selfefficacy perception influences individuals' thinking styles, problem-solving skills, and emotional reactions. Individuals, whose self-efficacy perception is not at a sufficient level, have a narrower viewpoint and cannot solve the problems they encounter. On the contrary, people with high self-efficacy perceptions are in the sense of comfort and confidence even in challenging tasks (Kaptan \& Korkmaz, 2001).

It is indisputable that teachers' self-efficacy perceptions are necessary for success in the process of education that requires social interaction, motivation, and determination. Concerning this, Şahin (2010) states that even if teachers are sufficient in terms of their content knowledge, the lack of self-efficacy sense towards the teaching profession causes the learning and teaching process not to be productive. In this case, as the teachers' self-efficacy perceptions become stronger, it may mean that they will exhibit more endeavor and responsibility to support the learning of students (B1kmaz, 2006). Goddard, Hoy, and Woolfolk-Hoy (2000) argue that according to the social cognitive theory, social influence shapes individuals' self-efficacy beliefs. According to the theory, teachers' expectations of success positively influence students to make an effort to help their learning. Azar 
(2010) notes that the self-efficacy belief is a guiding element to the quality of teaching and the organization of teaching and learning environments.

Self-efficacy plays a vital role in the occurrence of self-confidence and motivation, and it is a fact that it is based on cultural differences (Woulfe, 2008). When investigating human behaviors, it is important to consider cultural differences. In the development of self-efficacy, when the importance of environmental factors is considered, the culture comes to the forefront among them (Scholz et al., 2002; Kim \& Omizo, 2005). Teachers, peers, and parents are factors that affect self-efficacy (Bandura, 1994). These factors vary according to the culture and depend heavily on the values of a particular culture. It is important to consider the culture when examining self-efficacy, and both self-efficacy and culture are vital components that make us (Woulfe, 2008).

The results of the study carried out by Woulfe (2008) revealed the relationship between self-efficacy and culture. The perception of self-efficacy is of great importance in achievement. It is clear that the factors such as parents, peers, and environment are important in the development of the perception of selfefficacy.

The self-efficacy perception is a structure mostly influenced by experience. For this reason, it is necessary to consider self-efficacy as a cultural element. It has been determined in cross-cultural studies that the self-efficacy perception differs from each other. While in individual cultures (such as the United States of America (USA) the self-efficacy perception is found to be high, in collectivist cultures (such as Asian countries) the self-efficacy perception is found to be low (Scholz et al., 2002).

Teachers, while fulfilling their duties, make their way from their personal beliefs, theories and community expectations. Practices in the school and classroom environment are also under the influence of the community. Therefore, the professional activities, personal beliefs and social value judgments of teachers are related to each other (Bek, 2007). Balc1 (1991) defines the teacher as an educator, exam applier, discipline provider, advocate of middle-class morality, and proxy. This definition can state that the culture of teachers is more likely to represent a middle-class cultural structure. The qualities of teachers will be effective on the generations they raise.

\section{Cultural Capital}

At this point, it is essential to mention the important views expressed by the French thinker Bourdieu on culture and cultural differences. Bourdieu's scientific initiative is based on the fact that the most profound logic of the social world can only be grasped, as a result of an in-depth investigation of an experimental reality that has a precise place and time in history. (Bourdieu, 1995). In this context, in regard to being produced on the French social structure, Bourdieu's theory of stratification is unique to the French society in some respects, however, if it is applied to other societies, it will likely point to a similar social structure beside the specific characteristics of that society. 
Bourdieu (1986) defined cultural capital as the "instruments for the appropriation of symbolic wealth socially designated as worthy of being sought and possessed", including social roles, language competency and refinement, general cultural background, knowledge, and skills (DeMarrais \& LeCompte, 1998). Lareau (2015) defined cultural capital as "skills individuals inherit that can be translated into different forms of value as people move through different institutions".

Interpreting cultural capital as familiarity with high-culture, some researchers have found positive effects of cultural capital on grades or educational attainment (DiMaggio, 1982; Kalmijn \& Kraaykamp, 1996; Werfhorst et al., 2003). Others have found parental reading behavior to be positively associated with children's educational attainment whereas Beaux-arts participation is not (De Graaf et al., 2000).

From a different point of view, the concept of cultural capital comes from the work of Blackledge (2001), Lareau (2003). Considering cultural capital as a resource that facilitates the compliance of institutional standards, this group of scholars examines how dimensions such as gender, ethnicity, and social class function to generate distinctions that also serve as a basis for social exclusion. Employing mostly micro-interpersonal methods (ethnography and interviews), their findings not only highlight the arbitrary nature of institutional imposition within different social contexts, but also underscore the importance of considering how the individual strategic use of knowledge, abilities, and skills produce benefits within different fields (Lareau \& Weininger, 2004).

Bourdieu and Passeron (1990) explain that norms are developed and reproduced in society through the education system, which benefits the dominant class and oppresses others. For example, with regards to cultural capital, a dominant language is valued and language skills such as reading and writing in that dominant language are given priority over other skills. Therefore, those who speak the dominant language are at a greater advantage in school and in society. The relationship between cultural capital and educational capital is interdependent and conversion can occur in a variety of ways. The education system values cultural capital; however, as Bourdieu (1986) notes, it does not teach cultural capital

Cultural capital refers to the whole of culturally-induced gains that individuals have acquired through inheritance or from different channels during their life. The individual with cultural capital can achieve the most appropriate social life for him/her better by foreseeing the surrounding changes waiting for him/her. Therefore, the volume of cultural capital acquired takes the individual to a different social position and functions in a way to distinguish him/her from the others. It has been determined that individuals with high cultural capital for which the variables such as educational background and lifestyle form the basis further realize the changes around them and demand for a more excellent social life (Arun, 2009). Many experimental studies (Cheadle, 2008; DiMaggio, 1982; Kingston, 2001; Symeou, 2007; Xu \& Hampden-Thompson, 2012) have determined that there is a positive relationship between cultural capital and educational achievement. 
Bourdieu made significant contributions to the emergence of the concept of cultural capital and to the foundation of cultural capital. According to Bourdieu, "there are no social classes, classes are in virtual states, on lines that are not clear, not given but as a matter to be done, spaces of differences in which they exist" (Bourdieu, 1995). The cultural capital on which Bourdieu discourses is considered to be all cultural accumulations that provide a socio-economic advantage. Cultural capital is the social and cultural knowledge of the society and the individual related to heritage, which makes social mobilization of individuals valuable (Yosso, 2005). Cultural capital indicates not only the acquisitions acquired from the family and the environment, but also latent powers, talents, and achievements that are acquired through education by one's own efforts or inherited in the body. Bourdieu emphasizes the differentiation of society in semi-autonomous social systems. "For example, the field of art, the field of religion, or the field of economy are subject to different logics: The economic field has emerged historically as a universe, in which "business is business," and in which principally the relationships of emotional kinship, friendship and love are excluded. On the contrary, the field of art was established by the rejection of the law of material gain or by its reversal "(Bourdieu \& Wacquant, 2003). Here, Bourdieu, while telling us that the difference between the field and system is struggles and historicity, expresses the idea that the field is the place of struggles and force relations which are in the transformation and change purpose. In other words, "fields are the localities of power relations; transcendental tendencies include objective possibilities. A field never orients to a direction by chance. In the same way, everything is not always possible or impossible" (Bourdieu, 2015).

\section{Purpose of the Study}

The main purpose of this study is to examine the relationship between teachers' self-efficacy and cultural capital levels. In this context, answers to the following questions were sought in the study:

In the quantitative part of the study:

1. What is the level of cultural capital competencies of teachers?

2. What is the level of self-efficacy perceptions of teachers?

3. How is the relationship between teachers' cultural capital competencies and self-efficacy?

4. Is the cultural capital competency of teachers a significant predictor of the self-efficacy perception?

In the qualitative part of the study:

In our two-stage study, depending on the results of the quantitative section: 
5. $34 \%$ of teachers' self-efficacy perceptions are explained by their cultural capital competencies. In other words, cultural accumulation has a share of one third in the formation of teachers' professional self-efficacy. According to the opinions of teachers, how is the one-third contribution of teachers' self-efficacy to cultural capital competencies formed and where does it originate from?

6. According to the results of the study, teachers' cultural capital competencies were determined to be at the "moderate" level. Teachers' cultural capitals are seized as intellectual accumulation, participation in cultural activities, cultural consciousness, the cultural potential they own around and in themselves. According to teacher opinions, what can be done to raise the level of cultural capital competency of teachers in each dimension?

\begin{abstract}
Method
This study has a mixed design in the explanatory mixed model. In the studies, qualitative and quantitative designs have strong and weak aspects (Glesne, 1992/2013). With the use of qualitative and quantitative designs together, it is thought that the research gains depth. In this regard, both quantitative and qualitative methods were used in the study. Explanatory mixed methods are mixed methods in which the researcher begins with quantitative research and tries to search specific results in the second stage (Y1ldırım \& Şimşek, 2006; Patton, 2002; Creswell, 2002, p. 17; Creswell \& Plano Clark, 2014). In this study, firstly, the cultural capital and self-efficacy levels of teachers were revealed and how much cultural capital explains self-efficacy was examined in the quantitative part, and in the second part, depth was brought to the study by posing questions to the participants with the structured interview form in the light of quantitative results.
\end{abstract}

\title{
Population and Sampling
}

\section{The Population and Sampling belonging to the Quantitative part of the Study}

The population of the study consists of 885,458 teachers working in Turkey (Ministry of National Education Strategy, 2016). Because of the difficulty in reaching the whole of the population, sampling was performed. The stratified sampling method was used to determine the participants. In the creation of the strata, the Ministry of Development was taken as the reference. The Ministry of Development gathered the provinces under six categories according to their development level, by assessing their socio-economic and cultural structures within the "SEGE (2011) Socio-Economic Development Ranking Survey of Provinces and Regions" (Republic of Turkey Ministry of Development, 2013). In this study, a province which is easy to reach based on the easy sampling method 
was selected from each category. The personal information of the participants is given in Table 1.

Table 1. Personal Information of the Participants in the Quantitative Part of the Study

\begin{tabular}{|l|l|c|c|c|c|c|}
\hline Variables & $\boldsymbol{f}$ & $\mathbf{\%}$ & Provinces & $\boldsymbol{f}$ & $\mathbf{\%}$ \\
\hline \multirow{5}{*}{ Gender } & Female & 1146 & 46.7 & $\begin{array}{c}\text { Istanbul (First degree } \\
\text { developed province) }\end{array}$ & 532 & 21.7 \\
\cline { 2 - 7 } & Male & 1306 & 53.3 & $\begin{array}{c}\text { Kayseri (Second degree } \\
\text { developed province) }\end{array}$ & 296 & 12.1 \\
\cline { 2 - 8 } & Total & 2452 & 100.0 & $\begin{array}{c}\text { Gaziantep (Third degree } \\
\text { developed province) }\end{array}$ & 480 & 19.6 \\
\hline \multirow{5}{*}{$\begin{array}{l}\text { Educational } \\
\text { Status }\end{array}$} & $\begin{array}{l}\text { Associate } \\
\text { Degree }\end{array}$ & 94 & 3.8 & $\begin{array}{l}\text { Elazı̆ (Fourth degree } \\
\text { developed province) }\end{array}$ & 321 & 13.1 \\
\cline { 2 - 8 } & $\begin{array}{l}\text { Bachelor's } \\
\text { Degree }\end{array}$ & 2068 & 84.3 & $\begin{array}{c}\text { Osmaniye (Fifth degree } \\
\text { developed province) }\end{array}$ & 265 & 10.8 \\
\cline { 2 - 8 } & $\begin{array}{l}\text { Master's } \\
\text { Degree }\end{array}$ & 290 & 11.8 & $\begin{array}{c}\text { Diyarbakir (Sixth degree } \\
\text { developed province) }\end{array}$ & 558 & 22.8 \\
\cline { 2 - 8 } & Total & 2452 & 100.0 & Total & 2452 & 100.0 \\
\hline
\end{tabular}

\section{The Study Group belonging to the Qualitative Part of the Study}

The study group of the qualitative part of the study consists of 29 teachers. The study group was selected from volunteer teachers by the use of the easily accessible sampling method. With regard to the adequacy of the number of the participants in the study, the researchers' belief that data saturation was reached was taken as the basis. According to Merriam (2013, p. 79), how many individuals the study group should include in qualitative studies is related to whether the researchers find the number of the obtained data sufficient. The personal characteristics of the participants in the qualitative part of the study are presented in Table 2:

Table 2. Personal Characteristics of the Participants in the Qualitative Part of the Study

\begin{tabular}{|l|c|c|c|}
\hline Teachers (T) & Gender & Income Level & Seniority \\
\hline T1 & Female & $2000-5000 \mathrm{TL}$ & $1-5$ years \\
\hline T2 & Male & $2000-5000 \mathrm{TL}$ & $1-5$ years \\
\hline T3 & Male & $2000-5000 \mathrm{TL}$ & $1-5$ years \\
\hline T4 & Male & $5001+\mathrm{TL}$ & $1-5$ years \\
\hline T5 & Male & $2000-5000 \mathrm{TL}$ & $1-5$ years \\
\hline T6 & Male & $2000-5000 \mathrm{TL}$ & $1-5$ years \\
\hline T7 & Female & $5001+\mathrm{TL}$ & $1-5$ years \\
\hline T8 & Female & $2000-5000 \mathrm{TL}$ & $1-5$ years \\
\hline T9 & Female & $5001+\mathrm{TL}$ & $1-5$ years \\
\hline T10 & Female & $2000-5000 \mathrm{TL}$ & $1-5$ years \\
\hline T11 & Female & $2000-5000 \mathrm{TL}$ & $1-5$ years \\
\hline T12 & Female & $2000-5000 \mathrm{TL}$ & $1-5$ years \\
\hline T13 & Female & $2000-5000 \mathrm{TL}$ & $1-5$ years \\
\hline
\end{tabular}




\begin{tabular}{|l|c|c|c|}
\hline T14 & Female & $5001+\mathrm{TL}$ & $1-5$ years \\
\hline T15 & Female & $2000-5000 \mathrm{TL}$ & $1-5$ years \\
\hline T16 & Female & $2000-5000 \mathrm{TL}$ & $1-5$ years \\
\hline T17 & Female & $2000-5000 \mathrm{TL}$ & $1-5$ years \\
\hline T18 & Female & $2000-5000 \mathrm{TL}$ & $1-5$ years \\
\hline T19 & Female & $5001+\mathrm{TL}$ & $1-5$ years \\
\hline T20 & Female & $2000-5000 \mathrm{TL}$ & $1-5$ years \\
\hline T21 & Female & $2000-5000 \mathrm{TL}$ & $1-5$ years \\
\hline T22 & Female & $2000-5000 \mathrm{TL}$ & $1-5$ years \\
\hline T23 & Male & $2000-5000 \mathrm{TL}$ & $1-5$ years \\
\hline T24 & Male & $2000-5000 \mathrm{TL}$ & $1-5$ years \\
\hline T25 & Female & $2000-5000 \mathrm{TL}$ & $1-5$ years \\
\hline T26 & Female & $2000-5000 \mathrm{TL}$ & $1-5$ years \\
\hline T27 & Female & $2000-5000 \mathrm{TL}$ & $1-5$ years \\
\hline T28 & Female & $2000-5000 \mathrm{TL}$ & $1-5$ years \\
\hline T29 & Female & $2000-5000 \mathrm{TL}$ & $1-5$ years \\
\hline
\end{tabular}

\section{Data Collection Tools}

Since there are two variables to be measured in the quantitative part of the study, two different scales were used. The "Cultural Capital Competency Scale" developed by Tösten (2014) was used to measure the cultural capital competency levels of teachers. The Cultural Capital Scale is a 5-point Likert-type scale in which the teachers' levels of participation in the items are answered by scoring from 1 to 5 numerically from less to more. The 4-dimensional scale consists of 30 items, and the variance explained by the explanatory factor analysis is $57 \%$.

When the model was tested by the confirmatory factor analysis, the model was found to be compatible $(\chi 2=1018.93, \mathrm{~N}=256, \mathrm{sd}=393, \mathrm{p}=0.00$, RMSEA; 0.079; SRMR; 0.065; GFI; 0.79; CFI; 0.96; IFI; 0.97; NFI; 0.94). The dimensions of the scale were examined as intellectual accumulation, participation, cultural consciousness and cultural potential. The Cronbach's alpha internal consistency coefficient of the scale was found to be .94 , which was considered highly reliable. Cultural capital competencies for each dimension were found to be .089 in intellectual accumulation, .88 in participation, .82 in cultural consciousness and .87 in cultural potential. Some items related to each dimension in the dimensions of the scale can be exemplified as follows: "I have knowledge in the fields of science that carry cultural value", "I attend activities and courses for cultural purposes", "I am aware of the cultural potential of the city, in which I live", "I speak openly and comprehensible".

To measure teachers' self-efficacy levels in the study, the "Teachers' Selfefficacy Scale" developed by Tschannen-Moran and Woolfolk Hoy (2001) and adapted into Turkish by Çapa, Çakıroğlu, and Sarıkaya (2005) was used. The selfefficacy scale is a 5-point Likert-type scale in which the self-efficacy levels of teachers can be marked and scored from 1 to 5 as (1) indicating inadequate, (2) less than adequate, (3) somewhat sufficient, (4) quite sufficient, and (5) highly 
sufficient. The confirmatory factor analysis of the self-efficacy scale revealed that RMSEA was .061, compliance was $90 \%$, and item correlations ranged from .82 to .89. The self-efficacy scale is a total of 24 items with a single factor. The sample items for the scale are as follows: "How much can you succeed in reaching students, who are difficult to work with?" "How much can you ensure students' critical thinking?"

When the internal consistency coefficients are examined for the reliability of the scales, it is observed that in this study the internal consistency coefficient of the cultural capital consistency scale (Cronbach's Alpha value) is .94 and of the selfefficacy scale is .97 . It was concluded that both scales were reliable for their reliability values. Since a similar scale was used in the sample group for the validity of the study, the reconstruct validity was not tested, and expert opinions were found sufficient.

In the qualitative part of the study, the structured interview form prepared by the researchers was used. In the preparation of the interview form, the findings obtained from the quantitative part of the study were utilized. For the content validity of the measurement tool, attention was paid to preparing the questions covering the cultural capital dimensions in the literature. In the interview form, primarily questions about descriptive information of the participants were asked. Descriptive information includes gender, seniority, and income level of the family. The family income levels are categorized into two as 2,000-5,000 TL and $5001 \mathrm{TL}$ and above. The aim here is that the cultural capital is also related to socioeconomic indicators. In the interview form, the findings obtained from the quantitative part of the study were shared with the participants, and it was asked what the reasons for these might be. Moreover, questions about how cultural capital could be increased were included.

\section{Data Collection and Analysis}

In the quantitative part of the study, the measurement tool was applied by directly reaching the participants. Before the measurement tool was applied, the participants were briefly informed about the study, and it was emphasized that the application was performed on a voluntary basis. The participants were informed about the importance of the answers they would give to the items in the scale, enough time was given to fill in the scale forms. The forms were usually answered in the teachers' room and classrooms. All of the data obtained from 2,452 participants were processed. In the analysis of the data obtained from the study, descriptive statistics (frequency, arithmetic mean, standard deviation) in the personal information and level determination, Pearson correlation test in exhibiting the inter-variable relationship, and regression analysis in revealing how much the cultural capital competency explains self-efficacy were used. In the analyses, the $p$ $\leq 0.05$ level was taken as a basis. It was observed that the assumptions required for regression analysis were met, that the distribution was normal according to the skewness and kurtosis values and that the variances were homogeneous. 
In the qualitative part of the study, the interview form created was collected through face-to-face interviews conducted with the participants. Appropriate environments were selected to ensure that the interviews were healthy. Detailed information about the research was given to the participants before the interview, and the theoretical foundations and the results of the study were shared. The researchers tried to reflect the interviews that they had held with 29 people to the research neutrally as much as possible. Reliability in qualitative studies is assessed in the context of the convincing additional information the study adds to the literature (Y1ldırım \& Şimşek, 2006, p. 265). In this sense, the information of the study group and most of the answers given by the participants were shared. The credibility of the research was increased in this way. In the analysis of the data, the content analysis technique was used. The content analysis process is based on making sense from the data. Before beginning the data analysis, for preparation the researcher should read up the data until he/she understands them (Creswell, 2002, p. 217). Therefore, the data in the interview form were examined one by one, evaluated together with the related notes, and the codes and frequencies were extracted and reported. Frequency analysis reveals the frequency of the units that are reached as a result of the analysis numerically. The extraction of the codes is primarily the division of a particular finding into units and then gathering these units into categories according to certain criteria (Yıldırım \& Şimşek, 2006; Bilgin, 2006, p. 18-19).

\section{Findings and Interpretation}

In this section, the data obtained in accordance with the sub-objectives of the study were expressed in tables, and the results of the tables were interpreted. For the first two sub-problems of the study, the arithmetic means and correlation states related to the teachers' cultural capital competencies and self-efficacy levels are presented in Table 3.

Table 3. Teachers' Cultural Capital Competency - Self-Efficacy Levels and the Correlation State Between Them

\begin{tabular}{|l|c|c|c|c|c|c|c|c|c|}
\hline Variables & $\boldsymbol{N}$ & $\boldsymbol{X}^{-}$ & $\boldsymbol{s S}$ & $\mathbf{1}$ & $\mathbf{2}$ & $\mathbf{3}$ & $\mathbf{4}$ & $\mathbf{5}$ & $\mathbf{6}$ \\
\hline Intellectual accumulation & 2452 & 3.54 & .76 & 1.00 & & & & & \\
\hline Participation & 2452 & 3.05 & .94 & .62 & 1.00 & & & & \\
\hline Cultural consciousness & 2452 & 3.55 & .91 & .66 & .66 & 1.00 & & & \\
\hline Cultural potential & 2452 & 3.87 & .79 & .60 & .52 & .60 & 1.00 & & \\
\hline Cultural capital total & 2452 & 3.48 & .71 & .91 & .83 & .83 & .75 & 1.00 & $\mathbf{. 5 5}$ \\
\hline Self-Efficacy total & 2452 & 3.79 & .70 & .51 & .37 & .48 & .50 & .55 & 1.00 \\
\hline
\end{tabular}

$* \mathrm{p}<.05$ 
When teachers' cultural capital competency levels are examined, it is observed that they are in general at the "moderate" level $\left(\mathrm{x}^{-}=3.48\right)$. However, the dimensions with the highest mean in the sub-dimensions of cultural capital are observed to be cultural potential $\left(\mathrm{x}^{-}=3.87\right)$, cultural consciousness $\left(\mathrm{x}^{-}=3.55\right)$, intellectual accumulation $\left(\mathrm{x}^{-}=3.54\right)$ and cultural participation $\left(\mathrm{x}^{-}=3.05\right)$. Teachers' self-efficacy is found to be "fairly adequate" $\left(\mathrm{x}^{-}=3.79\right)$.

When the correlation between teachers' cultural capital competencies and self-efficacy levels is examined, a moderately positive correlation is observed in Table $3(\mathrm{r}=.55 ; \mathrm{p}<.05)$. Accordingly, when the relationship between self-efficacy and the sub-dimensions of cultural capital competency is examined, it is observed that there are moderately positive relationships between self-efficacy and intellectual capital $(\mathrm{r}=.52 ; \mathrm{p}<.05)$, participation in social activities $(\mathrm{r}=.37 ; \mathrm{p}$ $<.05)$, cultural consciousness $(\mathrm{r}=.48 ; \mathrm{p}<.05)$, cultural potential $(\mathrm{r}=.50 ; \mathrm{p}$ $<.05)$, and moderately positive relationships betwenn self-efficacy and the total of cultural capital $(r=.55 ; p<.05)$.

Table 4. Regression Analysis Related to the Explanation of Teachers' SelfEfficacy by Their Cultural Capital Competency

\begin{tabular}{|l|c|c|c|c|c|}
\hline Predictor Variables & $\boldsymbol{R}$ & $\boldsymbol{R}^{2}$ & $\boldsymbol{B}$ & $\boldsymbol{T}$ & $\boldsymbol{p}$ \\
\hline Intellectual accumulation & \multirow{3}{*}{.583} & \multirow{3}{*}{.339} & .279 & 11.409 & $.000^{*}$ \\
\cline { 1 - 4 } & \multirow{3}{*}{ Participation } & & -.058 & -2.471 & $.014^{*}$ \\
\hline Cultural consciousness & & .179 & 7.084 & $.000^{*}$ \\
\hline Cultural potential & & .257 & 11.629 & $.000^{*}$ \\
\hline
\end{tabular}
$* \mathrm{p}<.05$

In Table 4, it is observed that teachers' cultural capital competencies explain their self-efficacy by $34 \%$. According to this, it is observed that the model, in which the effect of teachers' cultural capital competencies on self-efficacy is revealed, is significant $(\mathrm{p}<0.05)$. When the sub-dimensions of cultural capital competencies and " $\beta$ " values, in the prediction of self-sufficiency, are taken into account, it is observed that the most effective subdimensions are intellectual accumulation, cultural potential, cultural consciousness, and participation, respectively.

The question "34\% of teachers' self-efficacy perceptions are explained by their cultural capital competencies. In other words, cultural accumulation has a share of one third in the formation of teachers' professional self-efficacy. In your opinion, how is the one-third contribution of teachers' cultural capital competencies to self-efficacy formed and where does it originate from?" was asked to the teachers, and it was attempted to determine how a relationship between cultural capital and self-efficacy arises according to teachers' opinions. Although two teachers declared ideas in more than one category, three teachers did not express an idea. Teachers' statements are given in categories in Table 5. 
Table 5. Cultural Capital Self-Efficacy Relationship and Resource

\begin{tabular}{|l|c|}
\hline Codes & $\boldsymbol{F}$ \\
\hline The effects of cultural consciousness on self-efficacy & 2 \\
\hline The effects of intellectual accumulation on self-efficacy & 7 \\
\hline The effects of general cultural capital on self-efficacy & 15 \\
\hline The effects of cultural potential on self-efficacy & 3 \\
\hline Total & $\mathbf{2 9}$ \\
\hline
\end{tabular}

The most emphasized aspect of teachers' cultural capital and self-efficacy relationship and its resource is that cultural capital in general affects self-efficacy positively and cultural capital is a significant source of self-efficacy. The teachers firstly mentioned the effects of cultural consciousness on self-efficacy and indicated that it could be the source. The examples of teachers' statements given categorically are as follows:

Individuals shape their self-consciousness and capital with the cultural structure of the society in which they live and shape themselves by taking advantage of many factors such as feelings and behaviors. In the future, this cultural accumulation can affect how they look at events and even at students, and how they behave (T1).

It could be in the field of history. To know the history of our country from past to present and to know its geographical characteristics make many contributions to teachers in the cultural sense. The constitution and citizenship rights must be known. Besides, current events and news should be followed (T4). It may originate from having comprehensive knowledge in the areas such as history, culture, and guidance, and of course, the reflection of these on the occupation is natural (T5).

The teacher is not the person who only directly transfers the information he/she has learned. At the same time, he/she also shares his/her social and cultural experiences with us. Self-efficacy increases as a person is enriched from the cultural aspect. These concepts are directly related to each other (T8). I think that the effect of the general cultural knowledge of a teacher, his/her approach to different cultures on self-efficacy will be great (T11). Since people are influenced by the social environment they grow up in, they are also affected by cultures. Culture can contribute to the individual from the social point of view. In my opinion, it has a contribution to teachers, especially from the social point of view (T14). Teachers, who are culturally rich, can gain confidence in themselves. At the same time, their communication with people/students in the classroom or around them gets easier. The self-expression power improves (T16).

Teachers are individuals who carry the values of the society they belong to and who transmit them most accurately through education and training. This situation will affect their communication with students and the approach of students to them (T17). Communication skills should be high. Being aware of their own culture and other cultural values and transferring this to his/her courses/students (T25). It would contribute to being able to adequately respond to the questions of students, expressing themselves better, and being able to show themselves as having knowledge and culture in a wide range of fields when required (T28). 


\section{Development of the Intellectual Accumulation Dimension}

The answers given to the question "How can we increase cultural capital in the Intellectual Accumulation dimension" directed to the teachers are presented in Table 6.

Table 6. Increasing the Intellectual Accumulation Dimension

\begin{tabular}{|l|c|}
\hline Codes & $\boldsymbol{F}$ \\
\hline Cultural activity & 12 \\
\hline Policy & 4 \\
\hline Research & 4 \\
\hline Reading & 9 \\
\hline Providing different opportunities & 2 \\
\hline Guidance & 2 \\
\hline Total & $\mathbf{2 9}$ \\
\hline
\end{tabular}

In order to increase teachers' intellectual accumulation dimension competencies, the most emphasized view is organizing cultural activities and participating in them, and reading books. Teacher expressions are presented in categories. Two teachers did not declare any ideas on this topic, but six teachers expressed opinions in more than one category. The examples of the teachers' opinions by the direct citations according to the categorical order in the table are as follows:

More excursions, more exhibitions have to be organized. Domestic and international visits should be arranged, and teachers should participate in informative seminars more (T8). To inform them, programs can be made. Cultural trips can be arranged, and training given under different conditions in different places can be provided to them. To reach the international level, international activities should be organized (T9). Any kind of activities like seminars and trips that require the active participation of teachers and students can be carried out (T12).

I think that intellectual accumulation must be acquired at a young age. For individuals, who cannot acquire it, education faculties at universities should be able to increase intellectual accumulation. For example, Erasmus is a very nice advantage. I think that in the courses, the programs that are based on research should be prepared (T14). Since intellectual accumulation is gained through education, I see the benefit of changing the process of becoming a teacher. It is not possible to provide this accumulation only with a group of teachers who are struggling to pass the exam. In the long term, a radical change is needed (T23).

Intellectual accumulation is provided mainly by schools, so there are lots of work to be done by universities. Research should be done at schools, and the scientific results of these studies should be transferred to students. Scientific publications should be made (T3).

The National Education could make compulsory for teachers to read some books related to the literature, science and cultural values (T17). The book reading rate can be increased. Reading can be made compulsory for both students and teachers (T25). 
Different conveniences can be provided to teachers and students by providing free transportation or digital subscriptions to libraries and contents throughout the city. By expanding the opportunities, environments that enhance intellectual accumulation can be created (T24).

Directing to different areas can be increased before the educational life ends and during the educational life. It can be given as responsibility and duty (T28).

In relation to the sixth sub-problem of the study, teacher statements related to developing the sub-dimensions of cultural capital are given respectively.

\section{Development of the Cultural Participation Dimension}

The answers given to the question "How can we increase cultural capital in the dimension of Cultural Participation" directed to the teachers are presented in Table 7.

Table 7. Increasing the Cultural Participation Dimension

\begin{tabular}{|l|c|}
\hline Codes & $\boldsymbol{f}$ \\
\hline Cultural activity & 19 \\
\hline Raising awareness & 6 \\
\hline Supporting & 2 \\
\hline Policy development & 2 \\
\hline Total & 29 \\
\hline
\end{tabular}

In order to increase teachers' cultural participation dimension competencies, the most emphasized dimension is cultural activity. The examples of the teachers' opinions according to the categorical order stated in the table are as follows:

Within the scope of significant cultural differences in Turkey between East and West, teachers may come across major obstacles. Providing knowledge and experience about the cultural structure of different regions preclude many problems and disruptions in the life of the teacher (T1). Activities such as directing to the theater, exhibition and cinema areas according to the interests, making more frequent trips and creating interaction with the cultures of neighboring countries could be carried out (T6). We must ensure that teachers participate in various trips, conferences, and social activities (T11).

Seminars ensuring that teachers become conscious and in which participation is mandatory can be organized. Awareness courses for different areas of interest can also be arranged (T9). Like the advertisement of a product, acculturation should also be advertised, since a teacher with low awareness is unlikely to become aware and motivate himself/ herself in this respect. At least, I think it is necessary to draw interest and to raise awareness about developing themselves (T20).

It should be ensured that teachers can participate in such cultural activities. For example, time must be given to them by reducing their workloads (T22). 
Annual plans for cultural participation can be given to schools. For example, elementary school $x$ must attend the $A, B, C$ museums, $X$ city and $Y$ exhibition during the 2019-2020 academic year. In the beginning, it will seem like an external motivation, but if it is understood that it is loved, it will turn into internal motivation (T23).

\section{Development of the Cultural Consciousness Dimension}

The answers given to the question "How can we increase cultural capital in the dimension of Cultural Consciousness" directed to the teachers are presented in Table 8 .

Table 8. Increasing the Cultural Consciousness Dimension

\begin{tabular}{|l|c|}
\hline Codes & $\boldsymbol{f}$ \\
\hline Supporting & 3 \\
\hline Education and training & 13 \\
\hline Cultural activity & 16 \\
\hline Total & $\mathbf{2 9}$ \\
\hline
\end{tabular}

In order to increase the teachers' cultural consciousness dimension competencies, the most emphasized opinion is determined as to provide participation by organizing cultural activities and to train by providing education. Teacher expressions are presented in categories. Although a teacher did not declare any idea on this issue, four teachers expressed opinions in more than one category. The examples of the teachers' opinions in categorical order are as follows:

I do not think teachers participate in cultural activities in this regard. The visits to museums or historical places are at the minimum level because of either financial aspect or the aspects of different interests. Probably once in a month, separate budget for such events, or incentive materials may be given (T1).

Seminars about the importance of culture can be organized. I am sure that teachers will become more conscious in this regard. The importance of being cultured should also be grasped (T12). In-service seminars can be held for teachers on cultural issues (T22). Courses that are related to culture, or enhancing cultural consciousness can be added to teacher training programs (T13).

This consciousness can be increased by traveling a lot, an individual who travels a lot knows a lot, becomes aware of the culture (T10). Teachers should take their students to a museum, a theater or an outdoor trip to inform them about artistic activities at least once a month, by cooperating with the school principal and teachers (T15). Teachers can be exchanged with teachers in other cities once a month to visit the cities for three days. Of course, this program should be supported by the National Education (T17). Within the scope of the school, visits to places of cultural value can be organized starting from the immediate vicinity (T25). Teachers and students should be able to go abroad by benefiting from international exchange 
programs, in order to gain awareness of different cultures and to provide at least one foreign language learning (T26). More activities such as movies, cinema, theater, etc. that reflect our culture can be organized, and students' participation can be encouraged (T29).

\section{Development of the Cultural Potential Dimension}

The answers given to the question "How can we increase cultural capital in the dimension of Cultural Potential" directed to the teachers are presented in Table 9.

Table 9. Increasing the Cultural Potential Dimension

\begin{tabular}{|l|c|}
\hline Codes & $\boldsymbol{f}$ \\
\hline Education and training & 21 \\
\hline Reading & 3 \\
\hline Cultural activity & 2 \\
\hline Supervising & 1 \\
\hline Total & $\mathbf{2 9}$ \\
\hline
\end{tabular}

The most emphasized opinion for enhancing the teachers' cultural potential dimension competencies is to give education to the student or teacher and training. Teacher expressions are presented in categories. Four teachers did not declare any ideas on this issue, but two teachers reported ideas in more than one category. Teacher opinions are given below in categorical order.

Diction courses, clear and comprehensible talking can be encouraged. More attention can be given to reading books and talking (T1). Vocational and personal development courses can be organized. Courses can be given on subjects such as cooperation and communication (T9). It must be ensured that teachers express themselves well, are open and comprehensible and that they are trained as a cultured person (T11). In my opinion, cultural potential should be given with some elective or compulsory courses at the university, or it can also be improved after graduation with some cultural activities for it (T13). Cultural potential can be increased with inservice training (T22). This actually ends in the person himself. Many factors such as family, school, a circle of friends can affect this. What we can do is to ensure that they have a say with entrepreneurship seminars. If it is thought to be inadequate, there may be diction and speech courses, but inviting a person of a certain age to this course may cause misunderstanding. Therefore, these courses and seminars should be given at the latest in university education (T23).

They should read more books (T2).

I think teachers should be supervised periodically throughout their professional lives so they can be individuals who continually develop. Of course, there should be supervision in a cultural sense. Moreover, he/she can participate in various projects in the sense of cultural potential, question himself/herself(T15). 
When the relationship between teachers' self-efficacy perceptions and cultural capital competencies is examined, it is observed that there is a "positive" relationship at the "moderate" level. This is the answer for the Research Question 3 .

The cultural capital competencies that teachers had were found to be a significant predictor of self-efficacy perceptions. It was observed that the teachers put forward mainly intellectual accumulation when they were asked how cultural capital competencies and how the areas in which cultural capital competencies contribute to the perception of self-efficacy could be increased. The most mentioned areas by the teachers in relation to the things that could be done to increase cultural capital competencies were reading, participation in cultural activities, cultural education, and training. This is the answer for the Reseach Question 4.

\section{Discussion}

This study aims to determine the self-efficacy and cultural capital competency levels of teachers and to reveal the relationship between them. According to the research findings, it is observed that the cultural capital competency levels of teachers are "moderate." Likewise, Tösten (2017) found out that teachers' cultural capital competency levels were "moderate" in their studies conducted on Hotel Management and Tourism Vocational High School teachers. However, Tösten (2015) determined that teachers' cultural capital competency levels were "high."

As a result of the study, it is observed that the teachers' self-efficacy level is "quite adequate." The results of the studies carried out on self-efficacy perceptions show that there are evaluations at different levels and types in relation to teachers' self-efficacy perceptions. In the study conducted by Doğan (2013), primary school teachers were studied, and it was determined that the primary school teachers' self-efficacy was at the moderate level. In the study conducted by Kahyaoğlu and Yangin (2007), it was determined that pre-service teachers' self-efficacy was quite sufficient. In the study carried out by Akdere (2012), it was determined that the self-efficacy of pre-service teachers was at the average level. This finding is parallel to the findings of Kahyaoğlu and Yangın (2007), Akdere, and Doğan. However, the finding obtained from the study conducted by Aktağ and Walter (2005), which reveals that the self-efficacy of physical education pre-service teachers is "above the average," differs from the findings of this study.

Teachers with high self-efficacy teach in a more effective and academicfocused way in the class and provide more different and successful feedbacks that will enrich the teaching environment compared to teachers with low self-efficacy (Gibson \& Dembo, 1984; as cited Tschannen-Moran \& Hoy, 1998). Teachers with a high level of self-efficacy have the ability to recover quickly in difficult situations, in the face of setbacks, by showing patience and effort (TschannenMoran \& Hoy, 1998). Teachers with high self-efficacy perceptions prefer a collaborative working environment and exhibit a more explicit attitude towards organizations and changes related to teaching and staff development (Collins et al., 
2002). As teacher competency increases, more humanistic approaches to the control of students manifest themselves (Goddard \& Goddard, 2001), and commitment to teaching comes to the forefront (Coladarci, 1992). Teachers' selfefficacy perceptions are their perceptions related to the ability to influence their student's performance of success. Self-efficacy beliefs in the field of education are evaluated for the purpose of explaining individual differences in the performances of teachers and understanding and improving teachers' behaviors (Demirtaş, Cömert, \& Özer, 2011; Kurt, 2012). It is observed that teachers with the high selfefficacy perception level have higher motivation levels, make more effort to teach, and experience lower levels of stress (Oğuz, 2009; Demirtaş, Cömert, \& Özer; Kurt, 2012). On the contrary, when teachers' self-efficacy beliefs begin to decrease, a transformation toward exhaustion starts, physical and emotional tiredness may be accompanied by the loss of self and sense of uselessness (Kurt, 2012). Upon examining the studies conducted, it is possible to say that teachers with the high self-efficacy perception are very different from other teachers in the teaching process and that they give the basic subjects to students successfully. According to the results of the study, it is stated that teachers with the high selfefficacy belief exhibit features such as being zealous in the teaching process, being quick in making instructional decisions, willingness to teach, susceptibility to applying new ideas and methods, and criticizing less when students make mistakes (Özenoğlu Kiremit, 2006). If it is thought what the teacher and the educational process could gain through self-efficacy, making efforts to identify and increase the supporting components of self-efficacy, such as cultural capital, may be regarded as important. It appears that there is a moderately positive relationship given the correlation between teachers' cultural capital competencies and their self-efficacy levels. In the study of Tösten (2017), they found a moderately positive relationship between teachers' cultural capital competency levels and their self-efficacies. Teachers expressed an opinion that cultural capital positively affects self-efficacy. In other words, they expressed an idea that by nature there is a positive relationship between cultural capital and self-efficacy. Besides, the view that cultural capital competencies can be increased mostly with cultural activities and education has emerged. A moderately positive correlation was determined between cultural capital and self-efficacy. In the interviews, teachers stated that cultural capital and self-efficacy are intertwined by nature, and it is reasonable that cultural capital acquisition affects self-efficacy positively. In this regard, Tösten (2017) achieved similar results in their studies.

It was concluded that teachers' cultural capital competencies explain a part of their self-efficacy. In this case, it can be said that the model, in which the effect of teachers' cultural capital competencies on self-efficacy is revealed, is meaningful. When the sub-dimensions of cultural capital competencies and " $\beta$ " values, in the prediction of self-efficacy, are taken into consideration, it is observed that the most effective subdimensions are intellectual accumulation, cultural potential, cultural consciousness, and participation, respectively. Tavakoli, Pahlavannezhad, and Ghansooly (2017) found out that there was a positive relationship between teachers' cultural capital competencies and their self-efficacy. Teachers with a high level of cultural capital competency have directly proportionally high self-efficacy 
levels. Similarly, this result was supported by the study carried out by Tösten (2017), in which it was observed that teachers' cultural capital competencies explain 33\% of their self-efficacy. Gibbs (2002) classified teachers' self-efficacy into four categories and also included cultural self-efficacy in self-efficacy elements. Cultural self-efficacy is the belief in the ability of a teacher to perform certain actions in culturally appropriate ways in certain teaching situations. Furthermore, effective teachers know well that students can learn in the best way, when students' cultures, backgrounds, and abilities are accepted by the teacher, and when the methodology and procedures are adapted to students (Zeichner, 1993). As a matter of fact, in the interviews, teachers expressed that in general, cultural capital involves cultural competencies due to its structure and it contributes to self-efficacy directly and indirectly.

When all these results are considered, in order to increase self-efficacy which has an important place in ensuring the productivity of teachers, it is necessary also to increase the cultural capital competency, which is at the "moderate" level. As indicated in the interviews with teachers, the things to be done to increase cultural capital competencies in each sub-dimension can be listed as follows: In the intellectual accumulation dimension, organizing cultural activities, increasing the rate of research and reading, directing correctly, and providing guidance. In the participation dimension, cultural activities, raising awareness for self-improvement of the individual, supporting, and policy development. In the cultural consciousness dimension, educational opportunities, professional development, cultural activities, material and spiritual support. In the cultural potential dimension, educational opportunities, professional development, reading, cultural activities and the supervision of development.

\section{References}

Akdere, N. (2012). Turkish pre-service teachers' critical thinking levels, attitudes and selfefficacy beliefs in teaching for critical thinking. Unpublished $\mathrm{PhD}$ Thesis.

Aktağ, I., \& Walter, J. (2005). Öğretmen adaylarının mesleki yeterlik duygusu [Preservice teachers' sense of professional qualification]. Spormetre, 3(4), 127-131.

Alivernini, F., \& Lucidi, F. (2011). Relationship between social context, self-efficacy, motivation, academic achievement, and intention to drop out of high school: A longitudinal study. Journal of Educational Research, 104(4), 241-252.

Arun, Ö. (2009). Yaşlı bireyin Türkiye serüveni: Türkiye'de yaşlı bireyler arasında kültürel sermaye dağılımı [The adventure of an elderly individual in Turkey: distribution of cultural capital among the elderly in Turkey]. Gaziantep Üniversitesi Sosyal Bilimler Dergisi, 8(1).

Azar, A. (2010). Secondary school science and mathematics pre-service teachers' selfefficacy beliefs. ZKÜ Social Sciences Journal, 6(12), 235-252.

Balc1, E. (1991). Roles of teachers. Educational Sociology. Ankara.

Bandura, A. (1986). Social foundations of thought and action: A social cognitive theory. Englewood Cliffs, NJ: Prentice- Hall, Inc.

Bandura, A. (1989). Social cognitive theory. Annuals of Child Development, 6, 1-60. Greenwich, CT: Jai Press LTD. 
Bandura, A. (1994). Self -efficacy. In Encyhopedia of Human Behavior, V.S. Ramachaudran (ed.), vol. 4, (pp. 71-81). New York: Academic Press. (Reprinted in H. Friedman (ed.), Encylopedia of Mental Health. San Diego: Academic Pres, 1998. Retrieved from http://www.des.emory.edu/mfp/banEncy.html.

Bandura, A. (1997). Self-efficacy: Toward a unifying theory of behavior change. Psychological Review, 84, 191-215.

Bandura, A. (ed.) (1995). Self-efficacy in changing societies. New York: Cambridge University Press.

Bek, Y. (2007). Teacher's Social/ Professional Roles and Status.Trakya University, Social Sciences Institute. Unpublished Master's Thesis, Edirne.

Bıkmaz, F. H. (2006). Self-efficacy beliefs in science teaching and views about the effective science course. Educational Researches, 25, 34- 44.

Bilgin, N. (2006). Content Analysis in Social Sciences. Ankara: Siyasal Publishing

Blackledge, A. (2001). The wrong sort of capital: Bangladeshi women and their children's schooling in Birmingham, U.K. International Journal of Bilingualism, 5(3), 345-369.

Bourdieu, P. (1986). The forms of capital. In Handbook of Theory and Research for the Sociology of Education, J. G. Richardson (ed.), (pp. 241-258). New York, NY: Greenwood.

Bourdieu, P., \& Passeron, J.-C. (1990). Reproduction in education, society and culture (2nd ed.). London, UK: Sage.

Bourdieu, P. (1995). Practical Reasons. Translated by Hülya Tufan. İstanbul: Kesit Publishing.

Bourdieu, P. (2015). Sociological usage of the science: For Clinical Sociology of Scientific Field. Translated by L. Ünsaldı. Ankara: Heretik Publishing.

Bourdieu, P., \& Wacquant, L. J.D. (2003). The Answers for Reflexive Antrpology. Translated by Nazlı Ökten. İstanbul: İletişim Publishing.

Bussey, K., \& Bandura, A. (1999). Social Cognitive Theory of Gender Development and Differentiation. Psychological Review, 106(4), 676-713.

Cheadle, J. (2008). Educational investment, family context, and children's math and reading growth from kindergarten through the third grade. Sociology of Education, 81(1), s. 1-31.

Cheng, S.T. (2011). Cultural Capital, Economic Capital, and Academic Achievement: Some Evidence from Taiwan. Proceedings of the IASA-IOS Joint Workshop of Young Sociologists, University of Tokyo, Japan.

Coladarci, T. (1992). Teachers' sense of efficacy and commitment to teaching. Journal of Experimental Education, 60(4), 323-337. http://dx.doi.org/10.1080/00220973. 1992.9943869

Collins, K. M. T., James, T. L., Minor L. C., Onwuegbuzie, A. J. , Witcher, L. A., \& Witcher, A. E. (2002). Relationship between teacher efficacy and beliefs about education among preservice teachers. Paper Presented at the Annual meeting of the Mid-South Educational Research Association, Chattanooga, TN, November 6, 2002. http://www.eric.ed.gov/ERICDocs/data/ericdocs2sq1/content_storage_01/ 0000019b /80/1a/eb/a7.pdf.

Creswell, JW. (2002). Educational research: Planning, conducting, and evaluating quantitative and qualitative approaches to research. Upper Saddle River, NJ: Merrill/Pearson Education.

Creswell, J. W., \& Plano Clark, V. L. (2014). Conducting Design of mixed method studies. Translation editors Dede, Y., ve Demir S. B. Ankara: Anı Publishing.

Çapa, Y., Çakıroğlu, J., \& ve Sarıkaya, H. (2005). The validity and reliability study of the Turkish adaptation of the teachers' self-efficacy scale. Eg̈itim ve Bilim. 30(137), 7481 
De Graaf, N. D., De Graaf, P. M., \& Kraaykamp, G. (2000). Parental cultural capital and educational attainment in the Netherlands: A refinement of the cultural capital perspective. Sociology of Education, 73(2), 92-111.

DeMarrais, K.B., \& LeCompte, M. D. (1998). The way schools work: A sociological analysis of education. New York, NY: Addison-Wesley.

Demirtaş, H., Cömert, M., \& Özer, N. (2011). Pre-service teachers' self-efficacy beliefs and attitudes towards the profession. Education and Science, 36(159).

DiMaggio, P. (1982). Cultural capital and school success: the impact of status culture participation on the grades of U.S. high school students. American Sociological Review, 47, 189-201.

Doğan, S. (2013). Examination of primary school teachers' self-efficacy perceptions and their attitudes towards the teaching profession. Unpublished Master's Thesis. Erzincan University Social Sciences Institute, Erzincan.

Eccles, J. S., \& Wigfield, A. (2002). Motivational beliefs, values, and goals. Annual Review of Psychology, 53, 109-132.

Gibbs, C. (2002). Effective Teaching: exercising self-efficacy and thought control of action. Paper presented at the Annual Conference of the British Educational Research Association, University of Exeter, England.

Gibson, S. \& Dembo, M. H. (1984). Teacher efficacy: a construct validation. Journal of Educational Psychology, 76(4), 569-582.

Glesne, C. (1992/2013). Becoming Qualitative Researches. Translated by Ersoy, A. and Yalçınoğlu. Ankara: Anı Publishing.

Goddard, R. D., \& Goddard, Y. L. (2001). Multilevel analysis of the relationship between teacher and collective efficacy in urban schools. Teaching and Teacher Education, 17, 807-818.

Goddard, R. D., Hoy, W. K., \& Woolfolk-Hoy, A.W. (2000). Collective teacher efficacy: its meaning, measure, and impact on student achievement. American Educational Research Journal, 37(2), 479-507.

Kahyaoğlu, M., \& Yangın, S. (2007). Views of elementary school pre-service teachers about their professional self-efficacy. Kastamonu Education Journal, 15(1), 73-84.

Kalmijn, M., \& Kraaykamp, G. (1996). Race, cultural captial, and schooling: An analysis of trends in the United States. Sociology of Education, 69, 22-34.

Kaptan, F. and Korkmaz H. (2001). Effect of science teaching based on collaboration on self-efficacy levels of pre-service teachers, IV. Science Education Congress, Ankara.

Kim, B. S. K., \& Omizo, M. M. (2005). Asian and European American cultural values, collective self-esteem, acculturative stress, cognitive flexibility, and general selfefficacy among Asian American college students. Journal of Counseling Psychology, 52, 412-419.

Kingston, P. W. (2001). The unfulfilled promise of cultural capital theory. Sociology of Education, extra Issue, s. 88-99.

Kurt, T. (2012). Teacher's self-efficacy and collective competence perceptions. Journal of Turkish Educational Sciences, 10(2), 195-227.

Lareau, A. (2003). Unequal childhoods: class, race, and family life. Berkeley: University of California Press.

Lareau, A. (2015). Cultural knowledge and social inequality. American Sociological Review, 78(4), 633-661. http://doi.org/10.1177/0003122413491963.

Lareau, A., \& Weininger, E. B. (2004). Cultural capital in educational research. In After Bourdieu: Influence, Critique, Elaboration, D. L. Swartz \& V. L. Zolberg (eds.), (pp. 105-144). Dordrecht, The Netherlands: Kluwer Academic Publishers. 
MEB İstatistikleri (Mone Statistics) (2015-2016). Retrieved from http://sgb.meb.gov.tr/ meb_iys_dosyalar/2016_03/18024009_meb_istatistikleri_orgun_egitim_2015_2016. pdf.

Merriam, S. (2013). Qualitative Research. (Çev. Ed.) Turan, S. Nitel Araştırma Desen ve Uygulama için Bir Rehber [A Guide to Qualitative Research Design and Implementation]. Ankara: Nobel Yay.

Oğuz, A. (2009). Sinıf ögretmeni adaylarının akademik öz-yeterlik inançları [Academic self-efficacy beliefs of pre-service primary school teachers]. VIII. Ulusal Sinif Öğretmenliği Eğitimi Sempozyumu. 21-23 Mayıs 2009. Eskişehir.

Özenoğlu Kiremit, H. (2006). Comparison of pre-service science teachers' self-efficacy beliefs in teaching biology. Unpublished Dissertation. Izmir Dokuz Eylul University Educational Sciences Institute.

Patton, M.Q. (2002). Qualitative Research and Evaluation Methods. Thousand Oaks, CA: Sage.

Scholz, U., Gutiérrez-Doña, B., Sud, S., \& Schwarzer, R. (2002). Is general self-efficacy a universal construct? Psychometric findings from 25 countries. European Journal of Psychological Assessment, 18(3), 242-251.

Symeou, L. (2007). Cultural capital and family involvement in children's education: Tales from two primary schools in Cyprus. British Journal of Sciology of Education, 28(4), s. $473-487$.

Şahin, E. (2010). The effect of instructional style preferences and genders on self-efficacy levels of elementary school classroom teachers, IV. Congress of Science Education, 2000, Ministry of National Education: Ankara.

Tavakoli, F. H., Pahlavannezhad, M.R., \& Ghonsooly, B. (2017). A mixed methods study of the relationship between cultural capital of senior high school english teachers and their self-efficacy in tran's english language classrooms. https://us. sagepub.com/en-us/nam/open-access-at-sage.

TCKB (2013). (SEGE-2011). Research of Socio-Economic Development Rankings of Provinces and Regions, The Republic of Turkey Ministry of Development publishing, Ankara.

Tösten, R. (2015). The investigation of teachers' cultural capital competencies. Unpublished Dissertation. University of Gaziantep, Social Sciences Institute, Gaziantep.

Tösten, R. (2014). Cultural capital scale: validity and reliability study. International Journal of Social Science Research.

Tösten, R. (2017). The relationship between cultural capital qualification levels and selfefficacy levels of hotel management and tourism vocational high school teachers. Academical View Journal, 64(November-December).

Tschanen-Moran, M., \& Woolfolk, A. H. (1998). Teacher efficacy: its meaning and measure. Review of Educational Research, 68, 202-248.

Tschannen-Moran, M., \& Woolfolk-Hoy, A. (2001) Teacher efficacy: Capturing an elusive concept. Teaching and Teacher Education, 17, 783-805.

Werfhorst, H. G. V. D., Sullivan, A., \& Cheung, S.-Y. (2003). Social class, ability and choice of subject in secondary and tertiary education in Britain. British Educational Research Journal, 29(1), 41-62.

White, K. R. (1982). The relation between socioeconomic status and academic achievement. Psychological Bulletin, 91, 461448.

Woulfe, J. (2008). Self-efficacy and culture: A comparison of Denmark and the United States. Gustavus Adolphus College. Thesis. 
Xu, J., \& Hampden-Thompson, G. (2012). Cultural reproduction, cultural mobility, Cultural resources, or trivial effect? A Comparative approach to cultural capital and educational performance. Comparative Education Revie, 56(1), s. 98-124.

Yesilyurt, E. (2013). Teacher self-efficacy perceptions of pre-service teachers. Electronical Social Sciences Journal, 12, 88-104.

Yıldırım, A., \& ve Şimşek, H. (2006). Qualitative research methods in Social Sciences. Ankara: Seçkin Publishing.

Yosso, T. J. (2005). Whose culture has capital? A critical race theory discussion of community cultural wealth. Race Ethnicity and Education, 8(1), 69-91.

Zeichner, K. M. (1993). 16 Key elements of effective teacher education for diversity, educating teachers for cultural diversity (NCRTL special report), East Lansing, Michigan: National Center for Research on Teacher Learning, (ERIC Document Reproduction No. ED 359167). 


\title{
New Approaches to Individual Instrumental Tuition in Music Education
}

\begin{abstract}
By Anastasia Hasikou*
Individual instrumental tuition has been the focus of some new research in musical scholarship during the last two decades. The main conclusions that appear to be shared by scholars in this field such as Gerald Jones, Knud Illeris, John Heron, Andrea Creech and Helena Gaunt is that a combination of modern social circumstances together with rapidly advancing technological innovations have considerably widened accessibility to music experience of different kinds and as a consequence has affected individual instrumental tuition. Based on a considerable analysis of new teaching approaches to individual tuition on a conservatoire level, this paper will endeavor to suggest that the traditional mode of instrumental tuition, which encompasses a hierarchy and mostly directive mode of teaching, has shifted significantly towards a responsive mode of teaching and a more autonomous, self-directed mode of learning. This paper will conclude with a consensus that one-to-one instrumental tuition is shifting dramatically and new approaches whose aim is to facilitate the best possible learning outcomes need to be taken into consideration by music instrumental tutors.
\end{abstract}

Keywords: directiveness and responsiveness, effective feedback, evolutionary mentoring, individual instrumental teaching, reflective dialogue.

\section{Introduction}

Individual instrumental tuition had been, traditionally, based on teaching practice that had passed on from teachers to their students. In this way, a mostly directive teaching approach had prevailed in this domain with routines and patterns that mainly aimed to the acquisition of specific technical and interpretative skills of primarily western art music. Pedagogical literature produced over the past two decades, had severely challenged conventional teaching practice as being incompatible with the overwhelming contemporary cultural and social environment and thus, in some cases, completely unsuccessful.

In an effort to overcome obstacles that occurred in teaching and learning such as lack of motivation and progress and appearance of anxiety symptoms, we have encompassed evolutionary mentoring techniques in our teaching practice and subsequently evaluated learning results in different situations. After a few years of experimentation, evaluation and reconsideration of particular teaching routines and patterns, we suggest that the implementation of developmental or evolutionary mentoring techniques in instrumental tuition, provides a comfortable teaching and

\footnotetext{
*Adjunct Lecturer, ARTE Music Academy, Cyprus.
} 
learning environment that facilitates students to overcome obstacles and improves learning outcomes.

Through a literature review of modern educational theories in this field and reflecting on personal piano teaching experience of the past ten years, this paper will examine new approaches to individual instrumental teaching. The paper will draw on literature reviews of recent research on one-to-one instrumental tuition, focusing on ideas taken by evolutionary or developmental mentoring approach. It will also encompass discussion of an innovative approach developed by $\mathrm{Liz}$ Lerman, called Critical Response Process (CRP). The paper will, finally, exemplify ideas of evolutionary mentoring and CRP through three examples taken from the author's teaching experience with individual piano tuition.

\section{Directiveness Vs Responsiveness in One-to-one Instrumental Tuition}

As Creech \& Gaunt (2012) have rightly pointed out, "traditionally, instrumental tuition has been conceptualized predominantly in terms of the masterapprentice model [...] which premised fundamentally on the acquisition of practical skills" (p. 5). In this respect, the prevailing approach to instrumental tuition focused mostly "on the immediate context of the particular music and specific instrumental points of technique" (Creech \& Gaunt, 2012, p. 5). This approach might have, in the past, produced some very brilliant results in the music domain; however, it has proved insufficient in response to changes in the modern social and cultural world. Active teaching practitioners of instrumental tuition have begun to indicate highly directive approaches as being problematic in terms of effective learning.

The questions about how directive and how responsive a teacher should be and in which cases certain elements of each approach can be effective for teaching and learning have often been the subject of concern in modern pedagogical literature. Many authors have come to the conclusion that elements of both approaches can prove more or less appropriate under certain conditions. It is a general consensus that, usually, there is a complexity of reasons which could prevent a student from experiencing satisfactory learning. Illeris (2004), has identified a number of dimensions that should be examined in this respect. According to him, an important aspect that should be taken into account is the "emotional dimension" of non-learning which identifies as the "mental defense" against an overwhelming number and complexity of impulses and influences that learners are exposed to every day. Also, Illeris points out that, in some cases, there is a matter of "identity defense", when learners get into a situation in which they feel their identity is threatened. This second dimension that the same author notes is the "social dimension" which is defined as a mental resistance being revealed as an active non-acceptance and objection with strong personal forces and engagement (Illeris, 2004, p. 85).

Heron (1999), defines the role of the teacher as "the facilitator" who relies on the desire of each learner to implement the purposes which have meaning for them. Examining different modes of facilitation in teaching and learning, he 
discusses this subject under the scope of "the politics of learning" (p. 9-10). He distinguishes three modes which he deems appropriate in different levels of the learning process as follows: (1) hierarchy early on; (2) co-operation mid-term; and (3) autonomy later on (p.10). Although his general argument focuses on group teaching, there are elements that can be well-applied to individual instrumental tuition in which a hierarchical framework may be needed in the first stages in which the teacher takes responsibility over teaching in order to create conditions within which learners can soon exercise full self-determination in their learning. Finding the balance between hierarchy and autonomy in learning is in Heron's view the classic dilemma in all educational reform: "Students have the need and the right to be released from oppressive forms of education and should be encouraged to participate in educational decision-making. But they are conditioned and disempowered by these forms and may not have the motivation or the personal, interpersonal and self-directing skills required, to break out of them" (1999, p. 11).

Elements that relate to the above dilemma in terms of different teaching modes have also been discussed by Jones (2005). His very inspiring perspective focuses on different kinds of learning alignments between the teacher, the learner and the material which lead to three distinct teacher's roles termed "the gatekeeper", "the midwife" and "the fellow traveler". According to Jones analysis in the "gatekeeper alignment" the teacher is closely aligned with the material. $\mathrm{He} / \mathrm{she}$ is the gatekeeper to it. The learner is expected to digest the material and regurgitate it. In this respect, the learners "quickly realize that they are there to learn from the person standing at the front of the class" (p. 5). Some learners enjoy the passivity of their role in this alignment since there is no compulsion to contribute to the class and therefore, they remain safely within their comfort zones. Within the worst deployments of this alignment, the learner is not allowed to question the material and there is a little room for critical discussion (p. 4-5). In the "midwife alignment" the teacher takes the position of the facilitator whose role is to enable the learners to discover the material for themselves. Learners take the position of participants who are offered stimulating activities and material to experiment with and they have the chance to contribute to discussions (p. 5-7). Finally, in the "fellow traveler alignment" the teacher steps down from his/her role as teacher and becomes a fellow learner in a class of learners who are out to analyze, refine, or discover the material (p. 7-9).

Depicting a quite conventional debate on teaching domains, this symbolic distinction of existing teaching roles often challenges a variety of traditional pedagogical ideologies and also stimulates further awareness regarding teaching practice. Concluding his discussion of essential arguments of this debate, Jones points out the view on this issue taken by the ancient philosopher Aristotle, who considered the skill of the teacher in aligning the three elements as "an ability to make the optimum and most appropriate decision in every circumstance" (quoted in Jones, 2005, p. 10). Contributing to the alignment debate, Jones (2005) emphasizes that "conscious shifting of alignments by an expert practitioner enables her to reap the benefits of each alignment, whilst avoiding their potential pitfalls" (p. 10). 


\section{The Concept of Evolutionary Mentoring in Teaching Situations}

A number of modern innovational teaching theories have recently turned their attention to the concept of evolutionary mentoring as a method that challenges the traditional highly directive teaching approach. Several ideas and elements taken from the concept of evolutionary mentoring have been proved to respond well to modern instrumental teaching practice and facilitate the teaching and learning progress. Responding to the changing face of modern societies, Creech \& Gaunt (2012) have suggested that modern instrumental teaching practice should consider the concept of mentoring where "the mentors help the mentees to make their own decisions by fostering and encouraging independence, help to remove fear of failure by building confidence, prioritize creating an environment of trust, commitment, and active involvement between mentor and mentee" (p. 6).

Brockbank \& McGill (2006) have defined evolutionary mentoring as a person-centered process that leads to transformation (p. 75). It offers the person a chance "to identify the prevailing discourse and challenge it, through reflective dialogue" (Brockbank \& McGill, 2006, p. 14). The same authors have pointed out that a dialogue form in which "the speaker's intention is to hold forth in order to convey his or her knowledge is unlikely to lead to some new understanding. This form of dialogue is often characterized by one party claiming to be expert in interaction with another who may not be" (2006, p. 45). On the other hand, "reflective dialogue engages the learner's realities and subjective experience, giving space for the learner to consider and reconsider without haste" (Brockbank \& McGill, 2006, p. 57). Applying the concept of "reflective dialogue" to instrumental tuition as part of evolutionary mentoring can sometimes prove painful and difficult to maintain. Nonetheless, "it may generate new learning, forged from the discomfort and struggle of dialogue, which emerges as the reflective learning we seek as an outcome of the mentoring relationship" (Brockbank \& McGill, 2006, p. 57-58).

The concept of reflection has been identified by several educational theories as essential for deep and significant learning (see Boyd \& Fales, 1983; Boud, Keogh, \& Walter, 1985). A method that has been promoted by theorists such as Whitmore (1996 [1992]), Rogers (2012 [2004]) and Brockbank \& McGill (2006) as facilitative for reflective learning is the use of thoughtful questioning. Applying questioning for raising "awareness and responsibility" (Whitmore, 1996, p. 39-41) and consequently improvement can be a very powerful mentoring technique for instrumental tuition. Crucial elements for developing skillful questioning techniques relate to the choices of the place and the type of questions. As Brockbank \& McGill (2006) pointed out, "the place of questioning comes after listening [...] without judgement so that some trust and confidence have been established" (p. 184). Furthermore, considering different types of questioning is also important in raising learning potential. In most cases, questions which do not include judgments and advice but instead encourage active thought prove more effective in reflective process (Whitmore, 1996 [1992]). Hence, a "defensive response" to a question in a teaching situation is often evidence of a failed attempt to develop the skill of questioning (Whitmore, 1996, p. 39-40). 
Another element that is often linked to the concept of evolutionary mentoring in instrumental tuition is the teacher's role in giving effective feedback. The development of a skillful feedback technique can be a powerful element that contributes to the creation of a balance between directive and responsive teaching. For many learners the prospect of receiving feedback often inspires fear, "as most people expect negative feedback and are not in a receptive listening mode" (Brockbank \& McGill, 2006, p. 190). Moreover, giving feedback in a teaching process is indeed of little worth for the recipient unless he or she can understand it and of course use it. According to Brockbank \& McGill (2006), "effective feedback [...] increases self-awareness and offers us more options and the opportunity to change" (2006, p. 190). Moreover, it is a common consensus that "destructive feedback is unskilled feedback that leaves the recipient simply feeling bad with little to build on" (Brockbank \& McGill, 2006, p. 191). Brockbank \& McGill (2006) focus their discussion on, specifically, the development of certain skills and methodology on giving effective feedback. According to them, first and foremost, the person offering feedback must make a judgment about appropriateness by answering questions such as: "Is this the right time? Is it a good place? Am I the right person to give it? How can I do it most effectively?" (2006, p. 191). Moreover, a number of key elements for giving effective feedback can be summarized as follows: 1 . Begin with the positive. People need to know when they are doing something well. Do not take the positive aspects for granted, 2. Be specific and not general, 3. Own the feedback by using phrases such as "I believe (...), In my view (...)", 4. Leave recipients with a choice, 5. Limit negative feedback to one or two areas if you're giving feedback on weaknesses (Brockbank \& McGill, 2006, p. 193-195).

In an effort to develop a feedback system that emphasizes the values of dialogue, the choreographer Liz Lerman (2003) has designed a four-step, group method known as the "Critical Response Process (CRP)". The main aim of this inspirational feedback system is to make the recipient eager to go back to work. In this respect, principles of Lerman's method can prove very valuable to instrumental tuition. There are three roles assigned within CRP: the artist, the responders and the facilitator. The artist is the person who is prepared to present his/her work to the group of CRP, discuss their work openly and be in a position to receive positive and constructive comments. Responders are the CRP group which may include friends, public, peers or strangers, experts or novices. The group of responders should be invested in the potential of the artist to do their best work. The facilitator is the person who is in charge to lead the whole process, ensuring that the four-step method is going as appropriate. In this regard, the facilitator ensures that all participants understand the sequence of steps involved in the process and intervene when opinions or suggestions are given too early in the process. It is also the facilitator's role to check that the artist is comfortable with the direction of discussions throughout the process, to help the artist break down questions if needed, and to encourage participation from the responders (Lerman \& Borstel, 2003).

The CRP begins with the artist presenting their work that they would like feedback on. This presentation is followed by the first step of the process, called 
"statements of meaning", in which the facilitator invites positive feedback from the responders. This feedback may include comments about what was meaningful for the audience including elements that they perceived as exciting, memorable, challenging, unique, different, surprising, touching etc. Meaningful thoughts are followed by the second step of the process in which the facilitator invites the artist to comment on an aspect of their work and to request feedback from the responders asking questions on specific matters of their work. Responders should answer honestly, staying within the topic of the artist's question. The process is most fruitful when artists are open to learning something of value from others that may apply to the future evolution of their work. In the third step of the process the facilitator invites responders to address questions to the artist about their work. These questions should remain neutral and avoid being leading or opinionated. In fourth step, with the artist's permission, responders can offer opinions on what they have seen or hear. Responders can articulate opinions on chosen matters relating to the artists work or performance only if the artist wishes to hear their opinions on the particular subject. In case the artist is not open to hearing an opinion, it is not useful to continue a discussion around it. In fifth step which is optional, depending again on the artist's agreement, the artist is invited by the facilitator to share with the responders what was helpful in moving him/her forward with their learning, or what they will take away from the session (Lerman \& Borstel, 2003).

CRP is a stimulating practical illustration of the most fundamental principles in developing a skillful feedback technique, underpinned by theorists such as Whitmore (1996[1992]), Brockbank \& McGill (2006), and Rogers (2012[2004]). The value of Lerman's ideas for the instrumental practitioner is the development of responsive skills with regards to learners' concerns expressed in the form of questions. At the same time, through the practice of stating meaningful thoughts focusing on the positive elements as well as asking permission to express any opinions foster conditions where directiveness can be applied in a non-traditional way that contributes to learning improvement.

\section{Blending Directiveness and Responsiveness in Piano Teaching Practice}

Our personal attempts to shift between directive and responsive modes in our piano teaching practice have led us to apply ideas drawn from the concept of evolutionary mentoring for which we have worked toward developing further over the past few months. Applying elements drawn from the concept of evolutionary mentoring is, in our opinion, a powerful method that creates conditions of balance between directiveness and responsiveness in individual instrumental teaching and facilitates learning improvement. Appreciating the importance of reflection in teaching and learning, we strive to engage our students in reflective dialogues bearing in mind ideas and concepts that we believe to be essential for the development of their musical and technical skills in piano learning.

One example is the idea that deeper levels of learning and understanding occur when we move "beyond our current skills with small and attainable steps", an idea that is embraced in the more general concept of scaffolding learning (Creech, 2012, p. 389). Given the fact that contemporary social relations move at 
an extremely high speed, and modern societies focus more attention on the final product/spectacle (Debord, 1995 [1967]), modern students often rush to achieve the final performance, giving little appreciation to the fact that there is a process which precedes it.

Andreas ${ }^{6}$ is a charismatic 18 -year old student who studies piano as a second instrument. He is a brilliant laouto player, engaged with traditional forms of local music, but he struggled with piano learning. Andreas showed great unwillingness to follow any conventional scaffolding strategies, that included separate-hand practice focusing on the articulation, dynamics and phrasing, and he followed a completely self-directed learning approach aiming directly to the final performance. After a few weeks of piano lessons, Andreas was disappointed by his lack of progress and revealed anxiety and frustration when he came to class. At the same time, his refusal to follow any of our scaffolding suggestions together with the little progress he was making also made us anxious and frustrated. So, instead of insisting on a primarily "hierarchical mode" (Heron, 1999), we chose to engage him in a "reflective dialogue" (Brockbank \& McGill, 2006). This dialogue focused on giving him space to consider his piano learning experience without haste and challenge the idea of skipping the process and pursuing, from the outset, the final performance.

Drawing ideas from evolutionary mentoring approach, we applied the tool of questioning. In doing so, our main concern was to avoid defensive responses from Andreas so we tried to give some thoughtful consideration to our questions beforehand. Thus, we started our dialogue by focusing on his laouto playing, showing interest in his recent repertoire and concert performances. It was obvious that talking about his laouto playing made him feel strong and confident since he showed great willingness to share his ideas and opinions with us. So, after a while we tried to focus our dialogue on issues about the laouto learning process: When did you start playing the laouto? How long did it take you to learn your first piece? What do you remember from the first few months of laouto lessons? Our aim was to create parallels between the learning of the instrument that he obviously enjoyed and the piano learning. Answering these questions, we observed that Andreas started reflecting on his piano learning approach and identified similarities and differences between the two instruments, something that has proved very important for his progress. After this first honest conversation, our communication during the lessons greatly progressed and even now reflective dialogues intervene in many lessons as a tool to facilitate improvement. In terms of teaching and learning approach, we ended up applying some scaffolding strategies found in conventional directive models while embracing Andreas' innovative ideas and experimentation at the same time. In this way, both of us often find ourselves out of our comfort zones, as we shift between the "midwife" and "fellow traveler" alignments with a few moments of "gatekeeping" (Jones, 2005), thus making our lessons much more effective and stimulating.

Encouraging students to build "awareness and responsibility" (Whitmore, 1996 [1992]) in their learning is also a significant element that embraces the idea of skillful questioning in evolutionary mentoring. Ioanna is a 15 -year old student

${ }^{6}$ Student names are not real. 
who has recently been focusing on the technical aspects of piano learning such as posture, shoulder and wrist position. A conventional practice concerning the above kinds of technical skills gives full responsibility to the teacher, who builds on previous common consensuses on the domain. Pursuing a questioning model that encourages building awareness and responsibility for posture and hand position proved extremely effective for Ioanna. Instead of using common language such as "keep your wrist steal!" (because this is the way it should be!), we pursued a reflective dialogue with the student that included questions such as "Which hand position feels more comfortable for you? What do you think would help you achieve this allegro speed considering the wrist position? What quality of sound can be produced with a high wrist/low wrist? How does wrist movement affect the shape of the melodic lines?" At the end of this process that went on for a few weeks, we were impressed to see that Ioanna started building awareness of the importance of the wrist position in achieving faster tempos and better sound quality and took responsibility for correcting her wrist movement while playing as a way to achieve improvement, showing interest in possible suggestions on this issue from our part. Teaching and learning, in this case, was clearly shifting from a predominantly hierarchical mode to a more co-operative relationship, while at the same time setting the groundwork for the student to develop autonomous and selfdirected learning. In this regard, directiveness and responsiveness, illustrated by Jones (2005) and Heron (1999), were blended with regard to Ioanna's specific needs.

Another powerful tool that we drew from evolutionary mentoring concept and applied to our teaching is the idea of effective feedback. Maria is a 20-year old student who studies the piano as a principle instrument. She is preparing a demanding repertoire for her final recital next year. She is a hard-working person and devoted to piano performance; however, she is exhibiting low confidence linked with increased anxiety, a situation that led to her giving some poor performances. Appreciating that the student could be significantly helped by receiving the appropriate type of feedback, we drew on Brockbank \& McGill's ideas (2006) while also incorporating practical examples taken by Lerman's system (2003). Hence, we ensured that our first response to listening to her work in progress started with meaningful thoughts that pointed out the positive elements. So, we began with statements such as, "I liked very much the way you emphasize the main subject every time it occurs. It shows the great amount of independence that you have achieved between your two hands!". Another comment was: "There were moments that I was overwhelmed by the musical sensitivity that you reveal in terms of sound quality, variety of dynamics and phrasing". Starting with meaningful thoughts by pointing out the positive elements in a specific and not general way, with us owning the feedback by using phrases starting with "I" or "In my opinion" as suggested by relevant theories, proved extremely useful in Maria's case. She became more talkative and we could see in her facial expression that she felt happy and confident. We were also impressed to find out that Maria responded to this feedback in an honest and open way, sharing concerns about what she considered as weaknesses. She seemed more aware of aspects of her performance, and she developed more responsibility in her 
performing choices. In most cases, her concerns were so reasonable and straightforward that our role in responding to them with appropriate suggestions and problem-solving strategies had become extremely significant. This approach increased the effectiveness of our lessons since Maria felt eager to go back to work on elements that we discussed, making essential improvements not only for her performance but also her life in general.

\section{Conclusion}

Applying evolutionary mentoring and CRP techniques in one-to-one instrumental teaching is an approach that incorporates a number of ideas which foster a human-centered music pedagogy. As shown by the three teaching examples above, this approach facilitates individual learners to overcome concerns, remove obstacles and achieve their potential. In doing so, the combination of traditional and modern educational methods and the consequent blending of directiveness and responsiveness in teaching and learning process is essential.

It is apparent that the teaching approach proposed by this paper requires an on-going thoughtful consideration and evaluation of each teaching and learning situation separately. This approach also requires more time. But it is the time that should not be denied a learner as soon as he has been placed in the center of teaching concern. It is the time that leads to essential and deep levels of understanding, progress and real learning. It is definitely worth it.

\section{References}

Boud, D., Keogh, R., \&Walter, D. (1985). Turning experience into learning. London: Kogan Page.

Boyd, E., \& Fales, A. (1983). Reflective Learning: key to learning from experience. Journal of Humanistic Psychology, 23(2), 99-117.

Brockbank, A., \& McGill I. (2006). Facilitating reflective learning through mentoring and coaching. London: Kogan Page.

Creech, A. (2012). Interpersonal behavior in one-to-one instrumental lessons: An observational analysis. B.J. Music Ed. 29(3), 387-407. Cambridge: Cambridge University Press.

Creech, A., \& Gaunt, H. (2012). The changing face of individual instrumental tuition: Value, purpose and potential. In G. McPherson \& G. Welch (Eds.), Oxford Handbook of Music Education, (pp 1-19). Oxford: Oxford Handbooks Online.

Debord, G. (1995 [1967]). The society of the spectacle. New York: Zone Books.

Heron, J. (1999). The complete facilitator's handbook. London: Kogan Page.

Illeris, K. (2004). Transformative learning in the perspective of a Comprehensive Learning Theory. Journal of Transformative Education, 2(2), 79-89.

Jones, G. (2005). Gatekeepers, midwives and fellow travelers. learning alignments and pedagogy in adult education. London: Mary Ward Centre. 
Lerman, L., \& Borstel, J. (2003). Liz Lerman's critical response process. A method for getting useful feedback for anything you make, from dance to dessert. U.S.: Dance Exchange Inc.

Rogers, J. (2012 [2004]). Coaching skills. A handbook. Berkshire: Open University Press.

Whitmore, J. (1996 [1992]). Coaching for Performance. The new edition of the Practical Guide. London: Nicholas Brealey Publishing Limited. 


\title{
The Real-Life Experience of Visual Art in Czech Extracurricular and Co-curricular Education
}

\author{
By Zuzana Pechova*
}

\begin{abstract}
In 2016, the characteristics and approaches to art mediation as an educative approach to facilitation of understanding and experiencing art in Czech extracurricular field trips and school outreach programmes were defined and investigated by faculty members of Department of Primary Education within an independent research project. This paper presents a theoretical background to the investigation results. The research study used a qualitative research method of semi-controlled interviews with professionals from different extracurricular establishments. The goal was to achieve a holistic view of the current concept of visual art on the basis of extracurricular school programmes and their pedagogical potential and to describe and define the methodological specifics of this phenomenon using a research design based on datas gained from six extensive interviews The open-coding analysis method used here reveals a generalised view of the topic. Thus it will provide clear reasons and way of implementation of art mediation from extracullicular environment to schools.
\end{abstract}

Keywords: co-curricular education, extracurricular, experiential education, object-based education, Visual art.

\section{Introduction}

Educational systems worldwide are based on the idea of academic skills. The global economy is fuelled by innovation and creativity. Social discourse demands communication using images in addition to text (Duncan, 2012; Fulkova, Hajduskova, \& Sehnalikova, 2012). Therefore, visual art education is an important part of the school educational system. Yet, its importance worldwide is underestimated in the hierarchy of core subjects (Eisner, 2002; Kress, 2000).

Multiple research results prove positive outcomes from the effect of arts education on children's learning and development. Education through and in the visual arts produces positive learning outcomes, develops a sense of personal and cultural identity, supports socio-personal development and has a significant influence on cognitive development (Catterall, 2009; Bamford, 2006; Eisner, 2002; Fiske, 1999). Education is no longer associated only with classes, teachers or separated school subjects (Sobanova, 2012). Interdisciplinary education and that in arts are now required as part of learning about real-world issues. The real-life experience of art demands cooperation with the education community and with other institutions.

${ }^{*}$ Professor Assistant, Technical University of Liberec, Czech Republic. 


\section{Literature Review}

\section{Visual Art-Based Field Trip Activities and Outreach Programmes}

Extracurricular activities are defined as activities designed for school-aged young people to participate in learning activities outside of a standard curriculum (Bamford \& Wimmer, 2012). These co-curricular activities provide a channel for reinforcing lessons learned in the classroom offering students the opportunity to apply their academic skills in a real-world context, and are thus considered to be part of a well-rounded education (Massoni, 2011).

Visual art-based field trip activities (e.g. fine art gallery visit) and outreach programmes (e.g. an artist's workshop provided at school) are one of most frequently offered program of extracullicullar institutions for its potential of offering an encounter with artworks and resources not available at schools. They provide channels for reinforcing lessons learned in the classroom. These options offer students the opportunity to apply academic skills in a real-world context and give children a more direct, interactive experience of the arts (O'Brien \& Rollefson, 1995). Museums, community cultural institutions, art centres, artists and universities can become involved by providing art-based education programmes.

The first museum-provided educational programmes for schools and the origin of arts integration into other subjects took place in the U.S. (Wilson, 1997; Winslow, 1939). Art-based programmes are used in art education and are integrated into other subjects as one approach to teaching and learning that designates art as the primary pathway to learning. The emphasis on the educational value of arts and its connection with real-world issues is anchored in the Discipline Based Art Education (DBAE) approach (Basak, 2017). DBAE has expanded in other countries, and it has become a platform for the currently widespread Comprehensive Art Education approach, being an important approach for Czech art education.

In the Czech Republic, current art education curriculum documents and theories emphasise balance and cooperation between educational subjects and the community's involvement (Babyradova, 2007). There are four approaches to art education in Czech Republic. The art-centric approach is based on U.S. DBAE principles (Slavik, Hazukova, \& Samsula, 1997). Its actual development accents experiential attitudes of instruction (Babyradova, 2007), and thus the real-life experience of art outside the school (or brought to school) is highly desirable and very real.

\section{The Real-life Experience of Art Through its Mediation}

Object-based Education. The mediation of art is one way of perceiving artwork and facilitating its understanding. According to cuntructivism, the museum learning is seen as an active process (Hein, 1998; Hooper-Greenhill, 1999). The term "mediation of art" includes not only the work of pedagogues and lectors; it also covers publishing, art disclosure in media, exhibitions, fairs and other 
activities. In every locale and experience, there is always a piece of art present, even if only indirectly, for example, through its reproduction.

The real-life experience of visual art can be held through practical, experimental, mediating programmes called animations. The real-life experience of art is an essential precondition for the functional principles of animation, which is presented in the spirit of object-oriented learning (Horacek, 1998).

Object-based education and learning, or using objects for education, describes a partial method that supports gallery and museum education, for example. When it is not possible to work with a piece of art directly, an alternative object is used to facilitate the work - the interpretation and recognition of art. Object-based education is based on the idea that what is seen is more memorable than what is mediated only verbally (Chatterjee, 2010). This idea was already promoted by Comenius (Komensky, 1991). In most cases, the objects used in extracurricular and co-curricular programmes can be seen in natural settings and contexts; this aspect is often missing when working with art in school.

The Method of Animation as an Experiential, Creative, Educational Method of the Mediation of the Real-life Experience of Art. Animation is a broad term. Its interpretation is not clear, and the situation is made more difficult by the fact that its meaning is different in different countries and different languages. The Latin word "anima" means soul. The term "the animator" is more specific: one who gives life. Animation as an educational method within the real-life experience of art is called cultural animation (Siostrzonek, 2008). It incorporates gallery/ museum animation and the animation of cultural historical heritage.

Gallery/museum animation is a process involving contact with artwork. This process gives participants new possibilities of richer understanding and new experiences. Animation, therefore, adds the beautiful and irreplaceable element of effective practice to the cognition process. "Both thinking and learning get its tangible form" (Horacek, 1998, p.72).

Gallery/museum animation is a kind of accompanying programme for an exhibition institution called a mixed-method programme. It is a combination of a theoretical explanation or lecture and a practical part. During the theoretical part, a participant's role is passive and is that of receiving the information, while during the practical part, the participant is forced or encouraged to learn through an experience based on creative activities (Horacek, 1998). The practical part consolidates theoretical knowledge with enriching personal experience and reflection. The essence of the method of animation is therefore experimental and uses creative activity to work with art. These activities are a means to processes of natural learning.

The second type of cultural animation is the animation of historical heritage. This is viewed as one of the ways of caring for, presenting and popularising cultural historical heritage. It is mostly the tangible heritage of a country, region, city or a certain place. The animation of cultural historical heritage is more closely linked to methods of conservation, of cultural management and of art management. It is understood to be a method that works with the emotional side of its consumer. Animation is used in an interpretation programme as its motivating or experimental part. Just as with gallery/museum animation, there are conditional 
requirements for objects of heritage (Hicela \& Kuscevic, 2013). Example of such animation could be creative guided tours including drama and hand on activities organised by historical sites, museum, galleries, Non-Governmental organisations.

Existing research provide large scale of topics within the phenomenon of art mediation, object-based learning and the method of animation. However we found all the theoretic background fragmented into specialized topics with a lack of comprehensive view on intersections of its content and educative potential. It is therefore the research project was drawn up.

\section{Methodology of the Investigation of Approaches to Educational Programmes based on the Real-life Experience of Art out of the School Environment}

The interview research method was chosen to obtain data from an extracurricular environment. An interview is a form of questioning that allows us to obtain in-depth information and understand a problem more precisely, mainly because it requires personal contact with the respondent. It also enables the researcher to develop and influence the interview according to their needs.

This investigation consists of the analysis of six interviews conducted with experts from the Czech extracurricular establishment currently providing animation programmes to schools. Personal interviews were carried out over a period of four months. Each interview was recorded and then converted into text. The extracts of interview transcripts are part of the Findings, the respondents are coded as Respondent 1-6.

The aim of the interviews was a) to obtain data that are not available in the literature, are actual; b) to get a current view of how the Czech environment intersects with the animation of visual art outside the school.

The goal of the general interview guide approach was a) to obtain data for the analysis of an expert's personal subjective views on the current status of visual art animation in the extracurricular environment and b) to describe its learning potential and specific methodologies. To achieve our goal, we used a simple structure for the interview questions. We asked about the following:

1. The current status of visual art animation in extracurricular education,

- the ways of mediating cultural and historical heritage and animation,

- the definition of the concept of cultural and historical heritage and animation focused on specific field of interest of the respondent.

2. The pedagogical potential of visual art in extracurricular education,

- why/whether the cultural and historical heritage is valuable for education and for which field, subjects, thematic areas, key competencies,

- how does the respondent use the topics (and which exactly) of cultural historical heritage within the method of animation in his/her own practice. 
3. The methodological specifics of visual art mediation in extracurricular education,

- what makes the method of animation of cultural and historical heritage unique, compared to other ways of mediation and teaching methods,

- what are the disadvantages of the method of animation of cultural and historical heritage.

We conducted six extensive interviews at this stage of the research. Two interviews were conducted with a fine art gallery pedagogue, and one interview was conducted with each of the following: a lector of a historical monument, a leisure time animator, a university assistant professor and the founder of a nonprofit organisation engaged in the placement of artworks in public spaces. For capacity reasons, we present only the analysis results of the interviews. The presentation and citation of interviews is therefore missing.

The interviews were analysed to establish a system of categories to answer the research questions:

1. How is the method of visual art animation understood in real life and in professional practice?

2. What is the value and what are the characteristics of visual art animation in real life outside of school?

The method appropriate and chosen for collecting qualitative data was a purposive sampling, which focuses on particular characteristics of population that are in interest and will enable to answer given research questions. The type of purposive sampling best suiting our goals was the expert sampling, as the research needed to gain knowledge from peole with particular expertise. To avoid as much as possible the subjectivity and non-probability of unit selection, the counselling of non-involved faculty was used and 4 consultants from elementary school were gained by a snow-ball sampling method.

\section{Findings}

The collected data were processed by constant comparison and open coding. The aim of open coding is to create a categorised list of codes. The codes are further processed using an analytical strategy. The main goal of interview analysis is to try to understand how a person whose work is to mediate visual art in the extracurricular environment and school programmes views the topic. All respondents work with the animation method in their current work of art (in the form of an artwork or tangible or intangible cultural historical heritage).

The interviews were transcribed from audio recordings to digital text. The data were then processed using the paper and pencil method (Svaricek \& Sedova, 2007). The text was divided into units according to meaning. Codes were then assigned to each unit. As shown by Lee and Fielding (2004), each code is a word 
or a short phrase that captures a certain group of meanings. Each code can be distinguished in its content from others (Svaricek \& Sedova, 2007, p. 212).

Two main categories were created through the open coding of the first research question of: How is the method of visual art animation understood in real life and in professional practice?:

1. The dimensions of a work of animation

2. The ways of grasping the visual art in real life

The following categories were determined for the main category of animation dimensions:

Table 1. Open Coding for the Animation Dimension Category

\begin{tabular}{|l|l|}
\hline Category & Qualities \\
\hline \multirow{3}{*}{ Qualities of an animator } & Professionalism \\
& Active participation \\
& Flexibility \\
\hline \multirow{3}{*}{ Role of a participant } & Activity \\
& Personal deposit \\
& Internal will \\
\hline \multirow{3}{*}{ Nature } & Span \\
& Processability \\
& Creative activities \\
\hline \multirow{3}{*}{ Goal } & Enjoyment \\
& Communication \\
\hline & Meeting \\
\hline & Education for Art \\
& Facilitation \\
\hline
\end{tabular}

Visual art animation as an educational method includes certain dimensions that are divided among these categories. The dimensions represent the following:

1. The demands that animation requires from an animator

2. The demands that animation places on participants, whose role is fundamental to the functioning of the method

3. The specific means by which the educational goal of this method is achieved.

The content of this main category is expressed by the following text:

Animators are people who carry out animation with the participants, and if possible, they are authors of the programme. They are customarily teachers by profession-someone who is flexible and able to react spontaneously. The position of an animator is equal to that of the group participants. An animator is actively engaged and participates in programme activities. 
"The role of both the commentator and the guide is only to comment or to describe, to put the information into a context. But the animator, as well as the participants of animation, has to become a part of the story. Once he does not become a part of it, once he is not on the same frequency, he becomes just a guide."

Respondent 1. Personal interview. 25 April 2016

"Animator should be educated in pedagogy (unlike an actor or entretainer)...the best would be an education in leisure time pedagogy. I think it is important for him to be able to attract the participants, to entertain them well and to assure a quality output of the animation and interaction."

Respondent 3. Personal interview. 16 May 2016.

These findings shows the range of view on the profession of animator. There is a big amount of definitions or opinons on the quality needs of animator in Czech Republic differing in professional focus of author (Benes, 1980; Daniel, 2008; Juva, 2004; Jagosova, Juva, \& Mrazova, 2010; Sobanova, 2015).

Participants in animation are concerned and committed. They participate voluntarily in the programme.

Animation has no fixed form. There is a wide range of options for sharing information, experience and ways to shape or influence participants' education. Animation always emphasises both processual and creative activities.

"...the definition is extremely wide. But I would say that the gallery animation, pedagogy, or whatever we are going to call it, deals with the aducation towards the museum of gallery. And it complements art education in some ways."

Respondent 2. Personal interview. 3 February 2016

All respondents agreed on this width and thus confirm the fragmentation and variety of literature approaches.

Animation is based on experience as a route to knowledge. It is based on participants' communication with their groups, on their own work and on cooperation with the animator. It is based on their encounter with art, new horizons and new ideas. The goal of animation is art education and the facilitation of the process of learning. These findings could be enlarged by literature talking about this topic in a way, that art is here for your lives and encounter with art can be an enriching game (Daniel, 2008), animation help to rebuild the value system of participants (Horacek, 2006).

"Gallery or museum animation is an art mediation program, based on the principle of creative or expressive interpretation of the artefact. For me, animation is a performance place in which a group of participants represents art. It means the participant experiences art and learns through it, learns through artistic expression. I understand the animation as a story in time and space. I have come to the fact that the gallery animation is art education, it is a form of art pedagogy... and that is what I mean in the realization with any group of participants, it's not just professionals. This artistic communication lies in the key to unlocking the world. This key is the mediation of art."

Respondent 4. Personal interview. 15 September 2016 
The following categories were determined as being the main categories for ways to grasp visual art in real life:

Table 2. Open Coding for The Ways to Grasp Visual Art in Real Life

\begin{tabular}{|l|c|}
\hline Category & Qualities \\
\hline Multi-stratification & The basic element of culture \\
& Intangible heritage \\
Tangible heritage
\end{tabular}

The content for this main category is expressed by the following text:

The category of multi-stratification affects the breadth of perception of visual art in real life. It is most often seen in the context of tangible cultural historical heritage but also in the context of particular cultures. The understanding of cultural historical heritage as an essence of humans, who are a part of their culture, describes another particular dimension.

"The essence of cultural and historical heritage is a memory stored by mankind by those tangible and intangible monuments. Cultural and historical heritage is roots on which the whole culture and everything the men is part of, of should be part of, since the beginning of life. In its original meaning, the culture meant cultivation of the spirit, so men was a full men, in harmony of soul and body. That memory is the roots men could draw from it. It is not only the material part, but also spiritual."

Respondent 4. Personal interview. 15 September 2016

The avareness of respondents of the immense importance of cultural historical heritage is essential for the commitment for their work and anchored in professional discussion worldwide, as seen in recent research (Ocal, 2016; Hicela \& Kuscevic, 2013; Apostolopoulou, Covoeiras, \& Klorani, 2014).

"For me, cultural and historical heritage is probably public space and town in its whole, with all its aspects both tangible and intangible. It also means some genius loci, and not only tens and hundreds years old monuments, but also the new ones, including those not really nice. Its everything what makes a place unique, the less visible layers as well produced by people, tourist, residents."

Respondent 1. Personal interview. 25 April 2016

"Cultural and historical heritage is folklore, traditions, architecture, sculpture, art in public space. It is what originated on the basis of history, culture, tradition of a given locality, country, whether based on regional, national or European roots. It must be kept in order that it does not cease in globalisation, where the borders and limits are lost and we stop to perceive what is regional on national. We need to keep and 
maintain our heritage in order to not let it disappear. We need to keep our identity to know where our roots are, where do we come from...it is just so important."

Respondent 3. Personal interview. 16 May 2016

Cultural and historical heritage is a broad term. It is influenced by individual perceptions that we each have of the place, time and culture. The category of accessibility is descriptive and expresses a person's paths to cultural historical heritage.

1. The paths of an action take the form of animation, experimental programmes, art events, performances or workshops.

2. Then there are of course the classic routes such as tours, discussions, comments and lectures.

3. Finally, there are the impersonal paths in the form of the media, the printed word and so on.

One main category was created to answer the second research question:

1. What is the educational potential of visual art in real life?

The following categories were determined for the main category of animation dimensions and its qualities:

Table 3. Open coding for The Educational Potential of Animation of Cultural and Historical Heritage category

\begin{tabular}{|l|c|}
\hline Category & Qualities \\
\hline \multirow{2}{*}{ Difficulty/Demand } & Material \\
& Psychical \\
& Time demanding \\
Contribution to school education & Organizational \\
\hline Motivation to care & Part of school lesson \\
& Astray \\
Personal development & Accessibility \\
\hline \multirow{2}{*}{ Unconventional approach } & Meeting \\
& Strengthening \\
\hline
\end{tabular}

The qualities of the first, quite descriptive category summarises the demands that may constitute a barrier to the transmission of cultural heritage, such as the need for a competent animator, finance, technology, equipment, supplies, materials, time, emotional stress and the importance of reflection.

"Animation is often considered as the degradation or art and history by professionals. Art and history seems to be very serious for them and the playful form of animation bothers them. And, of course, finance - animation is quite expensive even if it does 
not look like this. You need a lot of material aid, more people, you spend paper, colours, .... I think every castle should use animation as part of the programme offer. But it demands an effort...you often need some technique as well, you need to maintain it...."

Respondent 3. Personal interview. 16 May 2016

\begin{abstract}
"You need to have a partner for animation, the other side: the participants from who the engagement is required. Ideally when you get a participant from non-participant and when he engages the others in some action, consciously or unconsciously. We could, so to say, divide the metamorphosis of participant from non-recipient to recipient and at the end the transmitter. Which is ideal."
\end{abstract}

Respondent 1. Personal interview. 25 April 2016

The barriers mentioned above can be completed by those mentioned in literature, as insufficient communication between heritage and education political sectors, Lack of structural timing for cultural heritage education within present school systems (Culture et Démocratie, 2009), failure to adequately disseminate good transferable examples past and present (Collard \& Witte, 2015).

The educational potential of animation of cultural historical heritage includes specific objects and skills where visual art in real life can serve as a source of education but also benefit from the specific qualities that make it interesting for education. It is the opportunity for direct work with the "object" of art, for a personal experience. The rapture from the conventional environment of a classroom and a school building plays out its importance as well. Last, it is the authority of an unknown or different lecturer, who can activate and motivate the participants to learn.

\footnotetext{
"At least, the meeting with original artwork is unique. Extraordinary and irreplaceable is also the environment of the gallery because children are educated directly in the environment of the gallery, right on place, inside of the show, in front of real piece of art....To take kids out of the school environment is enormous advantage. The kids do not take the process as education, when being somewhere else. The education becomes fun, leisure time activity, even when you use some of the typical school educational approaches. This is probably such a basic advantage. And other benefits, again, meeting art, as such. Also, interactivity is a huge advantage. Our programmes are based on the fact that children not only hear something, they also try it. In the meantime they can use it, do hand on things, play some games or demonstrate something."
}

Respondent 2. Personal interview. 3 February 2016

Visual art as a part of heritage is a part of each of us and of our identity. Its knowledge influences our attitude towards it. The potential for visual art mediation may arise from the first real, conscious encounter with its content. This is the moment that may initiate the creation of art with a sense of belonging and a responsibility towards culture, community or cultural historical heritage.

"The advantage is the action, the perfomativeness of the whole action. It has the ability to draw the kids into the process, and they naturally encounter both the 
information and the experience of the meaning of that information or knowledge, experience. And cultural and historical heritage becomes a part of life in a natural way. It is not just theory, but something that they themselves have experienced, so there is a relationship to it and they will carry on. They are interested ... The contribution of the artistic communication, which takes place in art mediation projects: for at least one moment, the artist creates, according to the means of expression, art that gives him a different view of it and thing out of art. The participant passes through a certain transformation that makes his being in the contemporary world real and present. Or we can say that he is inspired on the path to selfawareness and that after the animation programme he should be somehow relaxed, restored. And, it may sound mystical, but I think it is the natural impact of art education."

Respondent 3. Personal interview. 16 May 2016

The personal development category expresses the effect of an encounter with visual art in real life on a participant. It touches its whole personality, its emotional, cognitive and conative competencies towards oneself and to others. This unconventional approach consists of action and includes moving, performativity, participation, experience, innovative means of expression, the need for a voluntary approach and playfulness.

"The uniqueness of animation of the cultural and historical heritage consists of a work with an experience in the sense that it takes it seriously, as the basis of education. Programically, it deliberately works with the affective domain and can use the methods that work. It develops the creativity of people, encourages people to create. Helps people cultivate their emotions if it is done well. It learns to hear and respect each other."

Respondent 6. Personal interview. 25 March 2016

In next phase of evaluation the axial coding was processed. Axial coding (Introduction to Grounded Theory) is the process of relating codes (categories and properties) to each other, via a combination of inductive and deductive thinking. To simplify this process, rather than look for any and all kind of relations, grounded theorists emphasize causal relationships, and fit things into a basic frame of generic relationships. The frame consists of the following elements: 
Table 4. The Elements of Frame of Generic Relationships

\begin{tabular}{|l|l|}
\hline Element & \multicolumn{1}{c|}{ Description } \\
\hline Phenomenon & $\begin{array}{l}\text { The concept that holds the bits together. In grounded theory it is } \\
\text { sometimes the outcome of interest, or it can be the subject. }\end{array}$ \\
\hline Causal conditions & $\begin{array}{l}\text { Events or variables that lead to the occurrence or development of the } \\
\text { phenomenon. It is a set of causes and their properties. }\end{array}$ \\
\hline Context & $\begin{array}{l}\text { The specific locations (values) of background variables. A set of } \\
\text { conditions influencing the action/strategy. } \\
\text { Researchers often make a quaint distinction between active variables } \\
\text { (causes) and background variables (context). }\end{array}$ \\
\hline $\begin{array}{l}\text { Intervening } \\
\text { conditions }\end{array}$ & $\begin{array}{l}\text { Moderating variables and intervening conditions } \\
\text { with } \text { mediating variables. }\end{array}$ \\
\hline Action strategies & $\begin{array}{l}\text { The purposeful, goal-oriented activities that agents perform in response to } \\
\text { the phenomenon and intervening conditions }\end{array}$ \\
\hline Consequences & The consequences of the action strategies, intended and unintended. \\
\hline
\end{tabular}

Within the axial coding, the categories from open coding were processed and led to creation of new ones, introduced in the table below.

Table 5. The Axial Coding Categories

\begin{tabular}{|l|l|}
\hline Element & \multicolumn{1}{c|}{ Coding } \\
\hline Phenomenon & Functional animation of cultural and historical heritage \\
\hline Causal conditions & $\begin{array}{l}\text { Educational goals } \\
\text { Accessible and reviving opportunity to grasp the present work / object / } \\
\text { phenomenon }\end{array}$ \\
\hline Context & $\begin{array}{l}\text { Components of cultural and historical heritage } \\
\text { The relationship, role and participation of the animator and the participant }\end{array}$ \\
\hline $\begin{array}{l}\text { Intervening } \\
\text { conditions }\end{array}$ & $\begin{array}{l}\text { Ways of conceiving the mediation } \\
\text { Obstacles along the way. }\end{array}$ \\
\hline Action strategies & $\begin{array}{l}\text { Experience creativity } \\
\text { Live group process }\end{array}$ \\
\hline Consequences & $\begin{array}{l}\text { Motivation to care } \\
\text { Personal development }\end{array}$ \\
\hline
\end{tabular}

To explain the content of those new categories, next table shows how they relate to open coding.

Table 6. Open Coding Qualities in Axial Coding Categories

\begin{tabular}{|l|l|}
\hline Axial Coding Categories & Qualities from Open Coding Categories \\
\hline & $\begin{array}{l}\text { Qualities of an animator: professionalism, } \\
\text { active participation, flexibility } \\
\text { Role of a participant: activity, personal } \\
\text { Functional animation of cultural and } \\
\text { historical heritage }\end{array}$ \\
& $\begin{array}{l}\text { Multi-stratification: the basic element of } \\
\text { culture, intangible heritage, tangible heritage }\end{array}$ \\
\hline $\begin{array}{l}\text { Educational goals } \\
\text { Accessible and reviving opportunity to } \\
\text { grasp the present work / object / } \\
\text { phenomenon }\end{array}$ & $\begin{array}{l}\text { Goal: Education for Art, facilitation, } \\
\text { interpretation } \\
\text { Contribution to school education: Part of } \\
\text { school lesson, astray, accessibility }\end{array}$ \\
\hline $\begin{array}{l}\text { Components of cultural and historical } \\
\text { heritage }\end{array}$ & $\begin{array}{l}\text { Qualities of an animator: professionalism, } \\
\text { active participation, flexibility }\end{array}$ \\
\hline
\end{tabular}




\begin{tabular}{|l|l|}
\hline $\begin{array}{l}\text { The relationship, role and participation of } \\
\text { the animator and the participant }\end{array}$ & $\begin{array}{l}\text { Role of a participant: activity, personal } \\
\text { deposit, internal will } \\
\text { Multi-stratification: the basic element of } \\
\text { culture, intangible heritage, tangible heritage }\end{array}$ \\
\hline & $\begin{array}{l}\text { Difficulty/Demand: material. Psychical. time } \\
\text { demanding, organizational }\end{array}$ \\
Boundedness: consistency, borderline, \\
$\begin{array}{l}\text { Ways of conceiving the mediation } \\
\text { Obstacles along the way }\end{array}$ & $\begin{array}{l}\text { Accessibility: unconscious perception, } \\
\text { actions, classic, impersonal }\end{array}$ \\
\hline & $\begin{array}{l}\text { Unconventional approach: activity, } \\
\text { interactivity }\end{array}$ \\
Experience creativity & Nature: enjoyment, communication, meeting \\
Live group process & Personal development: internal, external \\
& $\begin{array}{l}\text { Meeting, strengthening } \\
\text { Internal, external }\end{array}$ \\
\hline Motivation to care (remain) & \\
Personal development (remain) &
\end{tabular}

The axial coding leads to the development of paradigm model that shows the relations between the categories. Is shown in scheme 1, the categories are linked non-circularly and nonlineary.

Scheme 1. Paradigm Model

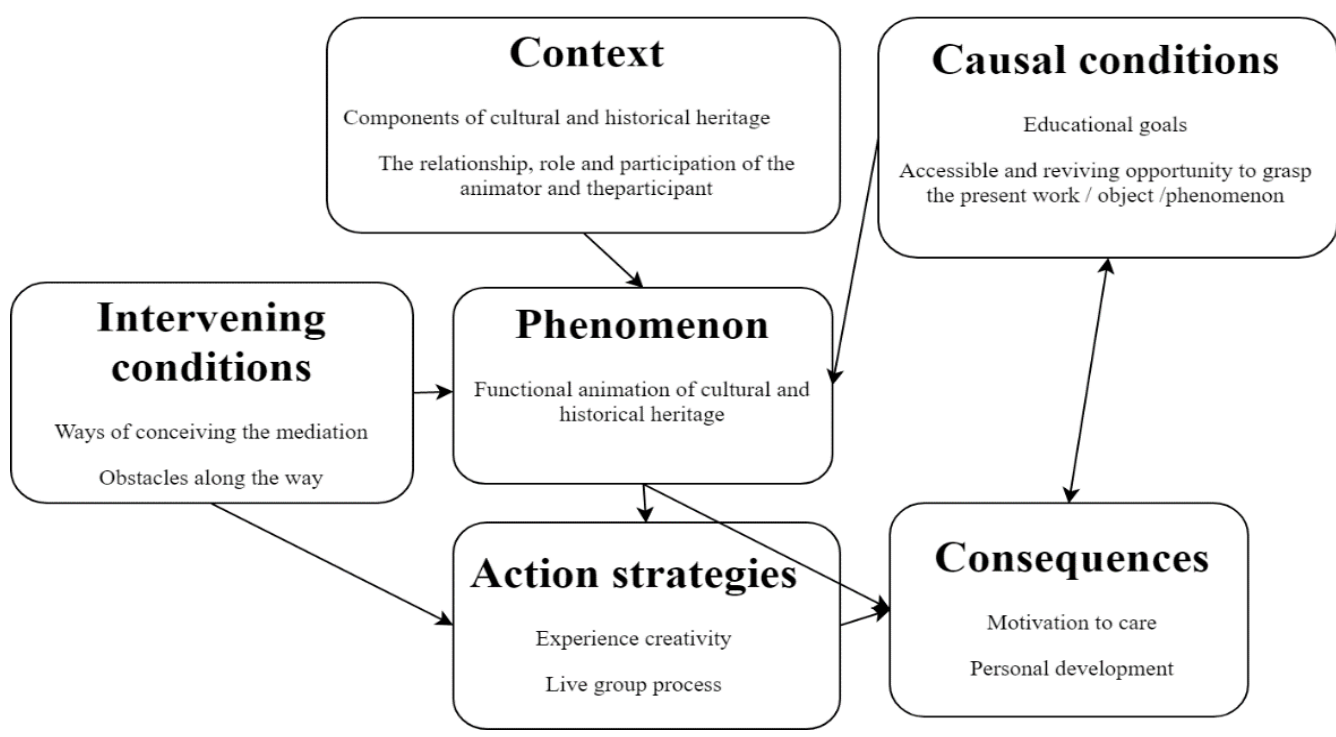

\section{Conclusions}

The Czech educational system requires connection and cooperation with school environments in its curricula documents. Although progress is visible, there is still a big gap between theory and practice. It is obvious from the results of our research study that the effort by extracurricular establishments and their lecturers to cooperate with schools shows a certain fragmentation and diversity in the approach to this phenomenon. 
The main statements summarizing the findings bring a concise view on the main research topics. The real-life experience of art outside of the school classroom in the Czech environment is understood as being an experiential, personal method. Instead of the position of teacher, the lecturer holds the position of partner or coordinator. The experience of art in an extracurricular environment is strongly related to historical heritage and its culture. The nature of this educational programme is best expressed with two basic principles: co-nativity and interactivity.

We believe that the concept of the mediation of the real-life experience of art as it is understood by extracurricular lecturers might become an opportunity for formal education as well (particularly art education). In accordance with existing curricula, these programmes could become an integral part of school education plans. Nowadays trends in Czech education strengthens the cooperation of schools and other institutions, but there is often a "free-time" reason for the participation, the teacher organizes an excursion, concert, museum visit as a supplementary program disconnected to current educational content of his lessons. And therefore there is a lack of preparation and continuing activities at school, that could link the contents of both school and out of school educational process.

The methodology using in depth interviews enables to get really personal information, direct and open approach of respondents secured acquisition of a large number of datas. However, the combination of multiple qualitative research methods could be useful, for example an observation of particularral programmes may bring clearer view on animators role and position in relation to participants or environment.

\section{References}

Apostolopoulou, A., Cavoeiras, L.M., \& A. Klonari, (2014). Cultural Heritage and education. In European Journal of Geography ,5(4), 67-77.

Babyradova, H. (2007). Nove proudy ve vytvarne vychove. In H., Babyradova, H., Grecmanova, \& P., Exler (eds), Skola muzejni pedagogiky 4 (pp. 9-24). Olomouc: Vydavatelstvi Univerzity Palackeho.

Bamford, A. (2006). The WOW factor: Global research compendium on the impact of arts in education. New York: Waxmann Munster.

Bamford, A., \&Wimmer, M. (2012). Audience building and the future Creative Europe Programme, EENC Short Report.

Basak, R. (2017). The Discipline-Based Art Education (DBAE) and the Visual Culutre Theory. Journal of Current Researches on Social Sciences, 7(4). Retrieved from https://bit.ly/2CoYlhG.

Benes, J. (1980). Muzeum a vychova. Praha: Ustav pro informace a rizeni v kulture.

Catterall, J. S. (2009). Doing Well and doing Good by Doing Art: The Effects of Education in the Visual and Performing Arts on the Achievements and Values of Young Adults. London: I-Group Books.

Chatterjee, H. (2010). Object-based learning in higher education: The pedagogical power of museums. Retrieved from https://bit.ly/2Fd3Q3q.

Collard P., \& Witte R. (2015). Creative Alliances for Europe, report prepared by the BkJ (Germany) and CCE (England) funded by Stiftung Mercator. 
Culture et Démocratie (2009). La culture au cœur de l'enseignement, un vrai défi démocratique. Cahier 2. Bruxelles: Communaute francaise de Belgique.

Daniel, L. (2008). Umění vidět umění: úvod do interpretace obrazu. Olomouc: Univerzita Palackého v Olomouci. ISBN 978-80-244-2000-4.

Duncan, A. (2012). It's March. Do you know How Strong Your Schools' Arts Programs Are? Retrieved from https://bit.ly/2W8VBMB.

Eisner, E. W. (2002). The Arts and the Creation of Mind. New Haven \& London: Yale University Press.

Fiske, E. B. (1999). Champions of Change - The Impact of the Arts on Learning. Washington, DC: The Arts Education and Partnership and the President's Comittee on the Arts and the Humanities.

Fulkova, M., Hajduskova, M., \& Sehnalikova L. (2012) Galerijni a muzejni edukace 1: vlastni cestou k umeni: vzdelavaci programy Umeleckoprumysloveho musea v Praze a Galerie Rudolfinum v roce 2011. Praha: Univerzita Karlova.

Hein, G. E. (1998). Learning in the museum. London: Routledge.

Hicela I., \& Kuscevic, D. (2013). School and the cultural-heritage environment: pedagogical, creative and artistic aspects. CEPS Journal, 3(2), 29-50.

Hooper-Greenhill, E. (1999). Education, communication and interpretation. In E. HooperGreenhill (ed.), The Educational Role of the Museum (2 ${ }^{\text {nd }}$ ed.), ( pp. 3-27). New York: Routledge.

Horacek, M. (2006). Galerijni pedagogove: klicnici rise krasy. Literarni noviny, 17(23), 915.

Horacek, R. (1998). Galerijni animace a zprostredkovani umeni. Brno: CERM.

Jagosova, L., Juva, V., \& Mrazova L. (2010). Muzejní pedagogika: metodologické a didaktické aspekty muzejní edukace, 1. ed. Brno: Paido.

Juva, V. (2004). Detske muzeum: edukacni fenomen pro 21. stoleti. Brno: Paido, Edice pedagogicke literatury.

Komensky J. A. (1991). Velka didaktika. Prel. M. Okal. Bratislava: SPN.

Kress, G. (2000). Multimodality. In B. Cope \& M. Kalantzis (eds.), Multiliteracies: Literacy learning and the design of social futures. Melbourne: Macmillan.

Lee, R., \& Fielding, N. (2004). Tools for qualitative data analysis. In M. Hardy, \& A. Bryman, Handbook of data analysis (pp. 530-546). SAGE Publications, Ltd doi: $10.4135 / 9781848608184$

Massoni, E. (2011). Positive Effects of Extra Curricular Activities on Students. In ESSAI, 9, Article 27 (Jan. 2011). Retrieved from https://bit.ly/2CrimDY.

Ocal, T. (2016). Necessity of Cultural Historical Heritage Education in Social Studies Teaching. Creative Education, 7, 396-406. http://dx.doi.org/10.4236/ce.2016. 73039.

Siostrzonek, J. (2008). Animace kultury (polské inspirace). Opava: Slezská univerzita v Opavě.

Slavik, J., Hazukova, H., \& Samsula, P. (1997). Vytvarna vychova a jeji teorie v ceskych zemich ve svetovych kontextech. Praha: Pedagogicka fakulta UK.

Sobanova, P. (2012). Muzejni edukace. Olomouc: Univerzita Palackeho v Olomouci.

Sobanova, P. (2015). Vzdělávací obsah v muzejní edukaci. Olomouc: Univerzita Palackého v Olomouci. 2015.

Svaricek, R., \& Sedova, K. (2007). Kvalitativni vyzkum v pedagogickych vedach. Praha: Portal.

Wilson, B. (1997). The Quiet Revolution: Changing the Face of Arts Education. Los Angeles: The Getty Institute for the Arts.

Winslow, L. L. (1939). The Integrated School Art Program. New York; London: McGraw-Hill Book Company. 



\title{
Differentiating the Curriculum to Achieve "Learner Growth" when using 1:1 Mobile Devices for Learning
}

\author{
By Arthur Firipis ${ }^{*}$, Siva Chandrasekaran ${ }^{\dagger} \&$ \\ Matthew Joordens ${ }^{*}$
}

\begin{abstract}
With the increasing use of 1:1 mobile devices within the curriculum space, differentiating its use to support "learner growth" has become an important discussion amongst policy makers, researchers, educators and learners. This research study provides an insight into how learners are using their 1:1 mobile device to support their learning process. The premise of the discussion begins with the notion that a learner's success is dependent on the curriculum design been sufficiently differentiated using resources and scaffolding. Differentiating to develop technical skills that will lead to the production of artefacts as evidence of learning and creativity. This research study highlights the role of the digitally literate educational leader who can apply self-directed differentiation learning theory to model the use of 1:1 mobile devices to support "learner growth". The research study reveals learners come with pre, during and post learning perceptions, and understandings about how 1:1 mobile devices can be used to support their "learning growth". These perceptions and motivations for learning will need to be considered along with self-directed learning theory and applied to the delivery of linear and non-linear curriculum design.
\end{abstract}

Keywords: 1:1 mobile device technology, educational psychology, learning, critical thinking, differentiation and curriculum design.

\section{Introduction}

With the increasing use of 1:1 mobile devices within the curriculum space, differentiating its use to support "learner growth" has become an important discussion amongst policy makers, researchers, educators and learners. This research study provides an insight into how learners are using their 1:1 mobile device to support their learning process. The premise of the discussion begins with the notion that a learner's success is dependent on the curriculum design been sufficiently differentiated using resources and scaffolding. Differentiating to develop technical skills that will lead to the production of artefacts as evidence of learning and creativity. This research study highlights the role of the digitally literate educational leader who can apply self-directed differentiation learning theory to model the use of 1:1 mobile devices to support "learner growth". The

${ }^{*}$ PhD Student Researcher, Deakin University, Australia.

${ }^{\dagger}$ Lecturer, Swinburne University of Technology, Melbourne, Australia.

${ }^{\star}$ Associate Professor, Deakin University, Australia. 
research study reveals learners come with pre, during and post learning perceptions, and understandings about how 1:1 mobile devices can be used to support their "learning growth". These perceptions and motivations for learning will need to be considered along with self-directed learning theory and applied to the delivery of linear and non-linear curriculum design.

Tomlinson (2017) states, "The presumptive 'ability' we assign to a student too often becomes a sort of pedagogical predestination." Boser et al. (2014) reflects on a learning experience stating, "... the device erases disabilities that might otherwise be visible and humiliating. When all the answers are typed or spoken into the computer, every student's paper or audio response is as readable and understandable as any other." Grigorenko \& Sternberg (1997) state, "... the way an individual interacts with and processes experiences will vary and will have a tremendous influence on the way they learn." Fischer and Bidell (2006) conducted research using digital technologies such as fMRI (Functional Magnetic Resonance Imaging) and PET (Position Emission Tomography) brain activity scans, monitoring the human brain while active learning and completing tasks concluded, "... learners are highly variable and learning is highly dependent on the context." ${ }^{1,2}$ Fischer and Bidell, (2009), Siegler (1994), Van Geert \& Fischer (2009) provide supporting conclusions that every person is unique based on their natural genetic diversity (nature) and influenced by experiences over time (nurture). These experienced observers echo the complexity and humanity behind every decision an educator must make on behalf of their learners. Even within the broader context of emerging virtual learning spaces, differentiation becomes the "driving force" that positions the quality of the educational experience for all learners.

This research study provides an insight into how learner perceptions and motivations are influenced by the use of 1:1 mobile devices for learning within the context of a higher education engineering course. The research study results and discussion are presented as follows;

- Part A - Q.1 to 8 - Perceptions of Readiness to Learn;

- Part B - Q.9 to 14 - Learner Perceptions of Learning;

- Part C - Q.15 to 20 - Learner Perceptions when using 1:1 Mobile Devices

- Part D-Q. 21 to 25 - Bonus Materials Perceptions;

- Part E - Learning Growth Measurement (Effect Size).

The significance of this research study provides a discussion about the relevance of self-directed learning theory within the context of learners using 1:1 mobile devices. It raises further questions about how self-directed learning might affect academic success, how can curriculum differentiation theory be used to support educational leaders, to what extent will digital literacy influence future

\footnotetext{
${ }^{1}$ fMRI stands for functional Magnetic Resonance Imaging. The term "functional" indicates that this type of MRI is concerned with brain function during a specific experimental time period, as opposed to the static MRI most often used to diagnose brain (and other tissue) pathology.

${ }^{2}$ PET stands for "positron emission tomography". It is a nuclear medicine imaging test in which a small amount of liquid radioactive material is injected into the body and is used to diagnose a variety of diseases, including many types of cancers, and brain and heart disease.
} 
occupational choices, how does digital literacy improve learning, and what learning interventions will help learners to understand and adjust to self-directed learning when using 1:1 mobile devices. The survey instrument developed during this research study will be useful for educational leaders attempting to differentiate the learning classroom during formative assessment processes and will help learners articulate their learning perceptions and motivations for wanting to use 1:1 mobile devices to achieve learning outcomes.

\section{Definition}

1:1 mobile devices are defined as a portable handheld 1:1 device include iPad, mobile phone, Tablet or similar handheld Wi-Fi or Internet accessible device.

\section{Research Methodology}

In consultation with the research authors, a library search protocol was developed before the literature search commencing. A mixed search strategy via accessing electronic databases and drawing on library held hard copy resources was undertaken during 2017-18. The following electronic resources were accessed during the search:

- EBSCO (Elton B. Stephens Company) digital library service ${ }^{3}$

- IEEE (Institute of Electrical and Electronics Engineers) digital library service; and

- Google Scholar ${ }^{4}$

Keywords were used to facilitate searches: critical thinking, higher-order thinking, differentiated learning, active learning, self-regulated learning, differentiation, learning motivation, learning theory, mobile technology, mlearning, mobile learning, digital learning, tablet, iPad; 1:1 mobile device, instruction, instructional, learning, and Engineering learning. These search terms were chosen as they are the terms frequently used when describing mobile learning. Studies were included in the literature review if they were prepared by recognised peer-reviewed academics and research published by recognized academic publishers, and contributed to explaining the application of differentiation learning theories. Excluded from the literature search were studies not contextualised within a higher education setting and did not include a discussion involving differentiated learning. The guiding question for the literature review is: "How can learning growth be developed in the curriculum using differentiation when using 1:1 Mobile Devices for learning?"

The literature review includes the differentiation theories that contextualise and attempt to understand the links between educational leadership, differentiation occurring during the summative assessment and "learner growth" when using 1:1

\footnotetext{
${ }^{3}$ http://search.ebscohost.com/

${ }^{4}$ http://scholar.google.co.uk/
} 
mobile devices. Comparative study results from Vermunt (1998) is included to contextualise this study. This literature review is limited to acknowledging that early differentiating learning theory did not include a discussion about mobile technologies as a learning tool.

\section{Learning Growth Measurement}

An online pre-test of eight (8) questions was given to the students to determine KWL (What you KNOW, WHAT you want to LEARN, WHAT have you LEARNT) to determine misunderstandings and current knowledge before commencing the course of study. The pre-test results were collected and used as a measured benchmark of "learning growth". This was compared with final course results using Hattie's effect size methodology.

Hattie Effect Size. Effect size is measured by the number of standard $d=g \sqrt{\frac{N}{N-2}}$ deviations the means differ by. Cohen's deviation calculation which divides by $\mathrm{N}$. The formula used is shown. Effect size = Average - Average Spread (standard deviation, or SD).

\section{Online Survey}

The survey instrument aimed to identify learner perceptions of readiness to learn, perceptions of learning in progress, and perceptions of learning when using 1:1 mobile devices for learning. The survey instrument was modelled on research undertaken by Guglielmino (1977) Self Directed Learning Readiness (SDLR) and Vermunt (1998) Individual Learning Process (ILP). Firipis et al. (2016) tested an experimental survey instrument before the final online version of twenty-five questions were agreed upon for use in this research study. Responses were received from first to third year Engineering students enrolled between 2016 and 2017. Participants were aged between 18 to 35 years old (10\% females and 90\% males). The sample comprised of 180 volunteers recruited using approved research ethics guidelines for human research studies. Data returned 68 valid responses which were de-identified, compiled and analysed using small sample methodology using an Excel spreadsheet (see Table 1). Whisker graphs were also used to represent the results for comparisons.

Table 1. Small Sample

\begin{tabular}{|l|l|}
\hline Number of Responses & 37 \\
\hline Mean & 4.27027027 \\
\hline SD & 0.651862658 \\
\hline Spec & 4 \\
\hline Z & 0.414612291 \\
\hline$\%$ & $66.1 \%$ \\
\hline CV & $15 \%$ \\
\hline & Number \\
\hline Top Box & $14(37.8 \%)$ \\
\hline Top 2 Box & $33(89.2 \%)$ \\
\hline Agree & $33(89.2 \%)$ \\
\hline Net Top Box & $14(37.8 \%)$ \\
\hline
\end{tabular}




\section{Hypothesis}

If, 1:1 mobile devices are being used for learning, then there will be an improved perception of student engagement in the engineering unit of study. If, a measured perception of student engagement does exist, then, this will lead to measured learning growth.

\section{Literature Review}

\section{Defining Differentiation}

Tomlinson (2017) defines differentiating instruction as a means of redefining the learning in the classroom, providing learners with multiple entry points for taking in information, analysing and to discover existing and new ideas; and to produce products as an expression of creativity. Tomlinson (2017) explains that in a differentiated classroom, educational leaders aim to demonstrate three curricular elements:

1. content input; what students learn;

2. process; how students go about making sense of ideas and information; and

3. product; output, or how students demonstrate what they have learnt.

Rose, Meyer, \& Hitchcock, (2005) defined differentiation within a framework, "Universal Design for Learning", standardizing principles of learning using multiple representations to cater for learners regardless of ability (disability). For example, differentiating individual students learning with Autism Spectrum Disorder (ASD) using interactive technologies, for example, digital whiteboards blending video and interactive games fostering tactile and kinaesthetic delivery and adapting different learning strategies to foster student learning growth.

\section{What Differentiation is Not}

Tomlinson (2017) argues differentiation is not "individualised learning' where individual lesson plans are prepared for each of the thirty students in every subject or unit, delivered sequentially every hour of the academic day. The assumption that meaningful learning would result from the teacher's leading of whole class, small group and individualised learning activities is unsupported despite its popularity. Differentiation is linked to the teacher's ability to lead rather than the necessity to rely on classroom management using rules to motivate students to learn. An experienced teacher can motivate students by building on individual learner's interests, creating a culture of inquiry-based learning using self-directed learning principals. Tomlinson (2017) argues effective educational leadership is a measure of collaborative learning where individual and whole group activities result in a "mind-set" leading to a measured "learning growth". 
The concept of student "learning growth" is relatively new in the literature and is defined as agreed understandings between the teacher and the student. Tomlinson (2017) argues, "learning growth" is achieved when students can work collaboratively and independently within a framework of self-determined understanding of classroom rules and learning expectations. The subtle re-focus on the teacher's ability to lead and shape the student's "mindset" has a profound effect on how students develop their own "learning growth".

\section{Differentiation through Educational Leadership}

The educator's leadership role is to teach students how to differentiate their own learning through modelling and developing life-long learning skills. The implications of this "mind-set" of differentiation reset the way curriculum design, and delivery is viewed. Tomlinson (2017) explains, "Fluidity" in the way a teacher identifies student strengths, allowing for movement within a collaborative learning environment to allow freedom for students to share their skills and knowledge; and also, to acknowledge their weaknesses and build capacity to achieve "learning growth".

Table 2. Hattie (2009) Visible Learning - Domain Effect Size

\begin{tabular}{|l|c|c|c|c|}
\hline Dimension & Studies & Meta-Analysis & No. of Effects & Effect Size \\
\hline Student & 11,909 & 152 & 40,197 & 0.39 \\
\hline Home & 2,347 & 40 & 6,031 & 0.31 \\
\hline School & 4,688 & 115 & 15,536 & 0.23 \\
\hline Teacher & $\mathbf{2 , 4 5 2}$ & $\mathbf{4 1}$ & $\mathbf{6 , 0 1 4}$ & $\mathbf{0 . 4 7}$ \\
\hline Curricula & 10,129 & 153 & 32,367 & 0.45 \\
\hline Teaching & 28,642 & 412 & 59,909 & 0.43 \\
\hline Average & $\mathbf{6 0 , 1 6 7}$ & $\mathbf{9 1 3}$ & $\mathbf{1 6 0 , 0 5 4}$ & $\mathbf{0 . 4 0}$ \\
\hline
\end{tabular}

Effect size $=$ Average - Average Spread (standard deviation, or SD)

Source: Hattie (2009). Visible learning: A synthesis of $800+$ meta-analyses on achievement. London: Routledge.

Hattie (2018) researched effect size, and supports this view that "... an important influence on student achievement is how the teacher thinks about learning and their role as a professional educator." In Table 2 - Hattie (2009) Visible Learning Domain Effect Size, showing the role of the teacher as a significant influencer.

\section{Diagnostic Assessment for Differentiation}

Vermunt (1998), Volet, McGill, and Pears (1995), Duffy and Jonassen (1992), and Pask (1976) research suggests the ongoing improvement of the quality of learning is reliant on cognitive self-directed learning approaches to support "deep learning" when differentiating the curriculum to achieve a "learning growth" outcome. 
Table 3. Vermunt (1998) Individual Learning Process (ILP) - Regulation Strategies, Mental Learning Models and Learning Orientations

\begin{tabular}{|l|c|c|c|c|c|c|c|c|c|c|}
\hline $\begin{array}{l}\text { Processing } \\
\text { strategies }\end{array}$ & \multicolumn{2}{|c|}{$\begin{array}{c}\text { Relating \& } \\
\text { structuring }\end{array}$} & \multicolumn{2}{c|}{$\begin{array}{c}\text { Critical } \\
\text { processing }\end{array}$} & \multicolumn{2}{c|}{$\begin{array}{c}\text { Memorising \& } \\
\text { rehearsing }\end{array}$} & \multicolumn{2}{|c|}{ Analysing } & \multicolumn{2}{c|}{$\begin{array}{c}\text { Concrete } \\
\text { processing }\end{array}$} \\
\hline & $\begin{array}{c}\text { Open } \\
\text { Uni }\end{array}$ & $\begin{array}{c}\text { Regular } \\
\text { Uni }\end{array}$ & $\begin{array}{c}\text { Open } \\
\text { Uni }\end{array}$ & $\begin{array}{c}\text { Regular } \\
\text { Uni }\end{array}$ & $\begin{array}{c}\text { Open } \\
\text { Uni }\end{array}$ & $\begin{array}{c}\text { Regular } \\
\text { Uni }\end{array}$ & $\begin{array}{c}\text { Open } \\
\text { Uni }\end{array}$ & $\begin{array}{c}\text { Regular } \\
\text { Uni }\end{array}$ & $\begin{array}{c}\text { Open } \\
\text { Uni }\end{array}$ & $\begin{array}{c}\text { Regular } \\
\text { Uni }\end{array}$ \\
\hline
\end{tabular}

\begin{tabular}{|c|c|c|c|c|c|c|c|c|c|c|}
\hline \multicolumn{11}{|c|}{ Regulation strategies Self-regulation } \\
\hline $\begin{array}{l}\text { Learning } \\
\text { process \& } \\
\text { results }\end{array}$ & .38 & .41 & .34 & .25 & .22 & .18 & .31 & .20 & .15 & .22 \\
\hline $\begin{array}{l}\text { Learning } \\
\text { content }\end{array}$ & .06 & .15 & .13 & .19 & & & & .12 & .23 & .24 \\
\hline
\end{tabular}

External regulation

\begin{tabular}{|l|l|l|l|l|l|l|l|l|l|l}
\hline $\begin{array}{l}\text { Learning } \\
\text { process }\end{array}$ & & & -.08 & & .08 & $\mathbf{. 1 7}$ & $\mathbf{. 3 8}$ & $\mathbf{. 2 7}$ & .07 & \\
\hline $\begin{array}{l}\text { Learning } \\
\text { results }\end{array}$ & & & & -.07 & .06 & & .09 & .07 & & \\
\hline $\begin{array}{l}\text { Lack of } \\
\text { regulation }\end{array}$ & $\mathbf{- . 1 2}$ & -.07 & & & $\mathbf{- . 1 3}$ & & & -.06 & & .06 \\
\hline
\end{tabular}

\section{Mental models of learning}

\begin{tabular}{|c|c|c|c|c|c|c|c|c|c|c|}
\hline $\begin{array}{l}\text { Construction } \\
\text { of } \\
\text { knowledge }\end{array}$ & .15 & .07 & .15 & .14 & .06 & & & & & \\
\hline $\begin{array}{l}\text { Intake of } \\
\text { knowledge }\end{array}$ & -.08 & -.19 & & -.14 & .45 & .50 & .13 & .19 & -.09 & -.17 \\
\hline $\begin{array}{l}\text { Use of } \\
\text { knowledge }\end{array}$ & -.06 & & & & & & .08 & .07 & .43 & .30 \\
\hline $\begin{array}{l}\text { Stimulating } \\
\text { education }\end{array}$ & & & & & -.09 & -.10 & & -.07 & & \\
\hline $\begin{array}{l}\text { Co-operative } \\
\text { learning }\end{array}$ & & & & -.07 & & & & & & \\
\hline \multicolumn{11}{|c|}{ Learning Orientations } \\
\hline $\begin{array}{l}\text { Personally } \\
\text { interested }\end{array}$ & .07 & & .13 & & & .07 & .06 & & & .13 \\
\hline $\begin{array}{l}\text { Certificate } \\
\text { orientated }\end{array}$ & .06 & & & & & & & .10 & & -.06 \\
\hline $\begin{array}{l}\text { Self-test } \\
\text { orientated }\end{array}$ & & & & & & & & .06 & & \\
\hline $\begin{array}{l}\text { Vocation } \\
\text { orientated }\end{array}$ & .07 & & & & & & & & & \\
\hline Ambivalent & -.06 & & & & & & & & & -.06 \\
\hline
\end{tabular}

F-value: figures italics, $\mathrm{p}<5$; figures in bold, $\mathrm{p}<.01$. Weights $>-.05$ and $<.05$ omitted

Source: Vermunt, J. (1998) - The regulation of constructive processes. British Journal of Educational Psychology Vol 68, pp. 149-171. Published by The British Psychology Society. Great Britain

Vermunt (1998) successfully showed regulation strategies, mental learning models and learning orientations as predictors of the individual learning process. The study reported four significant learning dimensions including un-directed, reproduction-directed, meaning-directed and application-directed. Combinations of these indicative learning styles were motivated by cognitive self-regulation rather than external teacher directed learning (See Table 3 - Vermunt's Individual Learning Process (ILP) - Regulation strategies, mental learning models and learning orientations). For example, Table 3 - Vermunt ILP (1998) research shows "learning growth" occurs when the curriculum prioritises self-regulated learning including critical thinking (0.34), analysing (.31), using mental modes of learning by memorising and rehearsing (0.45), and to achieve concrete processing (.43) outcomes. 
Volet, McGill, and Pears (1995), considered cognitive and metacognitive processes for constructing and using knowledge. Duffy and Jonassen (1992) reported, "Learning is not a passive, knowledge-consuming and externally directed process, but an active, constructive and self-directed process in which the learner builds up internal knowledge representations that form a personal interpretation of his or her learning experiences."

Pask (1976), identified students who were given learning tasks that were forced on them to learn "deeply", tackled the activities in different ways. A dichotomy was evident with students applying a broad context from personal experience; while others were impulsive in deriving unsubstantiated conclusions (holistic strategy). For other students, it was evident a step-by-step, evidence-based learning approach was applied (serialist). Pask (1988), reported where students were observed adopting either learning approaches (holistic or serialist), this was categorized as a learning style or preferred learning process (comprehension learning - holistic; operation learning — serialist).

Curriculum design diagnostic assessment strategies have evolved and play an important role in providing evidence-based research to support current curriculum design planning processes. Tomlinson (2017) states, "Identifying assessment of students" developing readiness levels, interests, and approaches to learning and then designs learning experiences based on the latest, best understanding of students' needs." Broadly, understanding the importance of the "growth mindset" and its influence within the classroom before successful differentiation can be implemented.

\section{Differentiation to Achieve a "Growth Mindset"}

Achieving a "growth mindset" outcome in learners using differentiated learning is not a straight forward proposition, and to understand its practical implementation within the context of the curriculum, it is necessary to delve "deeper" into the theoretical context. A number of researchers (Piaget, 1950; Bloom et al., 1956; Schroder, Driver, and Streufert, 1967; and Marton \& Saljo, 1976; and Biggs \& Collis, 1982) have all provided theoretical frameworks to assist in understanding the curriculum design process. Each researcher shares common priorities including, considering the importance of establishing learning goals, sequencing of learning units with varying levels of complexity, and formative and summative assessment outcomes (see Table 4). These theoretical premises are not definitive, and it is important to acknowledge the role of the educator to know which differentiation learning theory is appropriate within the context of the learning space.

Hattie and Ziegler (2018) introduce the importance of educational leadership to support learning, highlighting "growth mindsets" that will lead to explicit "visible learning"; Thinking of and evaluating teacher impact on students' learning; The importance of assessment and feedback for teachers; Working collaboratively and the sense of community; The notion that learning needs to be challenging; Engaging in dialogue and the correct balance between talking and listening; Conveying the success criteria to learners; and, Building positive relationships. 
Setting learning outcomes, formative assessment and summative assessment underpins differentiated learning. Learning goals make explicit to learners what skills and knowledge are expected to be demonstrated by the end of the learning sequence. Formative assessment provides the opportunity to identify misunderstandings towards a concept that is critical to the Unit of learning.

Table 4. Models of Differentiation

\begin{tabular}{|c|c|c|c|c|}
\hline $\begin{array}{l}\text { Piaget }(1950) \\
\text { Developmental } \\
\text { Stages }\end{array}$ & $\begin{array}{l}\text { Bloom Levels } \\
\text { (1956) }\end{array}$ & $\begin{array}{c}\text { Schroder et al. } \\
(1967)- \\
\text { Autonomous } \\
\text { Learner }\end{array}$ & $\begin{array}{c}\text { Marton and } \\
\text { Saljo (1976) - } \\
\text { Evaluative } \\
\text { Classification }\end{array}$ & $\begin{array}{c}\text { Biggs (1982) - } \\
\text { Level of } \\
\text { Understanding }\end{array}$ \\
\hline $\begin{array}{l}\text { Sensorimotor } \\
\text { Intelligence } \\
\text { (Birth to } 18 \\
\text { months); Pre- } \\
\text { operational ( } 4 \text { to } \\
6 \text { years); }\end{array}$ & None & None & None & $\begin{array}{l}\text { Pre-structural - } \\
\text { No understanding }\end{array}$ \\
\hline $\begin{array}{l}\text { Early concrete ( } 7 \\
\text { to } 9 \text { years); }\end{array}$ & $\begin{array}{l}\text { Knowledge/ } \\
\text { Recollection }\end{array}$ & $\begin{array}{l}\text { Unidimensional - } \\
\text { minimal conflict, } \\
\text { rapid closure and } \\
\text { categorical } \\
\text { judgement. }\end{array}$ & $\begin{array}{c}\text { Qualitative } \\
\text { assessments of } \\
\text { student learning } \\
\text { as desirable and } \\
\text { necessary. }\end{array}$ & $\begin{array}{l}\text { Unistructural - } \\
\text { Learn one } \\
\text { relevant aspect of } \\
\text { the whole }\end{array}$ \\
\hline $\begin{array}{l}\text { Middle Concrete } \\
\text { (10 to } 12 \text { years); }\end{array}$ & $\begin{array}{l}\text { Comprehension } \\
\text { /Interpretation }\end{array}$ & $\begin{array}{l}\text { At least two } \\
\text { dimensions are } \\
\text { attended to, } \\
\text { which may lead } \\
\text { to conflicting and } \\
\text { inconsistent } \\
\text { judgements. }\end{array}$ & $\begin{array}{c}\text { Such } \\
\text { assessments } \\
\text { may be made in } \\
\text { terms of the } \\
\text { structural } \\
\text { complexity of } \\
\text { the outcome; }\end{array}$ & $\begin{array}{c}\text { Multistructural - } \\
\text { Learn several } \\
\text { relevant } \\
\text { independent } \\
\text { aspects of the } \\
\text { whole. }\end{array}$ \\
\hline $\begin{array}{l}\text { Concrete } \\
\text { Generalizations } \\
\text { (13 to } 15 \text { years); }\end{array}$ & Application & $\begin{array}{l}\text { Use subordinate } \\
\text { rules to relate } \\
\text { inconsistencies } \\
\text { and resolve } \\
\text { conflict, choice } \\
\text { which is less } \\
\text { determined by } \\
\text { external forces. }\end{array}$ & $\begin{array}{c}\text { The levels are } \\
\text { ordered in terms } \\
\text { of } \\
\text { characteristics } \\
\text { that include } \\
\text { progression } \\
\text { from concrete } \\
\text { to abstract; }\end{array}$ & $\begin{array}{l}\text { Relational - } \\
\text { Learn to integrate } \\
\text { several different } \\
\text { aspects into a } \\
\text { structure. }\end{array}$ \\
\hline $\begin{array}{l}\text { Formal (16 years } \\
\text { onward). }\end{array}$ & $\begin{array}{l}\text { Synthesis and } \\
\text { Evaluation } \\
\text { (Creation) }\end{array}$ & $\begin{array}{l}\text { Theoretically } \\
\text { orientated, able to } \\
\text { generate own } \\
\text { rules to cover all } \\
\text { cases, including } \\
\text { hypothetical ones. }\end{array}$ & $\begin{array}{l}\text { Organizing } \\
\text { dimensions, } \\
\text { hypothetical or } \\
\text { self-generated } \\
\text { principles being } \\
\text { used at the most } \\
\text { complex end. }\end{array}$ & $\begin{array}{c}\text { Extended } \\
\text { Abstract - Can } \\
\text { generalize what } \\
\text { has been learnt } \\
\text { and apply to a } \\
\text { new area of } \\
\text { knowledge. }\end{array}$ \\
\hline
\end{tabular}

Summative assessment occurs when the learning has finished. Both formative and summative analysis of understanding by the educator implies a meaningful relationship has been established as a measure of "learning growth". Differentiation must be contextualized within a time frame of established readiness to learn and clearly defined learning goals. Therefore, the research suggests that 
"differentiation" implies that "learning growth" of the learner has not ended, but is on a continuum and must be moving forward.

Biggs and Collis (1982) ask the question, "How do curriculum designers know the differentiation of individual learning and effective measurement of 'learning growth' has occurred?" (p.18)

Hattie (2009) has attempted to respond to Biggs question in his research study title, "Visible Learning" by conducting a literature review and reporting those influences using comparative "Effect Size" measurement. Hattie (2009) list of variables influencing learners is presented in a hierarchical order of influence to guide educators as to what effective teaching and what differentiation strategies should be considered when designing a learning sequence. Interestingly, Hattie and Zierer (2018) reported web-based learning effect size as 0.18 (Marginal response below the standard deviation average of .40) as a ranking of influence on student achievement. This low result effect size measurement may be due to the lack of research studies that focus on the effectiveness of 1:1 mobile devices as an influential learning tool.

\section{Differentiating using Learning Motivations}

Schunk and Zimmerman (2008), argued differentiating could occur by helping learners to recognise poor self-regulation, model how to set effective learning goals and implement supportive learning strategies. Elliot and Harackiewicz (1996), showed how learners could be differentiated by either "approach-performance" or "avoidance-performance". Learners that are performance goal orientated will try to outperform other students, aiming to demonstrate competence and superiority, whereas, the "avoidance-performers" may set themselves the goal to avoid failure by appearing incompetent.

Pachler (2010) stated the construction of digital artefacts using a 1:1 mobile device can be shared, peer critiqued and co-constructed, as evidence of developing critical thinking skills. Firipis, Chandrasekaran, and Joordens (2017) discussed how learners are differentiating their learning by using 1:1 mobile devices to "test" and "clarify" course concepts. In many cases, learners were attempting to find alternative ways to process and understand difficult content or to overcome a perceived barrier to their learning. Curriculum designers need to differentiate the curriculum by encouraging learners to develop critical thinking skills by researching for additional resources. For example, referenced readings, supportive technical knowledge and facilitate opportunities for sharing of knowledge selfsourced independently from online Internet sources using a 1:1 mobile device.

\section{Part A - Q. 1 to 8 - Perceptions of Readiness to Learn}

"Readiness to learn" as an indicator to measure and understand a cohort's disposition towards adopting a "growth mindset". This is done before the commencement of the sequence of learning. In the results shown, each question reveals a perception of self-motivation towards a "readiness to learn". 
The first data set is designed to help the curriculum designer and educator to identify patterns to micro-manage student learning. It would be prudent to use this information to include learning activities that will align with student personal interests and learning motivations.

In Table 5(a) Question 1 shows the majority of students in the sample are indicating a low level of "readiness to learn" with a mean score of 4.15 showing in the lower quarter percentile, followed by a similar pattern across all variables (Q.2 to 8). The sample is showing in Table 5(a), Questions 1, 4, and 5, learners have a desire to engage with the learning due to having a predisposition to value learning from past life experiences, and influenced by personal intrinsic and extrinsic values. Question 3 and 8 are showing the student cohort is lacking confidence and requires scaffolding to develop a "growth mindset" during the course.

Table 5 (a) - Q1-8 - Readiness to Learn

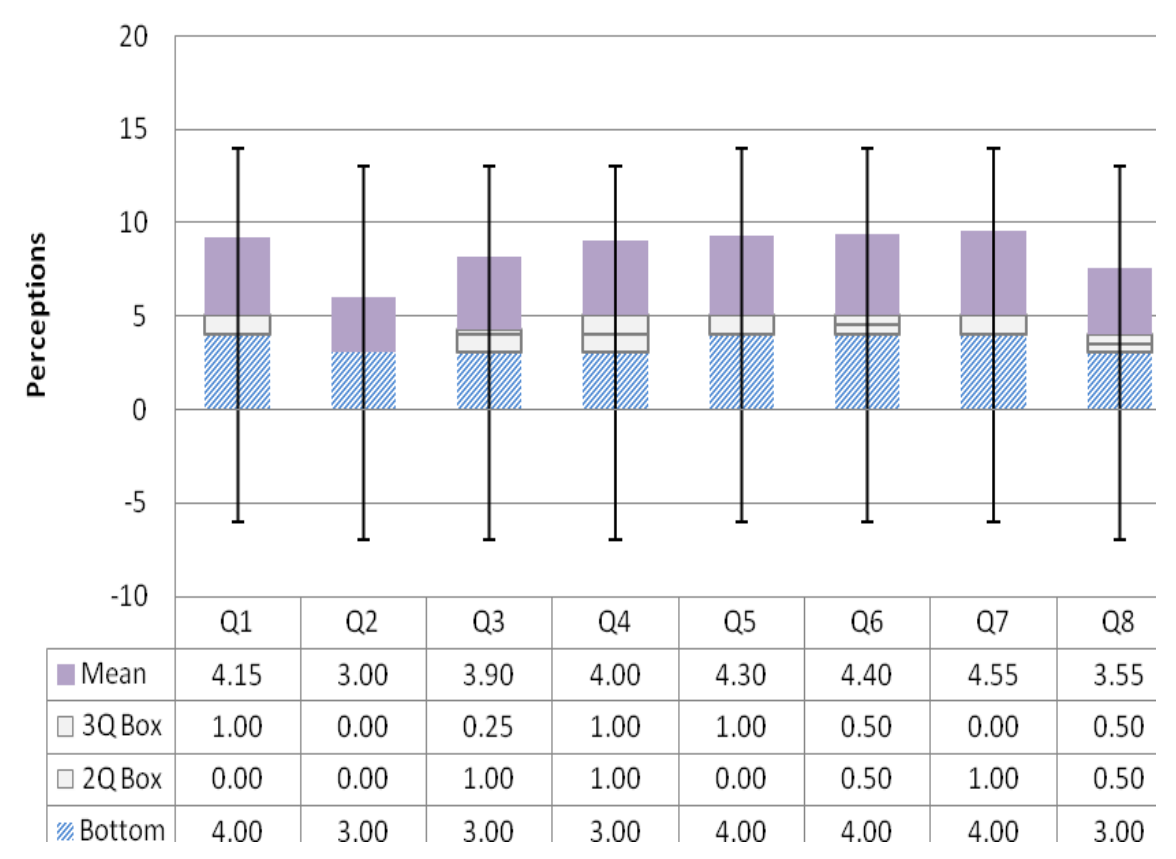

In Table 5(a), Question 3, 4, and 7 second quartile results are showing there are several students who are showing initiative towards their learning. This highlights the importance to differentiate the learning to cater to these highly motivated students.

The survey results help to explain the importance of developing a student "growth mindset" and can assist with prioritizing learning goals before the commencement of the course. For example, Table 5(b) Q2 indicates scaffolding is required to build a belief within the learner's "self-concept" that they can be an effective learner by setting achievable learning goals. Table 5(b) Q8 is suggesting some learners may benefit from learning how to take effective study notes during their learning. The curriculum could include teaching the students how to use the Pauk and Owen (2013) Cornell note-taking system using specific applications 
software when using a 1:1 mobile device. Learners responding to the "Readiness to Learn" survey questions may provide valuable feedback and an opportunity to form a learning relationship.

Table 5(b). Readiness to Learn

\begin{tabular}{|l|c|c|c|}
\hline & $\begin{array}{c}\text { Agree } \\
\text { \% }\end{array}$ & SD & $\begin{array}{c}\text { Learner Readiness - } \\
\text { Guglielmino (1977) }\end{array}$ \\
\hline $\begin{array}{l}\text { Q1. Learning enriches my understanding of } \\
\text { the world, and I like to embrace new } \\
\text { challenges. }\end{array}$ & 89.2 & 0.65 & $\begin{array}{c}\text { Openness to learning } \\
\text { opportunities }\end{array}$ \\
\hline $\begin{array}{l}\text { Q2. My ideas are inspirational to others; } \\
\text { however, I never seem to be able to } \\
\text { implement them myself. }\end{array}$ & 24.3 & 0.77 & $\begin{array}{c}\text { Self-concept as an } \\
\text { effective learner }\end{array}$ \\
\hline $\begin{array}{l}\text { Q3. I can learn from others; however, I prefer } \\
\text { to contribute to my own learning by deciding } \\
\text { what, how and when I will be learning. }\end{array}$ & 64.9 & 0.96 & $\begin{array}{c}\text { Initiative and } \\
\text { independence in learning }\end{array}$ \\
\hline $\begin{array}{l}\text { Q4. I like to be given the course notes in } \\
\text { advance, so I can plan and take responsibility } \\
\text { for my own learning. }\end{array}$ & 78.4 & 1.1 & $\begin{array}{l}\text { Informed acceptance of } \\
\text { responsibility for one's } \\
\text { own learning }\end{array}$ \\
\hline $\begin{array}{l}\text { Q5. I enjoy learning because it empowers me } \\
\text { to make good decisions. }\end{array}$ & 94.6 & 0.60 & Love of learning \\
\hline $\begin{array}{l}\text { Q6. Learning inspires me to be creative and } \\
\text { to think about new ways to solve problems. }\end{array}$ & 86.5 & 0.70 & Creativity \\
\hline $\begin{array}{l}\text { Q7. I like to experiment and use online } \\
\text { technologies that help me to learn. }\end{array}$ & 91.9 & 0.64 & Future orientation \\
\hline $\begin{array}{l}\text { Q8. I find it difficult to learn when open- } \\
\text { ended questions are given, and when there is } \\
\text { no set answer. }\end{array}$ & 40.5 & 1.11 & $\begin{array}{c}\text { Ability to use basic study } \\
\text { and problem-solving } \\
\text { skills }\end{array}$ \\
\hline
\end{tabular}

\section{Part B - Q.9 to 14 - Perceptions of Learning}

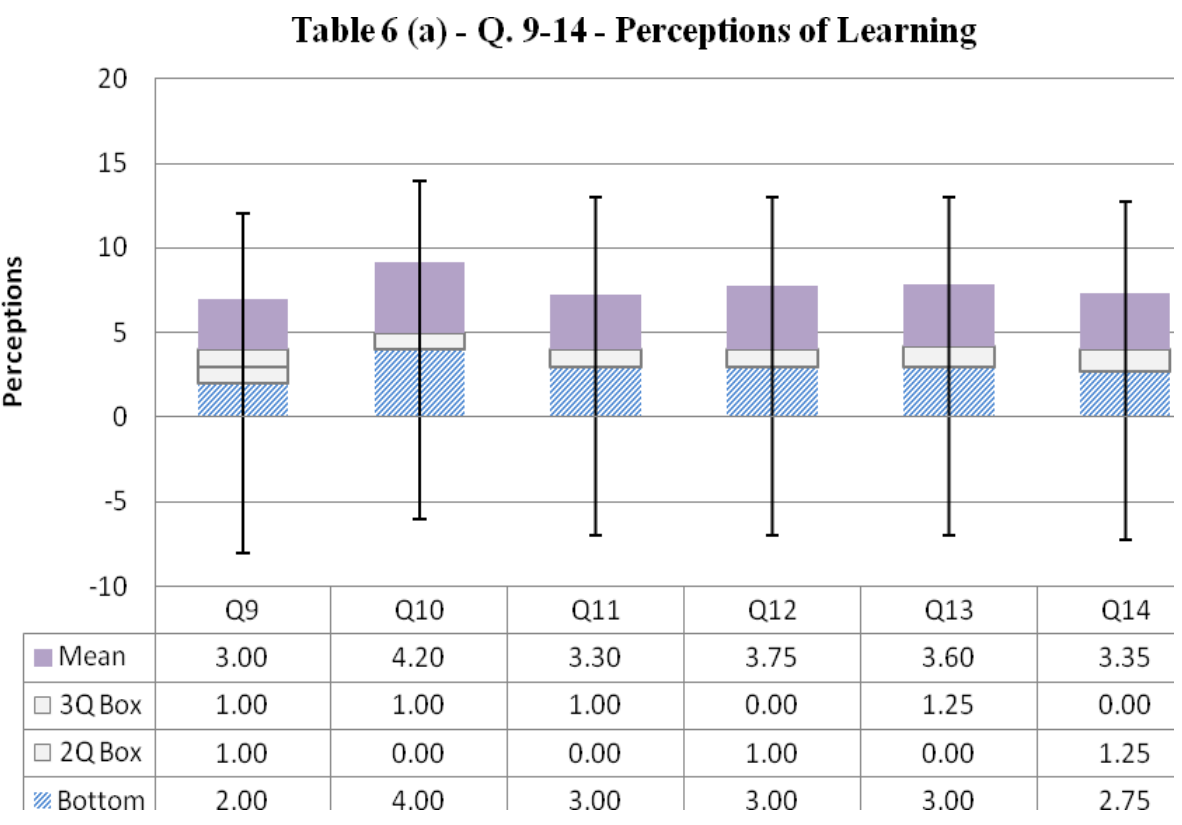


Learning is a continuum, and it is important to acknowledge that within every cohort, there will be a diversity of perceptions and motivations of learning and a range of prior learning experiences. Each cohort of learners is unique and is incomparable to the next group, who will have different perspectives and life experiences. Therefore, scaffolding and differentiating play a critical role towards ensuring the learning is uniquely engaging and is self-directed to appeal to the individuals within the cohort. The sample results in Table 6 (a) and (b) Perceptions of Learning provide feedback to the educator about key learning motivators occuring during the study.

Table 6(b). Learner Perceptions

\begin{tabular}{|l|c|c|c|}
\hline & $\begin{array}{c}\text { Agree } \\
\text { \% }\end{array}$ & SD & $\begin{array}{c}\text { Individual Learner Processes - } \\
\text { (Vermunt ILP (1998) }\end{array}$ \\
\hline $\begin{array}{l}\text { Q9. I place importance on the views } \\
\text { of authors in textbooks. }\end{array}$ & 32.4 & 1.21 & $\begin{array}{c}\text { (1) Meaning directed - deep } \\
\text { processing strategies, self- } \\
\text { regulation and learning viewed as a } \\
\text { personal construction; }\end{array}$ \\
\hline $\begin{array}{l}\text { Q10. I like to be provided with } \\
\text { explicit learning resources that } \\
\text { explain theoretical concepts step- } \\
\text { by-step. }\end{array}$ & 73.0 & 0.88 & $\begin{array}{l}\text { (2) Reproduction directed - surface } \\
\text { processing strategies, dependence } \\
\text { on external regulation, learning } \\
\text { viewed as intake of knowledge, } \\
\text { and desire to demonstrate ability; }\end{array}$ \\
\hline $\begin{array}{l}\text { Q11. I find it helpful to take the } \\
\text { initiative and write out possible } \\
\text { questions and their answers to } \\
\text { revise the course material. }\end{array}$ & 43.2 & 1.13 & $\begin{array}{l}\text { (1) Meaning directed - deep } \\
\text { processing strategies, self- } \\
\text { regulation and learning viewed as a } \\
\text { personal construction; }\end{array}$ \\
\hline $\begin{array}{l}\text { Q12. To test my learning progress, I } \\
\text { like to complete online quiz } \\
\text { questions and self-tests. }\end{array}$ & 78.4 & 0.89 & $\begin{array}{l}\text { (2) Reproduction directed - surface } \\
\text { processing strategies, dependence } \\
\text { on external regulation, learning } \\
\text { viewed as intake of knowledge, } \\
\text { and desire to demonstrate ability; }\end{array}$ \\
\hline $\begin{array}{l}\text { Q13. I find it difficult to know by } \\
\text { myself, if I have successfully learnt } \\
\text { the course content. }\end{array}$ & 48.6 & 1.18 & $\begin{array}{l}\text { (3) Undirected - poor self- } \\
\text { regulation, ambivalence in learning } \\
\text { orientation, and value is given to } \\
\text { external sources of help; and }\end{array}$ \\
\hline $\begin{array}{l}\text { Q14. I feel confident, that if I have } \\
\text { any misunderstandings about my } \\
\text { course content, I can find the } \\
\text { answer using online library } \\
\text { resources. }\end{array}$ & 56.8 & 1.32 & $\begin{array}{l}\text { (1) Meaning directed - deep } \\
\text { processing strategies, self- } \\
\text { regulation and learning viewed as a } \\
\text { personal construction; }\end{array}$ \\
\hline
\end{tabular}

In Table 6(a), Question 10, 11 and 13 are showing third quartile results within the sample; where students are showing a need towards receiving explicit, scaffolded teaching and learning. Tomlinson (2017) explains successful differentiation requires a commitment to demonstrate ongoing professional growth (leadership) by; (1) using preassessment data to identify student readiness to learn, (2) identify student interests and learning preferences, (3) facilitate multiple access to a variety of ways students can interact with information and ideas, (4) 
encourage students to "own" and share ideas, and (5) integrate course work that requires presentation criteria to encourage students to communicate (digital literacy) and show personal growth and expertise. In Table 6(a), Question 14 shows a perception where 1:1 mobile technology may be the answer to an unfulfilled motivation, where the student may feel they would be better equipped with the tools to become a confident learner.

Overall, the second data set provides and insight into motivational variables that may be useful when deciding adjustments to the curriculum to cater for individual interests and motivations. Also, to source valuable feedback from the learner about cognitive thought processes.

\section{Part C - Q.15 to 20 - Learner Perceptions using 1:1 Mobile Devices}

In Table 7(a), Questions 15 to 20 were designed to show the relationship students have with their 1:1 mobile devices and their perceived learning space (internal or external of their learning institution). In Table 7(a), Questions 15, 16, 18,19 , and 20 all show students' perceptions that favourably lean towards the use of 1:1 mobile device during self-directed learning. Firipis, Chandrasekaran, and Joordens (2017), (Table 7(a) and (b) - Learner Perceptions using 1:1 Mobile Devices) discusses motivational variables that help to explain why 1:1 mobile devices are highly valued. In Table 7(a), Q.17 is interesting in that students can multi-task by listening to music and engage in active learning at the same time. Question 19 and 20 highlights the tension that exists between learner perceptions about the effectiveness of linear verses a non-linear curriculum delivery.

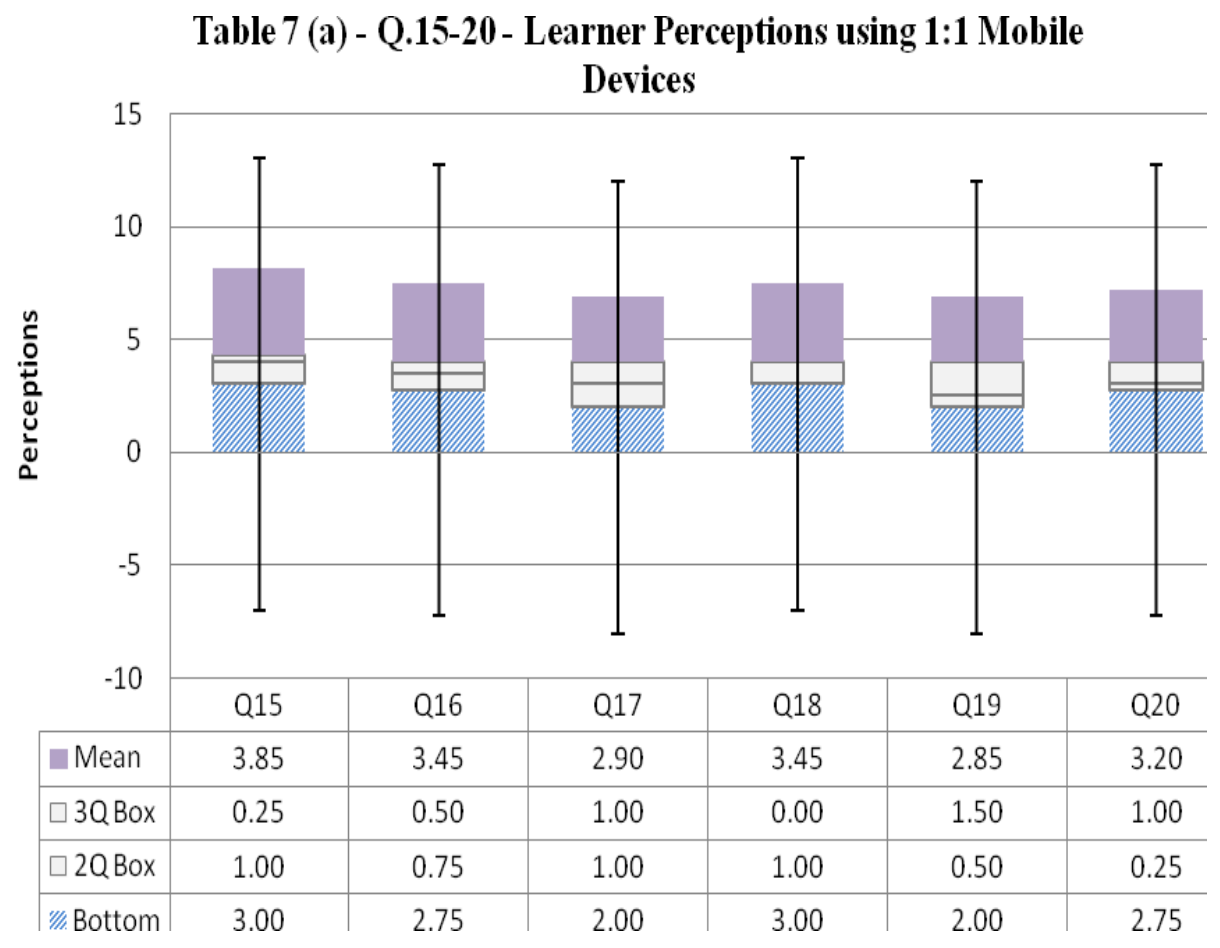


In Table 7(a), Question 16 shows students value connecting within the context of online learning communities, and this suggests the curriculum design should aim to include learning strategies that cater for collaboration. In Table 7(a), Question 19, the sample is showing a value judgement about how they perceive the learning space and course delivery. It would appear students are motivated when the learning space is integrated and flexible, and not static and fixed. This has implications for the curriculum design, where the course content and assessment tasks need to facilitate student desire to work "in and out" of traditional learning spaces. Mobile devices are a highly valued learning tool and must be considered when designing differentiated collaborative self-directed learning tasks to maintain a high level of student engagement to achieve "learner growth".

Table 7(b). Use of 1:1 Mobile Device Perceptions

\begin{tabular}{|c|c|c|c|}
\hline & $\begin{array}{c}\text { Agree } \\
\%\end{array}$ & SD & $\begin{array}{l}\text { Learner Motivations - } \\
\text { (Firipis et al. (2017)) }\end{array}$ \\
\hline $\begin{array}{l}\text { Q15. I like to use an Internet connected 1:1 } \\
\text { device (iPad, mobile phone, Tablet or } \\
\text { similar handheld Wi-Fi or Internet } \\
\text { accessible device), so I can look up facts to } \\
\text { test the 'truth' about what I am learning. }\end{array}$ & 70.3 & 1.04 & $\begin{array}{c}\text { Pre-conditioning to Learn } \\
\text { Extrinsic } \\
\text { Intrinsic } \\
\text { Recognition }\end{array}$ \\
\hline $\begin{array}{l}\text { Q16. I like to be a member of an online } \\
\text { learning community facilitated by an } \\
\text { educational leader. }\end{array}$ & 48.6 & 1.09 & $\begin{array}{c}\text { Self-regulation and Active } \\
\text { Learning } \\
\text { Feedback } \\
\text { Collaboration } \\
\text { Teacher as a role model } \\
\end{array}$ \\
\hline $\begin{array}{l}\text { Q17. Playing music on my 1:1 device } \\
\text { (iPad, mobile phone, Tablet or similar } \\
\text { handheld Wi-Fi or Internet accessible } \\
\text { device), at the same time as I am learning, } \\
\text { helps me to concentrate. }\end{array}$ & 32.4 & 1.4 & $\begin{array}{l}\text { Motivational Conflict } \\
\text { Setting Learning Goals }\end{array}$ \\
\hline $\begin{array}{l}\text { Q18. I like to use my 1:1 device (iPad, } \\
\text { mobile phone, Tablet or similar handheld } \\
\text { Wi-Fi or Internet accessible device), to } \\
\text { learn about career pathways and future } \\
\text { employment trends. }\end{array}$ & 51.4 & 1.22 & Career Goals \\
\hline $\begin{array}{l}\text { Q19. It is my perception that online } \\
\text { learning experience is better than attending } \\
\text { lectures, tutorials, and practical activities. }\end{array}$ & 32.4 & 1.39 & $\begin{array}{c}\text { Learning Styles } \\
\text { Choice and Personal } \\
\text { Interests } \\
\text { Environmental Factors }\end{array}$ \\
\hline $\begin{array}{l}\text { Q20. It is my perception that I am more } \\
\text { likely to succeed if I am using a 1:1 mobile } \\
\text { device (iPad, mobile phone, Tablet or } \\
\text { similar handheld Wi-Fi or Internet } \\
\text { accessible device), to access online } \\
\text { resources for learning. }\end{array}$ & 43.2 & 1.38 & $\begin{array}{c}\text { Social Orientation } \\
\text { Collaboration } \\
\text { Outcome Expectancy } \\
\text { Structured v's Unstructured } \\
\text { Cultural Values and Beliefs } \\
\text { Gender Identity } \\
\end{array}$ \\
\hline
\end{tabular}




\section{Part D - Bonus Materials}

The research study aimed to test the level of student engagement by including "Weekly Bonus Materials" in the same online directory as the existing course materials. The "Weekly Bonus Materials" were an additional resource presented in alternative ways to appeal to different student learning processes based on the research of Vermunt ILP (1998).

Students were alerted to the additional materials by the lecturer during Week 1 of the course. At the end of the course of study (Week 10), the students were voluntarily invited to complete a survey to ascertain their level of usage and weekly access. As each weekly bonus material was written intentionally with a specific motivational appeal, it was assumed that higher usage of one or more weekly bonus materials meant the content appealed to the student's preferred learning process.

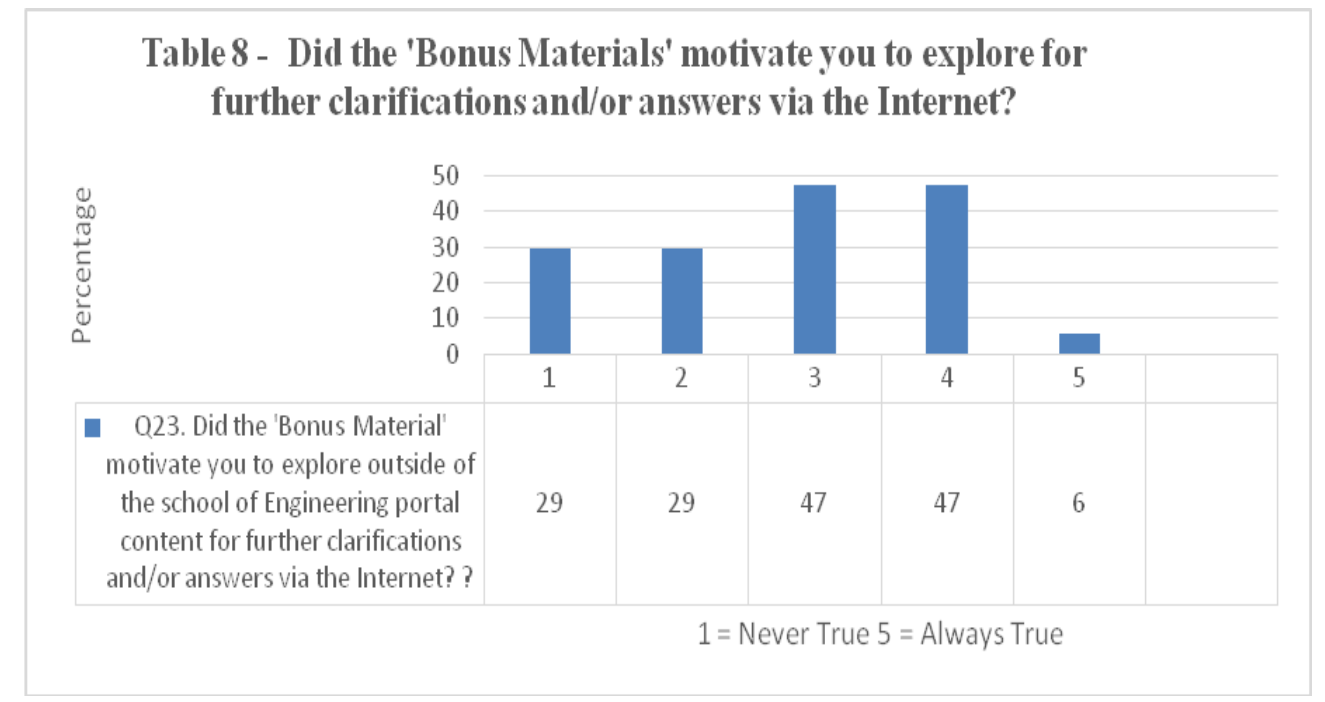

The initial analysis of the "Weekly Bonus Materials" survey responses revealed a trend where the interest level was high in the first week but then tapered off as the course progressed. Learners were accessing technical information in Week 4, and also accessed weekly content that had a practical "hands-on" application. For example, when shown how to make an amplifier using electronic parts, while the instructor explained the theoretical principles.

Table 8 is showing $47 \%$ of students held a perception they valued the "Bonus Materials", and it encouraged them to search for additional supporting learning resources outside of the course content. This implies learners are taking the initiative to seek clarification or find resources to solve unanswered questions that the course content or verbal lecture did not resolve. 


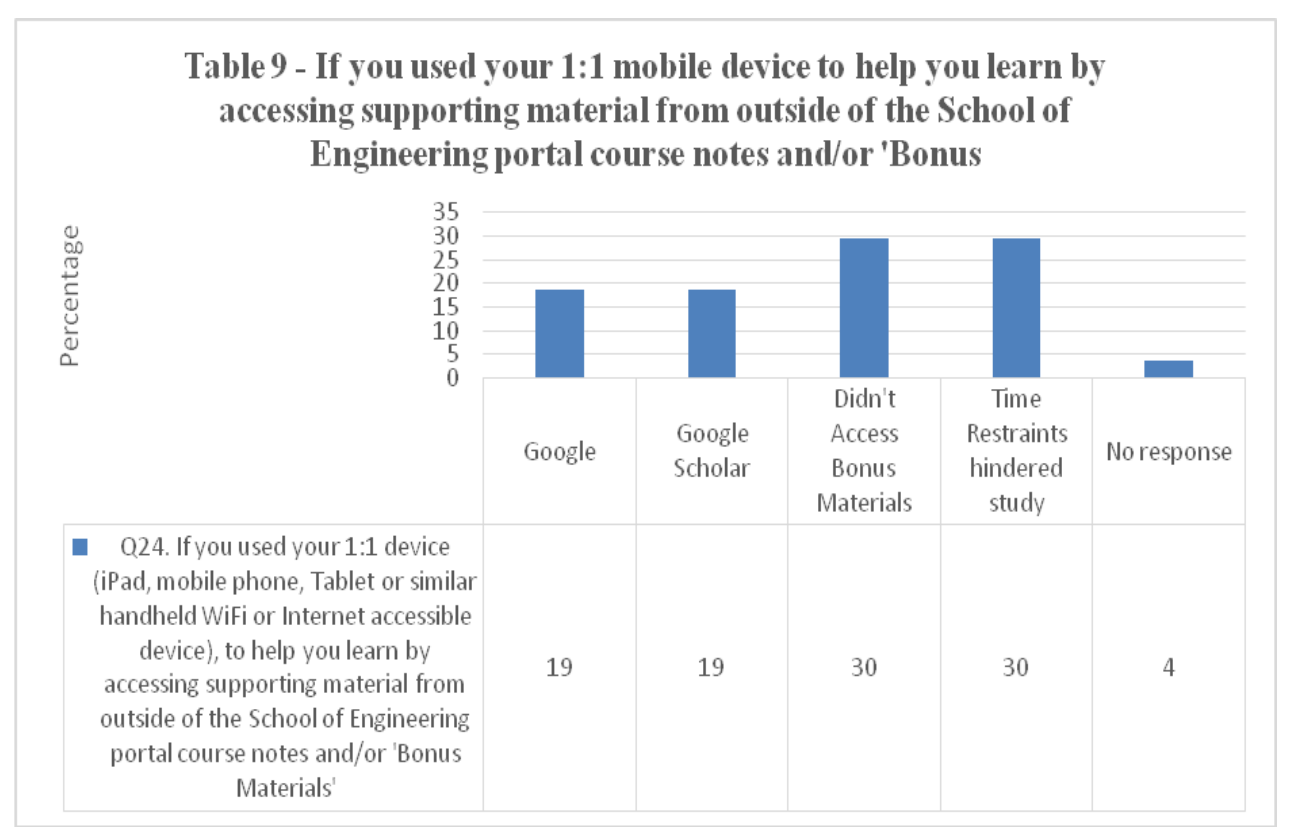

Table 9 shows the preferred Internet online search engine used with 19\% of students seeking further clarification independently using Google or Google Scholar.

\section{Part E - "Learner Growth" Effect Size}

The pre-test compromised of eight questions using an on-line testing facility and was designed to identify what understanding the students had before the commencement of the course. At the end of the course of study, students transcript results were collected. Both results collected were averaged and calculated to measure a "Hattie Effect Size" to determine learning growth. Data were de-identified, compiled and analysed using an Excel Spreadsheet. Responses then reported for this research study. An analysis of the results (See Table 10 Hattie's Effect Size - Pre-Test and Post-Test Results) showed a learning growth of 0.38 .

Table 10. Hattie's Effect Size - Pre-Test and Post-Test Results

\begin{tabular}{|l|l|l|l|}
\hline Sample & Pre-test & Post-test & Effect Size \\
\hline Average & 69.38 & 75.51 & \multirow{2}{*}{.38 } \\
\hline STDEV & 16.97 & 16.18 & \\
\hline AV Stdev & & 16.57 & \\
\hline
\end{tabular}

\section{Discussion}

Differentiating learners to achieve "learner growth" requires the educational leader to have a thorough theoretical understanding about how students learn, taking into consideration subject content, learning developmental stages, learner 
perceptions and motivations, "collaborative learning proximity", summative assessment tools, and most importantly professional judgement to know what constitutes "learner growth" when using 1:1 mobile devices. Twenty-first century learning (traditional classroom and collaborative virtual online learning spaces) need to be constructed as part of the curriculum design planning process, to equip digitally literate educational leaders to teach learners how to create self-directed artefacts that demonstrate the use of technical knowledge to produce evidence of "learner growth" while using 1:1 mobile devices. Dahlstrom (2012) reported students have an expectation that a course of study will include online learning as part of the curriculum design. The acceptance of 1:1 mobile devices and supporting online network services is exponentially leading the education industry, however, due to the lack of research in how to teach with technology, a "bridge needs to be built" to improve digital literacy to help students understand what is influencing their perceptions and motivations of learning to remain on the continuum of learner growth.

Curriculum designers who can understand the "dichotomy of need" where learners have developed a perception that 1:1 mobile devices are an allowable non-linear learning tool within the formal and informal learning space. Linear curriculum design culture is becoming contrary to the way students want to learn. The online Internet resource in its multi-facet virtual collaborative community, accessible via 1:1 mobile devices, now allows students to have access to knowledge. Learners can exert a position of power, testing the skill and expertise of the curriculum design and challenge its authenticity. So, the question arises, "How can a non-linear curriculum design be used to successfully determine student learning outcomes?" For example, an engineering student engaged in robotics can apply artificial intelligence theory to produce a self-directed learning program that uses algorithms to predict future societal needs and trends. At what point in the assessment cycle has the student plagiarised?

The key issue for curriculum designers is know how to articulate the learning space boundaries (physical and virtual), foster a high level of digital literacy, use summative assessment to differentiate the learning and seek ongoing feedback. Also, to create a safe and supportive online learning environment where creativity can be nurtured to produce artefacts as evidence of learning growth. Finally, using self-directed learning theory and interventions, for example, questions to stimulate critical thinking to support problem-solving, and support the development of technical skills when using 1:1 mobile devices for learning.

Guglielmino (1977) SDLR, Vermunt (1998) Individual Learner Process (ILP) survey instruments, and the assessment for pre, during and 1:1 mobile device perceptions survey learning instrument presented in this research study are useful for generating discussion amongst stakeholders about the influence learning perceptions and motivations for learning have on the curriculum planning process. Firipis, Chandrasekaran, and Joordens (2017) identified learning motivation variables and perceptions of learning reported in this research study, which help to explain the hypothesis showing that when 1:1 mobile devices are being used for learning, a measured learning growth (effect size) occurs. Finally, the research study has identified key perceptions and motivations for learning that will assist 
curriculum designers to understand how to support learners in the learning space (physical and virtual) for example, facilitating online learning spaces to encourage learners to access online resources supplementing existing course content, promote independence to learn anytime, anywhere, and acknowledge learners have pre, during course perceptions and learning motivations that provide an opportunity for formative feedback and differentiation to reduce learner anxiety. Also, feedback discussion will reveal a wide range of intrinsic and extrinsic learner motivations that can be used to modify the sequence and delivery of the curriculum to maintain curriculum engagement amongst learners.

The small sample size used in this research study places less weight on the results compared to previous studies reported by Guglielmino (1977) SDLR and Vermunt (1998) Individual Learner Process (ILP), and further research will need to be undertaken to test the population in different contexts to test the relevance of the reported "effect size" as an indicator of learning growth. The work of Guglielmino (1977) SDLR and Vermunt (1998), Biggs (2018) and Hattie (2009), and hopefully this research contribution will continue the discussion about how students can benefit from self-directed learning theory when using 1:1 mobile devices within the context of linear and non-linear curriculum delivery.

\section{Conclusion}

How best to integrate 1:1 mobile devices need to be considered during the curriculum design process by educational leaders who have a "deep" pedagogy understanding about how to achieve "learner growth". The online survey diagnostic tool developed and used in this research study is a useful way to generate a discussion between educators and learners about how to differentiate learning sequences when using 1:1 mobile devices in different contexts. Differentiation is asynchronous with the concept of educational leadership, and it is important to recognise that the quality of the classroom experience to achieve "learner growth" is linked to the curriculum design and highly digital literate educational leaders and learners.

\section{Disclosure Statement}

The authors of this research study acknowledge they have no financial interest or benefit arising from the direct application of this research study.

\section{References}

Biggs, J., \& Collis, K. (1982). Evaluating the Quality of Learning - The SOLO Taxonomy (Structure of the Observed Learning Outcome). Academic Press. New York. (ProQuest eBook Central,. Retrieved from http://ebookcentral.proquest.com.

Bloom, B., Englehart, M., Furst, E., Hill, W., \& Krathwohl, D. (1956). Taxonomy of Educational Objectives: The cognitive domain. New York: McKay. 
Boser, K., Goodwin, M., Wayland, S. (eds) (2014). Technology Tools for Students with Autism: Innovations that Enhance Independence and Learning (pp.23-24). Brookes Publishing.

Dahlstrom, E. (2012). ECAR Study of Undergraduate Students and Information Technology. Academic Press.

Elliot, A., \& Harackiewicz, J. (1996). Approach and avoidance achievement goals and intrinsic motivation: A meditational analysis. Journal of Personality and Social Psychology, 70(3), 461-475.

Duffy, T.M., \& Jonassen, D.H. (1992). Constructivism: new implications for instructional technology. In T.M. Duffy \& D.H. Jonassen (Eds.), Constructivism and the Technology of instruction -A Conversation (pp.1-16). Hillsdale, NJ: Erlbaum.

Firipis, A., Chandrasekaran, S., Lyons, L., Palmer, S., \& Joordens, M. (2016). What is Motivating Engineering Students to use 1:1 Mobile Devices for Learning? AAEE 2016 Conference Coffs Harbour, Australia.

Firipis, A., Chandrasekaran, S., \& Joordens, M., (2017). Engineering Curriculum Design Understanding motivational variables and their influence on self-directed learners when using 1:1 mobile devices. IJIER, 5(09), 8-31.

Fischer, K.W., \& Bidell, T.R. (2006). Dynamic development of action, thought and emotion. In W. Damon \& R.M. Lerner (eds.), Theoretical models of human development. Handbook of child psychology, 6th ed., vol. 1 (pp. 313- 399). New York, NY: Wiley.

Grigorenko, E., \& Sternberg, R.J. (eds.) (1997). Intelligence, heredity, and environment. Cambridge, England: Cambridge University Press.

Guglielmino, Lucy M. (1977). Development of the Self-directed Learning Readiness Scale. University of Georgia, ProQuest Dissertations and Theses Global.

Hattie, J., \& Zierer, K. (2018). Ten Mindframes for Visible Learning - Teaching for Success. Routledge - Taylor and Francis.

Hattie, J.A.C. (2009). Visible learning: A synthesis of 800+ meta-analyses on achievement. London: Routledge.

Marton, K., \& Saljo, R. (1976). On qualitative differences in learning: 1 - outcome and process. British Journal of Educational Psychology, 46(1), 4-11.

Pachler, N. (2010). The Socio-cultural ecological approach to mobile learning: An Overview. In B. Bachmair (ed.), Medienbildung in neuen Kulturräumen (pp. 153167). Berlin, Germany: Springer-Verlag.

Piaget, J. (1950). The psychology of intelligence. London: Routledge and Kegan Paul.

Pask, G. (1976). Styles and strategies of learning. British Journal of Educational Psychology, 46(2), 128-148.

Pask, G. (1988). Learning strategies, teaching strategies and conceptual or learning style. In Schmeck, R. (ed.), Learning Strategies and Learning Styles (pp. 83-100). New York: Plenum.

Rose, D.H., Meyer, A., \& Hitchcock, C. (2005). The universally designed classroom: Accessible curriculum and digital technologies. Cambridge, MA: Harvard Education Press.

Pauk, W., \& Owen, R. (2013). How to Study in College. Cengage Learning.

Schroder, H.M., Driver, M.J., \& Streufert, S. (1967). Human Information Processing. New York: Holt, Rinehart, and Winston.

Schunk, D., \& Zimmerman, B. (2008). Motivation ad self-regulated learning - Theory, research and applications. Taylor and Francis Group LLC.

Siegler, R.S. (1994). Cognitive variability: A key to understanding development. Current Dimensions in Psychological Science, 3(1), 1-5.

Tomlinson, C. (2017). How to Differentiate Instruction in Academically Diverse 
Classrooms, 3rd ed. Association for Supervision \& Curriculum Development.

Van Geert, P., \& Fischer, K.W. (2009). Dynamic systems and the quest for individualbased models of change and development. In J.P. Spencer, M.S.C. Thomas, \& J.L. McClelland (eds.), Toward a theory of development: Connectionism and dynamic systems theory re-considered (pp. 313-336). New York, NY: Oxford University Press.

Vermunt, J. (1998). The regulation of constructive processes. British Journal of Educational Psychology, 68(2), 149-171. Published by The British Psychology Society. Great Britain.

Volet, S., McGill, T., \& Pears, H. (1995). Implementing process-based instruction in regular university teaching: conceptual, methodological and practical issues. European Journal of Psychology of Education, 10(4), 385-400. 
